\title{
Population dynamics of selected Lepidoptera associated with gypsy moth [Lymantria dispar (L.)] in central Appalachia
}

\author{
Sandra Raimondo \\ West Virginia University
}

Follow this and additional works at: https://researchrepository.wvu.edu/etd

\section{Recommended Citation}

Raimondo, Sandra, "Population dynamics of selected Lepidoptera associated with gypsy moth [Lymantria dispar (L.)] in central Appalachia" (2003). Graduate Theses, Dissertations, and Problem Reports. 1835. https://researchrepository.wvu.edu/etd/1835

This Dissertation is protected by copyright and/or related rights. It has been brought to you by the The Research Repository @ WVU with permission from the rights-holder(s). You are free to use this Dissertation in any way that is permitted by the copyright and related rights legislation that applies to your use. For other uses you must obtain permission from the rights-holder(s) directly, unless additional rights are indicated by a Creative Commons license in the record and/ or on the work itself. This Dissertation has been accepted for inclusion in WVU Graduate Theses, Dissertations, and Problem Reports collection by an authorized administrator of The Research Repository @ WVU.

For more information, please contact researchrepository@mail.wvu.edu. 
Population Dynamics of Selected Lepidoptera Associated with Gypsy Moth

[Lymantria dispar (L.)] in Central Appalachia

\author{
Sandra Raimondo \\ Dissertation submitted to the College of Agriculture, \\ Forestry and Consumer Sciences, \\ Division of Plant and Soil Sciences at West Virginia University \\ in partial fulfillment of the requirements for the degree of \\ Doctor of Philosophy \\ in Agricultural Sciences - Entomology \\ Linda Butler, Ph.D., Chair \\ James Amrine Jr., Ph.D. \\ Henry Hogmire, Ph.D. \\ Todd Petty, Ph.D. \\ Kenneth Rastall, Ph.D. \\ Department of Entomology \\ Morgantown, West Virginia \\ 2003
}

Keywords: Population Dynamics, Lepidoptera, Bacillus thuringiensis, Sampling Methods

Copyright 2003 Sandra Raimondo 


\begin{abstract}
Population Dynamics of Lepidoptera Associated with Gypsy Moth
\end{abstract}

[Lymantria dispar (L.)] in Central Appalachia

\author{
Sandy Raimondo
}

Despite the wealth of research conducted on gypsy moth [(Lymantria dispar L.)(Lymantriidae: Lepidoptera)] populations dynamics, quantitative analysis of the native lepidopteran community in which gypsy moth has become naturalized is extremely limited. This study examined the population dynamics of native Lepidoptera in two gypsy moth management areas in West Virginia and Virginia. Data were collected between 1995 and 2001 on 18 plots distributed on two national forests (Monongahela National Forest, WV and George Washington National Forest, VA). Four lepidopteran sampling techniques (gypsy moth egg mass surveys, canvas bands and foliage clippings for larval sampling, and light trap samples for adults) were compared. Population estimates obtained from moths captured in light traps and egg mass counts were both correlated with abundance of larvae obtained from foliage clippings. Canvas band samples were only weakly to moderately correlated with data collected from foliage and light trap samples. The effects of the biological pesticide, Bacillus thuringiensis var. kurstaki, on several population parameters (annual abundance, population growth rate, coefficient of variation, and correlation of time series among plots) were negligible for 11 selected species. Quantitative analysis of Lepidoptera populations was performed through analysis of spatial synchrony. Synchrony of both intraspecific and interspecific local populations was compared with climate variables to assess the potential role of weather on population synchrony. Synchrony of conspecific populations was correlated with that of at least one weather variable for all species. Interspecific synchrony was related to within and among families and season of larval phenology, as well as geographic distribution of species relative to canopy vegetation. Interspecific synchrony was highest among species whose larvae were present during the same season compared to species whose larvae were present during different seasons. To test the hypothesis that Lepidoptera species within the same feeding guild may be synchronized by generalist predators, a model was developed that demonstrated synchronization of prey species by a predator functional response. Prey species projecting relatively similar search images to the predator were more highly synchronized than prey species projecting relatively distant search images. 


\section{Acknowledgements}

This research could not have been completed without the financial support provided by the USDA Forest Service as cooperative agreements 42-793 and 42-98-0006.

I thank my graduate advisor, Linda Butler, for all of her insight, knowledge, and teaching, for providing me with the opportunity to work with her research group, for many stimulating conversations on life and its evolution, for her encouragement of my ideas, and for making the incredibly vast world of entomology attainable to my mind. I am also grateful to the other members of my committee (James Amrine, Henry Hogmire, Todd Petty, and Ken Rastall) for sharing their expertise and for the time they worked on my behalf.

The enormous amount of data involved in this project could not have been collected and processed without the long hours and hard work of the LTS project staff (John Strazanac, Vicki Kondo, Deb Blue, and Greg Chrislip) and all of the graduate and undergraduate students that worked on this project.

I am indebted to Sandy Liebhold for all of his help with the quantitative analyses, insightful discussions, review of this work, and access to Forest Service facilities. He opened the door to areas of research that I never expected to explore and made it seem easy. I am grateful to George Seidel for statistical guidance. I also thank Nicole Edwards and Brock Reggi for assistance with map making.

I must emphasize extreme gratefulness to all of my family and friends for their constant support and undying confidence. And of course, I offer warm gratitude to my funny four legged friend for greeting me with overwhelming enthusiasm at the beginning, middle, and end of every day, and forcing me to stop, breathe, and take walks in fresh, although sometimes freezing, air. 


\section{Table of Contents}

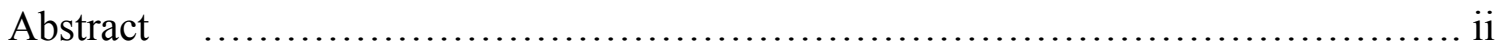

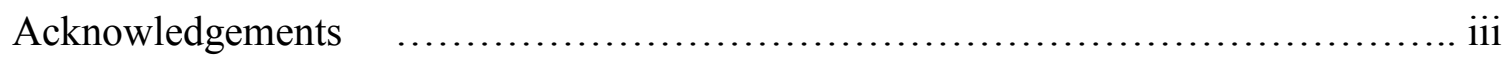

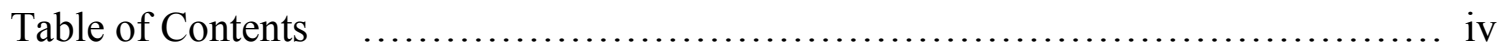

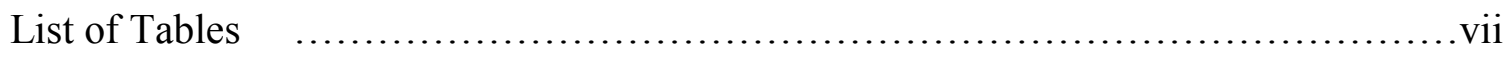

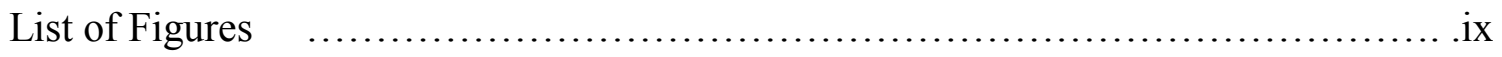

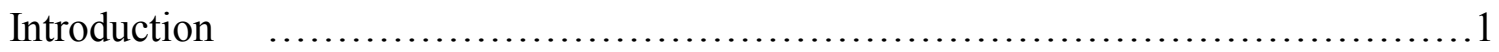

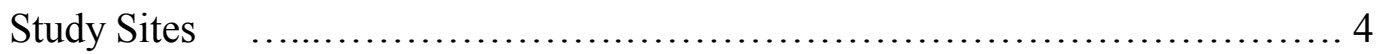

Environmental / Geophysical Characteristics $\quad \ldots \ldots \ldots \ldots \ldots \ldots \ldots \ldots . \ldots 4$

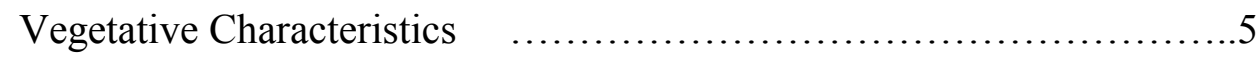

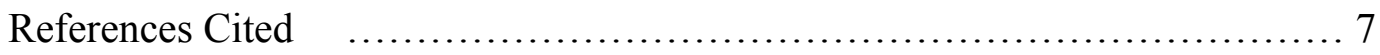

Chapter 1: Lepidoptera Sampling Methods: Correlation of Sampling Techniques Used to Study Lepidoptera Population Dynamics

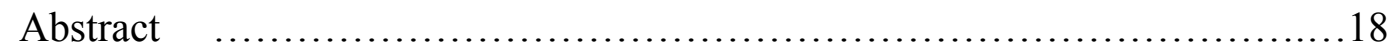

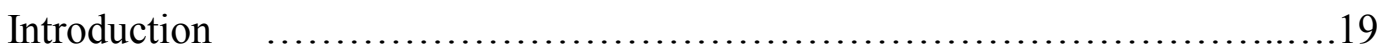

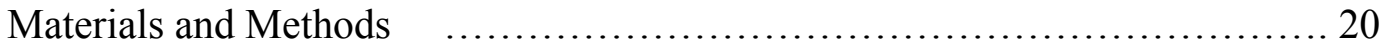

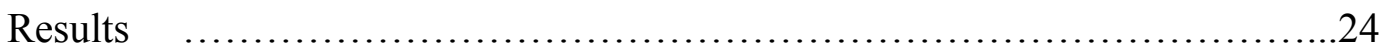

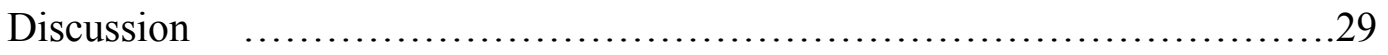

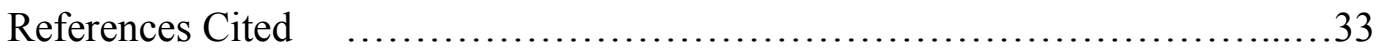

Addendum $\quad$.......................................................45

Chapter 2: Effects of Bacillus thuringiensis kurstaki on the Population Dynamics of Selected Non-target Lepidoptera

Abstract .46 
Introduction

Methods

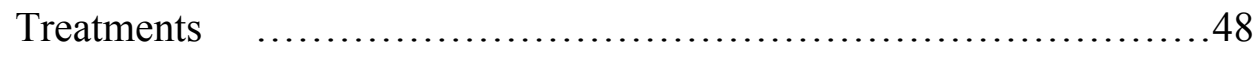

Statistical Analyses $\quad$............................................49

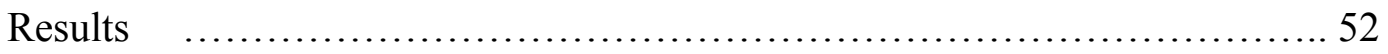

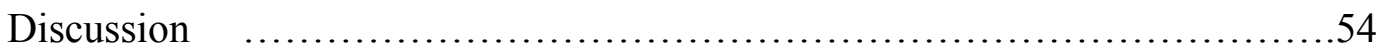

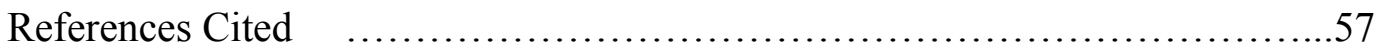

Chapter 3: Spatial Synchrony Within and Among Native Lepidoptera Species: Patterns of Synchrony with Relation to Climate, Phylogeny, Phenology, and Upper-Story Canopy

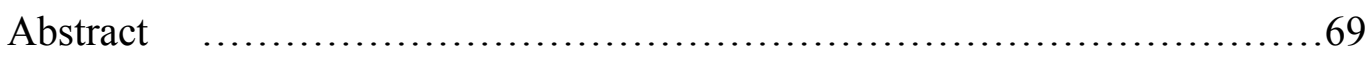

Introduction $\quad$.......................................................... 70

Methods

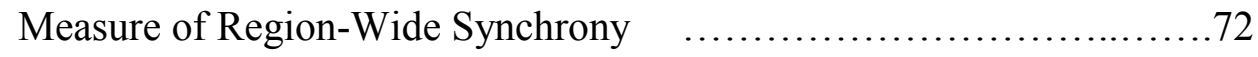

Synchrony of Lepidoptera Species and Climate $\quad \ldots \ldots \ldots \ldots \ldots \ldots \ldots \ldots 73$

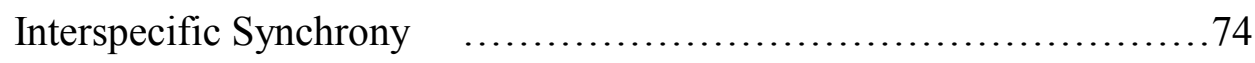

Results

Synchrony of Lepidoptera Species and Climate $\quad \ldots \ldots \ldots \ldots \ldots \ldots \ldots \ldots 75$

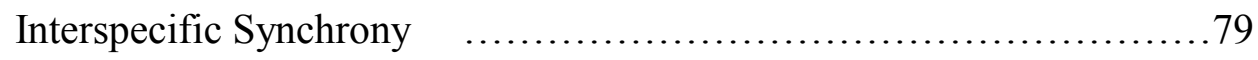

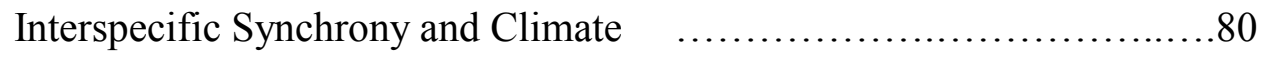

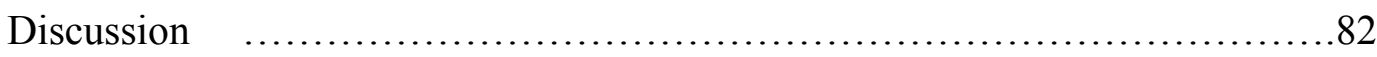

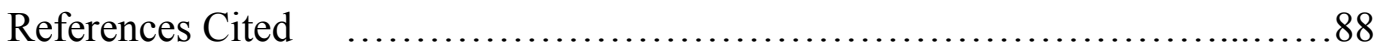


Chapter 4: Theoretical Approach to Interspecific Synchrony of Forest Lepidoptera: Theory of Guild-Level Synchrony by Generalist Predators

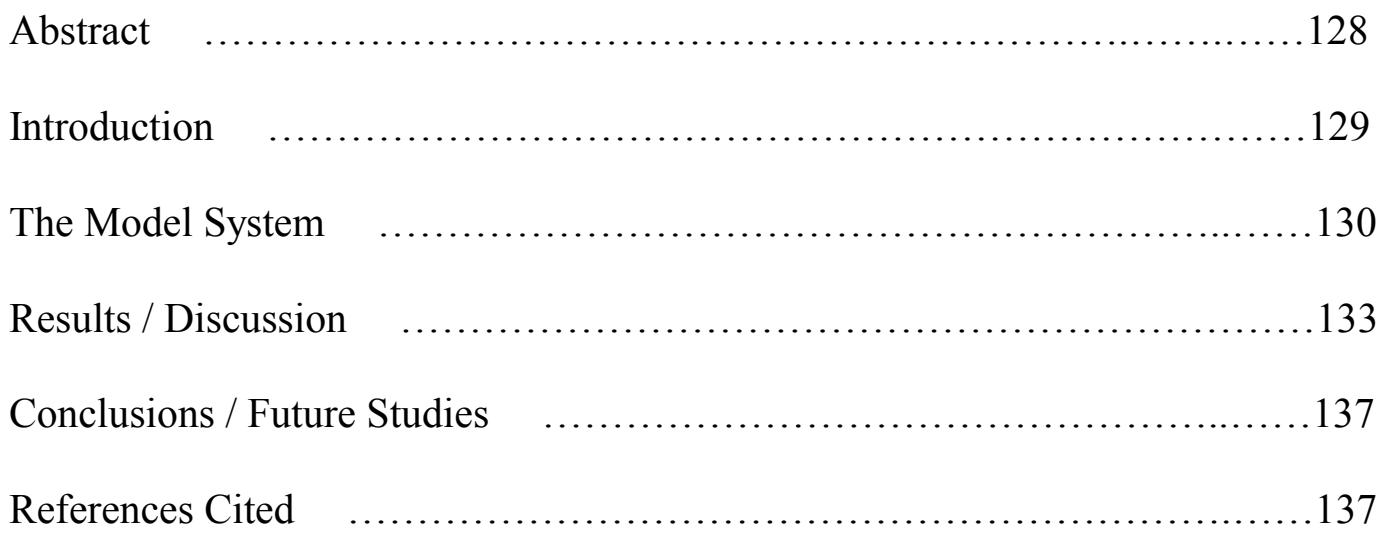

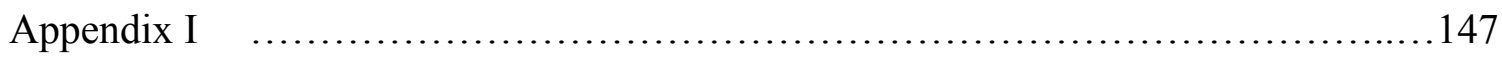

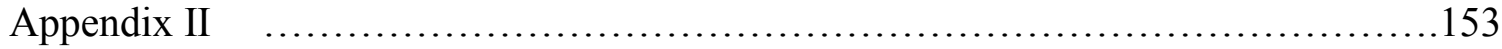

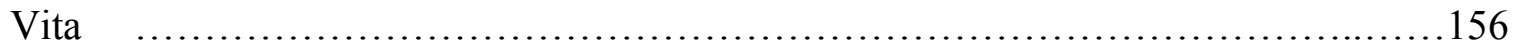




\section{List of Tables}

$\underline{\text { Introduction }}$

i.1. The most abundant species of oak, pines, maples, and hickories recorded from the plots .66

\section{Chapter 1}

1.1. Study species and total number of individuals from each sampling method

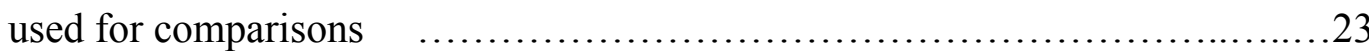

1.2. Pearson correlation coefficients for method comparisons $\quad \ldots \ldots \ldots \ldots \ldots \ldots \ldots . . . . .26$

1.3. Multiple regression table for the effects of environmental factors on the light traps, foliage samples, and canvas bands

\section{Chapter 2}

2.1. Treatment-plot designations and treatment dates

2.2. Results of mixed model ANOVA (d.f. $=15)$ for treatment effects on

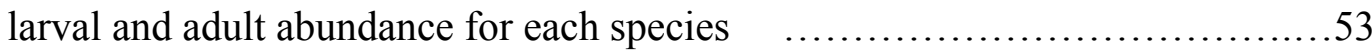

2.3. Pearson correlation coefficients for treatment time series of each species $\ldots . .54$

\section{Chapter 3}

3.1 Average region-wide cross-correlation coefficients for intraspecific and interspecific comparisons

3.2 Region-wide cross- correlation of Climate variables and Lepidoptera species abundance

3.3 Species family classification and designation in categories of larval phenology 
3.4 Species pairs with significant interspecific region-wide cross-correlation and significant correlation with Climate variables 


\section{List of Figures}

Introduction

i.1. Study sites in Pocahontas County, West Virginia, and Augusta

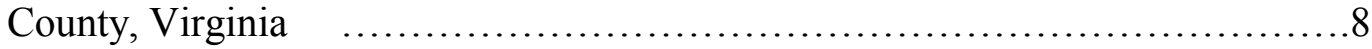

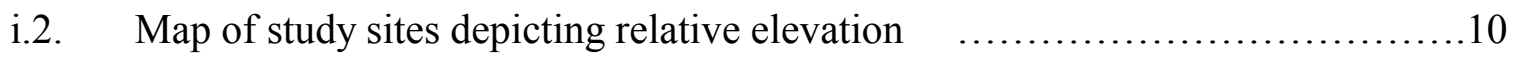

i.3. Average temperatures of the GWNF and MNF during the study period $\ldots . .12$

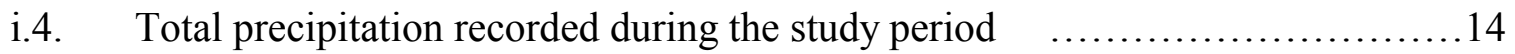

i.5. Distribution of the most common plant groups on the study plots $\ldots \ldots \ldots \ldots . . .16$

\section{Chapter 1}

1.1. Correlation of A. ovata, P. latex, and H. guttivitta using a temporal series,

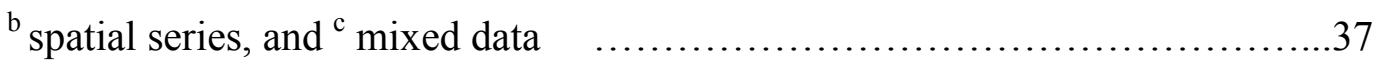

1.2. Weighted average collection week of larvae from foliage clippings

and from under canvas bands on the GWNF and MNF

1.3. Time series of yearly counts for gypsy moth collection methods

1.4. Average abundance of moths and larvae compared with environmental parameters

Chapter 2

2.1. Treatment time series of

a-c. H. fucosa, H. guttivitta, and H. unipunctata $\quad$........................59

d-f. I. pustularia, M. canadaria, and B. endropiaria $\quad$.....................61

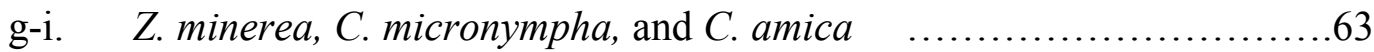

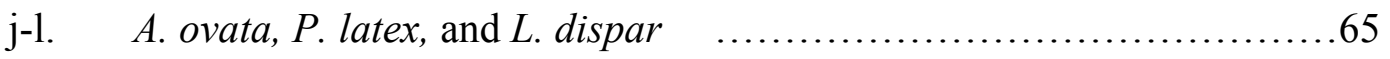

2.2. Coefficient of variation among treatments for each species $\quad \ldots \ldots \ldots \ldots \ldots \ldots . . .67$ 


\section{Chapter 3}

3.1. Spatial synchrony (cross-correlation) of conspecific populations and

Climate variables against distance

3.2. Relationship between the spatial synchrony of Lepidoptera populations and
a. Climate 1
b. Climate 2
c. Climate 3

3.3. Graphical representations of spatio-temporal interspecific synchrony.
a. Itame pustularia 100
b. Melanolophia canadaria
c. Hypagyrtis unipunctata 104
d. Besma endropiaria 106
e. Heterocampa guttivitta 108
f. Hypoprepia fucosa 110
g. Zale minerea
h. Catocala micronympha 114
i. Acronicta ovata 116
j. Polia latex 118

3.4. Interspecific synchrony of species present as larvae in the early season, late (mid-late) season, and all season

3.5. Species plotted against axis 1 and axis 2 of the Canonical

Correspondence Analysis

3.6. Species plotted against axis 1 of the CCA 
3.7. Interspecific cross-correlation coefficient against the distance of CCA axis 1

\section{Chapter 4}

4.1. Two prey species in the ${ }^{\mathrm{a}}$ presence and ${ }^{\mathrm{b}}$ absence of predators

4.2 Level of synchrony for various combinations of search image 143

4.3 Simulation results of two prey / predator systems with various combinations of search image and handling time 


\section{Introduction}

Population dynamics is a central issue of ecology and insects have historically provided models that served as a foundation for many fundamental theories. In the earliest years of theoretical ecology, Herbert G. Andrewartha and his colleague Louis C. Birch introduced the importance of density-independent regulatory factors in a milestone publication that was based on their study of insect populations (Andrewartha and Birch 1954). Since then, insect population dynamics have continued to inspire new theory and provide empirical support for evolving theories of population ecology. In recent years, a "New Synthesis" of ecology has arisen to focus on the development of empirically- based theory that reflects the diversity of the natural world, and is the challenge of contemporary ecologists (Cappuccino 1995).

Studies comparing outbreak and non-outbreak species of forest insects synthesize natural history characteristics with temporal fluctuations to study outbreak dynamics and density- dependent factors (Cappuccino 1995). The well-studied population dynamics of outbreak species, such as gypsy moth (Lymantria dispar (L.)), spruce budworm (Choristoneura fumiferana (Clemens)), and larch bud moth Zeiraphera diniana Guenée, demonstrate how applied ecology merges theory and numerical data for landscape-wide management practices.

The dynamics of outbreak species are likely affected by the non-outbreak species that feed on the same foliage and share similar predation pressures (Mason 1987), particularly in non-outbreak years. Cappuccino (1995) stated that the progress of understanding outbreak dynamics would be expedited by studying the non-outbreak species which use the same habitat. It has also been suggested that during non-outbreak 
years, outbreak and associated Lepidoptera species may be regulated as a whole rather than individually (Hebert et al. 1974, Markin 1982). Despite their importance to ecosystem stability, few studies have focused on the population dynamics of nonoutbreaking insects. The overwhelming majority of non-outbreaking species (generally $>90 \%$ of defoliating feeding guild, Markin 1982) impresses the importance of incorporating their population dynamics where outbreak species are intensely managed. The primary objective of this study is to examine the population dynamics of nonoutbreak Lepidoptera species in gypsy moth management areas.

This study is in conjunction with a non-target study conducted by West Virginia University, University of Georgia, and Marshall University, with cooperation of the U.S.D.A. Forest Service Forest Health Technology Enterprise Team, Morgantown, WV (USDA Forest Service Coop No. 42-793 and 42-98-0006). The primary objectives of the cooperative study are to determine the potential impact of the microbial insecticide, Bacillus thuringiensis kurstaki (B.t.k.) and the nuclear polyhedrosis virus product Gypchek $^{\circledR}$ (Gyp) on non-target arthropods, birds, and salamanders. Applications of B.t.k. and Gyp were made in two consecutive years in accordance with standard management practices on the leading edge of the gypsy moth range in Virginia and West Virginia. Two years of pre-treatment and three years of post-treatment data were collected during the seven year study period.

The current study utilizes the time series for gypsy moth and 10 non-target Lepidoptera to observe the population dynamics of the defoliating caterpillars in a gypsy moth management area in Central Appalachia. Four objectives of the current study will be addressed in four chapters: 


\section{OBJECTIVES:}

1. To compare four Lepidoptera sampling techniques and discuss their potential to be used to study population dynamics (Chapter 1),

2. To determine the effects of the biological pesticide, Bacillus thuringiensis var. kurstaki, on lepidopteran population dynamics (Chapter 2),

3. To measure the synchrony of conspecific and interspecific populations of 10 Lepidoptera species in the George Washington and Monongahela National Forests with an attempt to identify factors that influence the behavior of their populations (Chapter 3), and

4. To develop a model that demonstrates guild-level synchrony of forest Lepidoptera by shared generalist predators and evaluate the role of predator search image and handling time of prey on level of synchrony (Chapter 4).

The results of each chapter can stand alone in their ability to describe ecological processes and contribute to the baseline knowledge of Lepidoptera in gypsy moth management areas. It is hoped that their synthesis will provide information for a much needed comprehensive view of the lepidopteran community of eastern hardwood forests. 


\section{Description of Study Sites}

Eighteen 200 ha plots were established in the Monongahela National Forest (MNF), Pocahontas County, West Virginia, and in the George Washington National Forest (GWNF), Augusta County, Virginia (Figure i.1). Plots 1 through 9 were located in the Deerfield Ranger District of the GWNF while plots 10 through 18 were located in the Greenbrier and Marlinton Ranger Districts on the MNF. Plots were established in a completely randomized block design, based on vegetation type, with three blocks per forest and three plots per block. A 20-ha core sub-plot was established in each plot and was used for collection of environmental data and most insect sampling (Chapter 1).

\section{Environmental / Geophysical Characteristics}

The MNF plots are located in the West Virginia Ridge and Valley Province which range in elevation from 732 to $1231 \mathrm{~m}$ with an average elevation of $950 \mathrm{~m}$. The GWNF plots are located in the Deerfield Ranger District and range in elevation from 548 to $732 \mathrm{~m}$ with an average elevation of $635 \mathrm{~m}$ (Figure i.2).

One weather station containing a rain gauge and $\min / \max$ thermometer was placed in each core plot throughout the sampling seasons. In 1995, weather stations were set up in mid-June and were checked weekly through mid-August. From mid-May through mid-June of that year, weather data was obtained from NOAA weather stations in the nearby ranger districts. For all other years weather stations remained on the plots for a 15-week field season from mid-May through mid-August. Rain gauges and thermometers were placed $1 \mathrm{~m}$ above the ground with the thermometers facing north. A 
board sheltered the thermometer from direct sunlight. Rain gauges and thermometers remained on the plots throughout the field season.

Throughout the study period, average temperature was significantly higher on the GWNF plots than on the MNF plots (2-tailed t-test, $\mathrm{t}=66.2$, d.f. $=6, \mathrm{p}<0.0001$ ) (Figure i.3). Total precipitation was variable from year to year on both forests but total rainfall collected during the study period did not differ significantly between forests (2-tailed ttest, $\mathrm{t}=0.096$, d.f. $=6, \mathrm{p}=0.93$ ) (Figure i.4). In general, however, the GWNF is more xeric than the MNF plots based on its lower soil moisture and total annual precipitation as shown by a summary of 30 years of data from the region (Owenby and Ezell 1992).

\section{Vegetation Characteristics}

Vegetation was recorded on each plot in 1996. At the approximated center of each canvas band site ( 2 per plot, Chapter 1), four $50 \times 2$ meter transects were established in each cardinal direction (total area $=6.25 \mathrm{~m}^{2}$ ). Along each transect, all trees at least $2.5 \mathrm{~cm}$ in diameter were identified and diameter at breast height (DBH) was measured. Basal area of each tree was determined as:

$$
\text { Area }=\pi^{*}(\mathrm{DBH})^{2} / 4
$$

At each set of transects, the total basal area of each tree species was calculated and the average of the two sets of transects was used as the representative vegetation of each plot.

All plots were generally similar in vegetation and were primarily composed of oaks, pines, maples, and hickories (Table i.1). Other common tree species included black gum (Nyssa sylvatica Marsh.), flowering dogwood (Cornus florida L.), black locust (Robinia pseudoacacia L.), yellow poplar (Liriodendron tulipifera L.), and service berry (Amelanchier arborea Michx. F.). Common understory species included Vaccinium spp., 
Gaylussacia spp., Kalmia latifolia L., Azalea spp., Andromeda spp., and Rhododendron maximum $\mathrm{L}$.

Oaks were the dominant overstory vegetation on all plots (30.1 to $74.1 \%$ of total basal area) with the exception of plot 4 , which had a higher percentage of pines (oaks $=$ $30.1 \%$, pines $=39 \%)$. In general, the basal area of pines was greater in the GWNF $(10.6$ to $24.7 \%$ ) than the MNF ( 0 to $24.6 \%$ ), and the basal area of maples was greater in the MNF (3.5\% to $24.7 \%$ ) than in the GWNF (0 to $7.5 \%$ ) (Figure i.5). The differences in the distribution of pines and maples among forests are reflective of the xeric and mesic nature of the GWNF and MNF, respectively. Plot vegetation as it pertains to distribution of the study species will be further discussed in Chapter 3 .

Table i.1. The most abundant species of oaks, pines, maples, and hickories recorded from the plots.

\begin{tabular}{llll}
\hline \multicolumn{1}{c}{ Oaks (Fagaceae) } & \multicolumn{1}{c}{ Pines (Pinaceae) } & \multicolumn{1}{c}{ Maples (Aceraceae) } & \multicolumn{1}{c}{ Hickories (Junglandaceae) } \\
\hline \hline Quercus prinus L. & Pinus rigida Mill. & Acer rubrum L. & Carya glabra (Mill.) \\
Q. alba L. & P. pungens Lamb. & A. saccharum Marsh & C. cordiformis (Wangenh.) K. Koch \\
Q. coccinea Muenchh. & P. virginiana Mill & A. penslyvanicum L. & C. ovata (Mill.) K. Koch \\
Q. rubra L. & P. strobus L. & & C. tomentosa (Poir.) Nutt. \\
Q. veluntina Lam. & Tsuga canadensis (L.) Carr. & & \\
\hline
\end{tabular}




\section{References Cited}

Andrewartha, H. G. and L. C. Birch. 1954. The Distribution and Abundance of Animals. University of Chicago Press. Chicago. 276pp.

Cappuccino, N. 1995. Novel approaches to the study of population dynamics. In Population Dynamics: New Approaches and Synthesis. N. Cappuccino and P. W. Price (Eds.). 429pp.

Hebert, P. D. N., P. S. Ward, and R. Harmsen. 1974. Diffuse competition in Lepidoptera. Nature. 252. 389-390.

Markin, G. P. 1982. Abundance and life cycles of Lepidoptera associated with an outbreak of the western spruce budworm Choristoneura occidentalis (Lepidoptera: Torticidae) in southeastern Idaho. Journal of the Kansas Entomological Society. 55: 365372.

Mason, R. R. 1987. Nonoutbreak species of forest Lepidoptera. In Insect Outbreaks. P. Barbosa and J. C. Schultz (Eds.). Academic Press. San Diego, CA. 578pp.

Owenby, J. R., and D. S. Ezell. 1992. Monthly station normals of temperature, precipitation, and heating and cooling degree days 1961-1990. In. NOAA, National Climatic Data Center. Climatography of the United States. No. 81. Asheville, NC. 11pp. 
Figure i.1. Study sites in Pocahontas County, West Virginia, and Augusta County, Virginia. The gray area marks federal lands. 


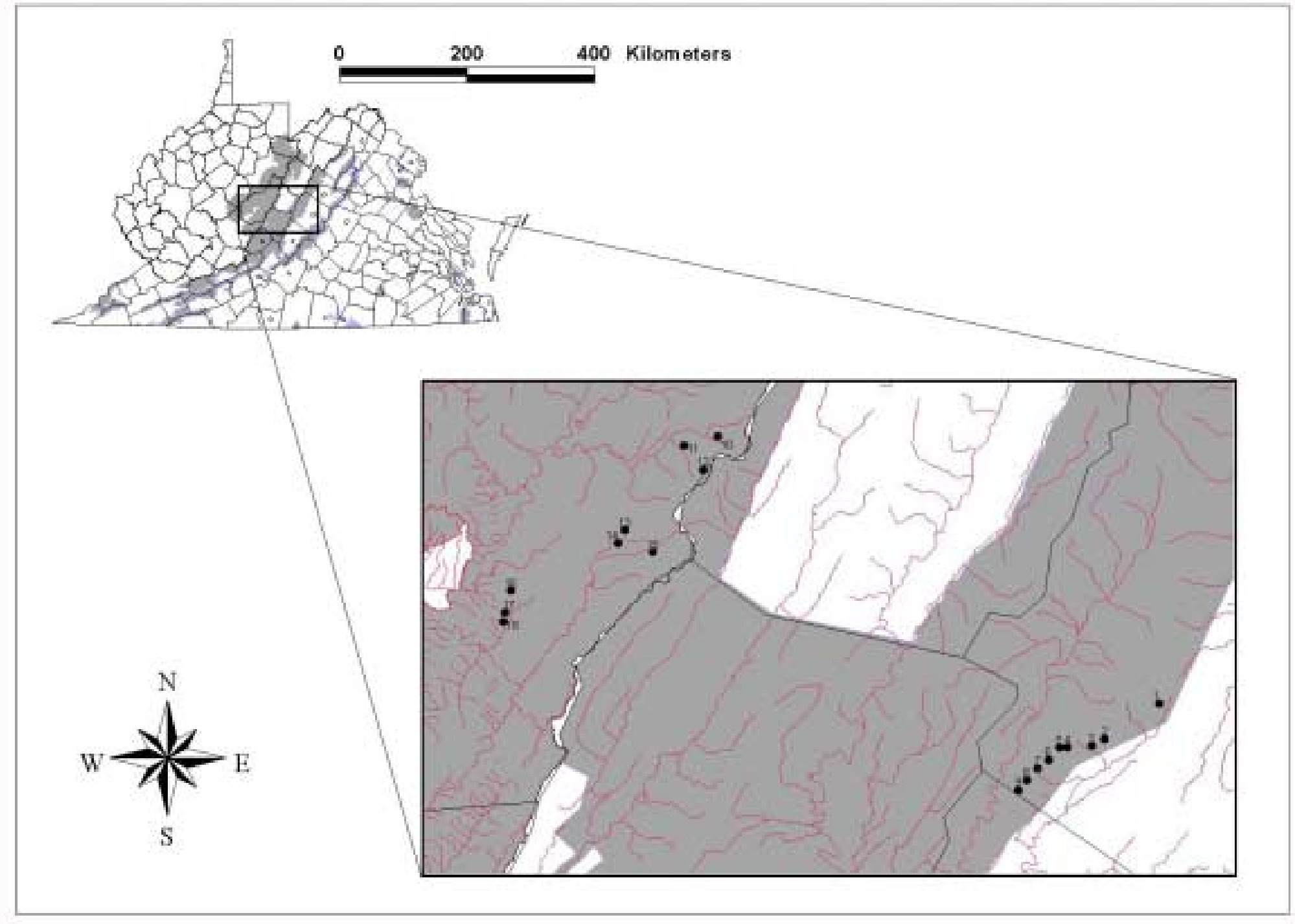


Figure i.2. Map of study sites depicting relative relief. 


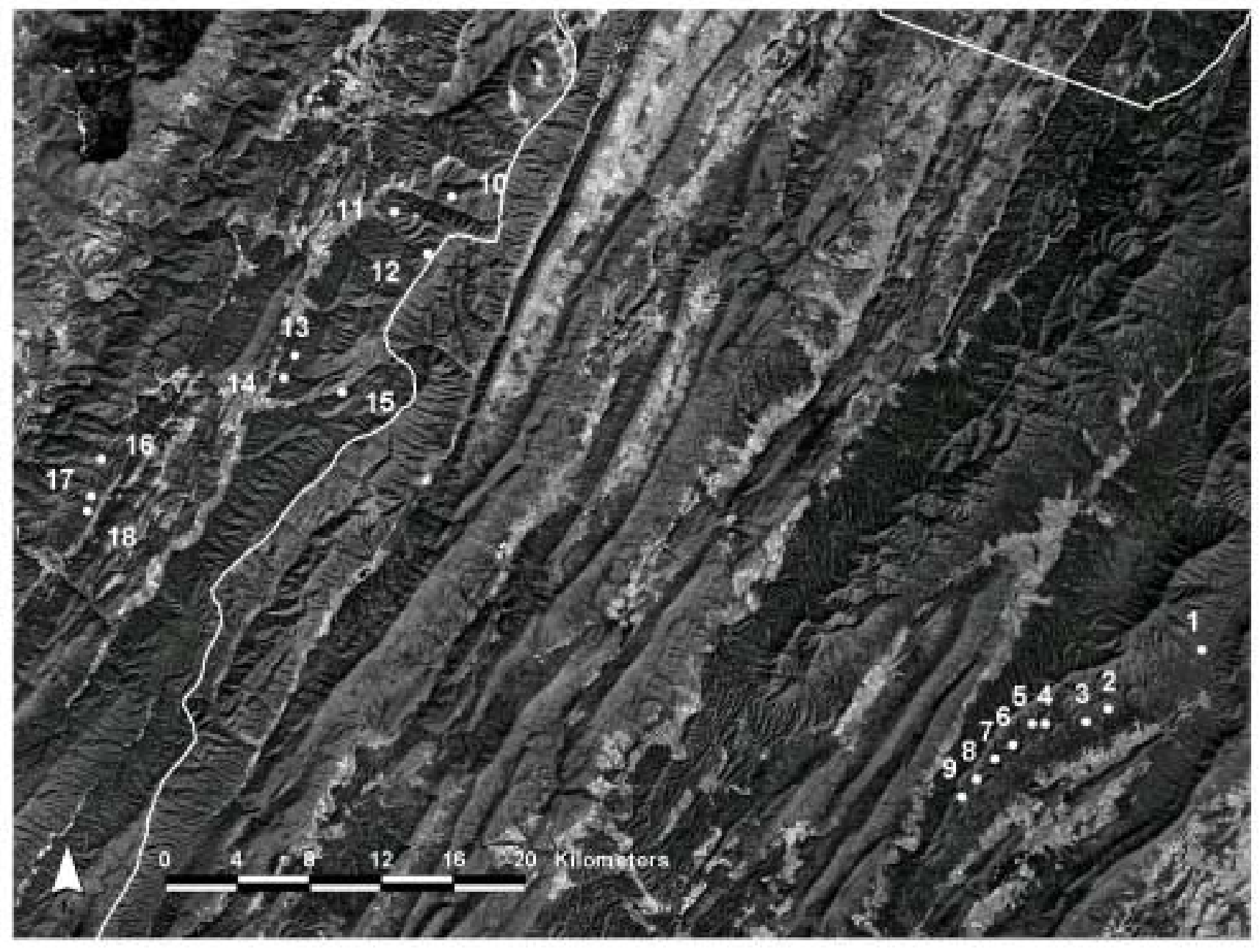


Figure i.3. Average temperatures of the GWNF and MNF during the study period. 


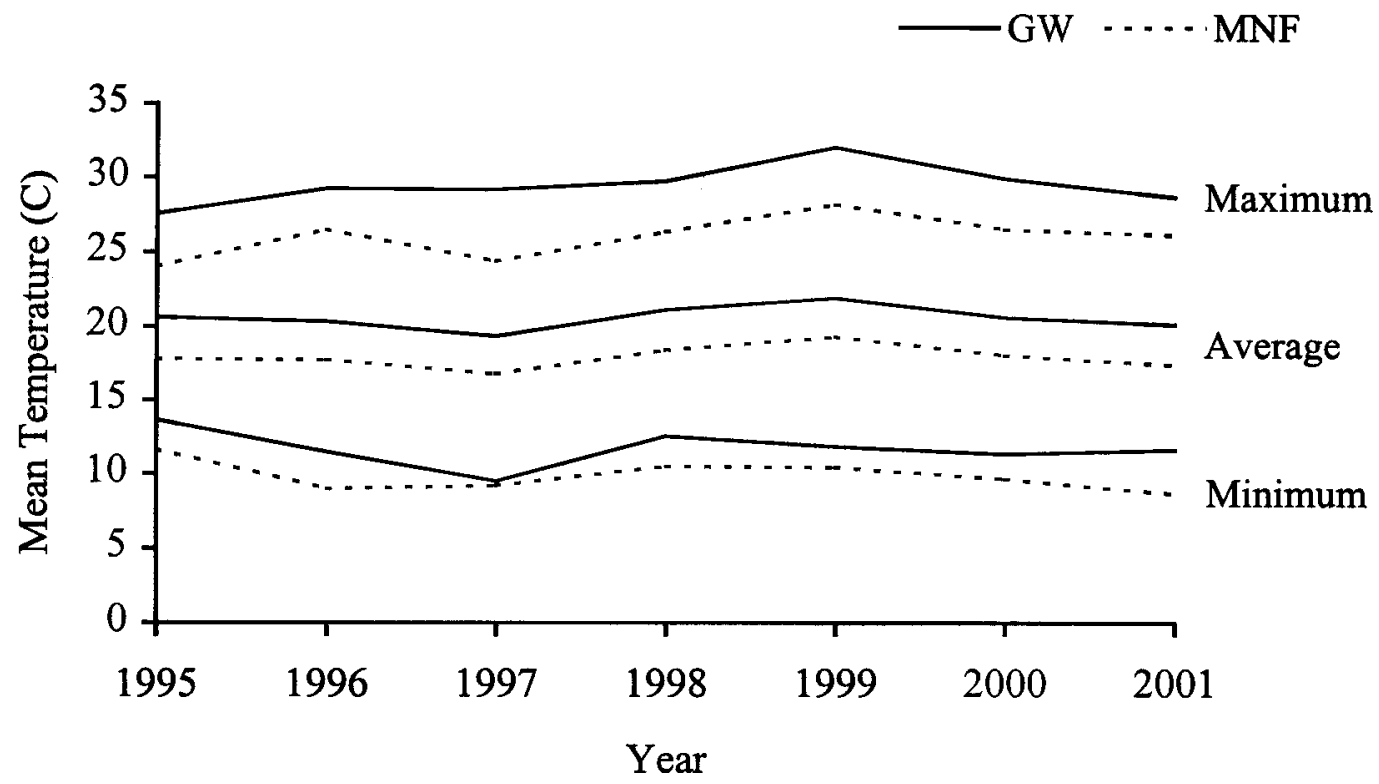


Figure i.4. Total precipitation recorded during the study period. 


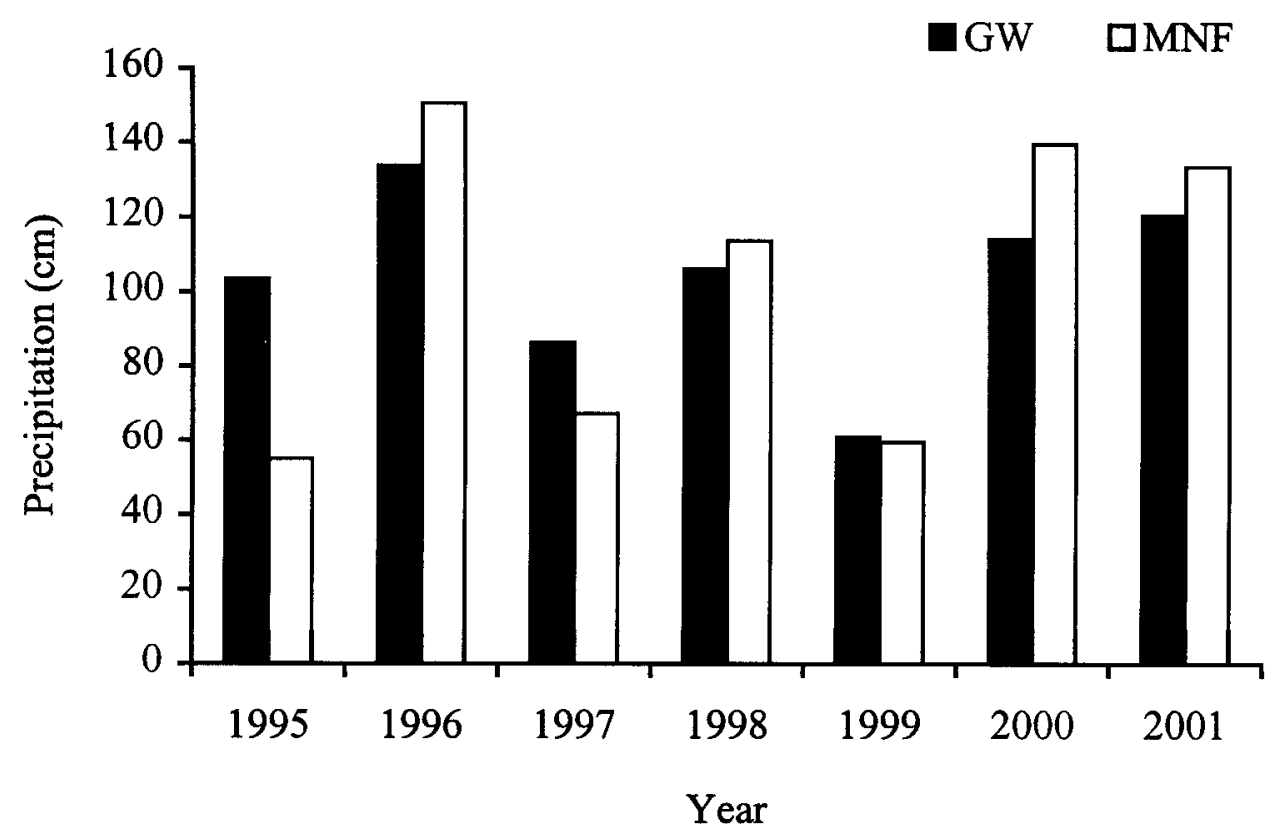


Figure i.5. Relative abundance of the most common plant groups on the study plots. Percentage represents total basal area. 


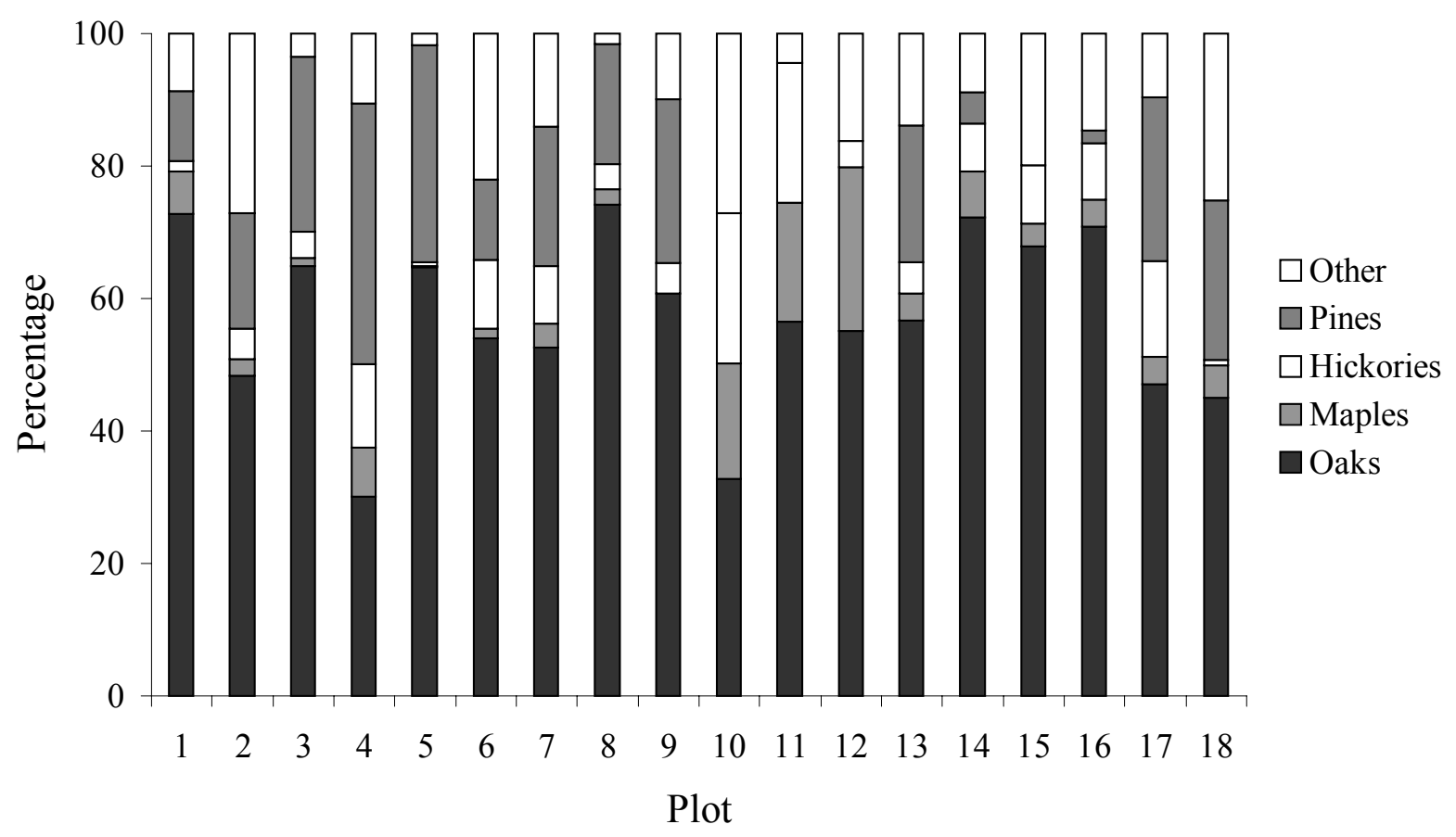




\title{
Chapter 1
}

\section{Lepidoptera Sampling Methods: Correlation of Sampling Techniques Used to Study Lepidoptera Population Dynamics}

\begin{abstract}
Four methods used to study the population dynamics of foliage-feeding Lepidoptera were compared. Ten species, including gypsy moth, Lymantria dispar (L.), were sampled weekly at 12 sites during a 15- week period in 1995 through 2001. Samples consisted of counts of gypsy moth egg masses, counts of larvae under canvas tree bands, counts of larvae collected from foliage clippings, and light trap counts of adults. For each species, Pearson correlation coefficients were used to compare all possible pairs of sampling methods using temporal series, spatial series, and mixed (spatio-temporal) data. For species collected in the greatest abundance, correlations among counts of moths in light traps and counts of larvae on foliage and under canvas bands were high. Larvae collected from foliage samples and canvas bands were weakly correlated in three species. Counts of gypsy moth egg masses were only correlated with foliage samples using temporal series but were correlated with both foliage and canvas band samples using mixed data. Temperature and moon phase significantly affected the number of moths collected from light traps. Strong correlations of light trap counts with larvae collected from foliage samples demonstrates that pooling weekly collections of moths from light traps can describe population dynamics as well as larval collection methods.
\end{abstract}

Key Words: Lepidoptera, sampling techniques, gypsy moth, population dynamics 


\section{Introduction}

Foliage-feeding forest insects are popular models for studying population dynamics (Royama 1992). Specifically, defoliating Lepidoptera (i.e. gypsy moth, Lymantria dispar (L.), and spruce budworm, Choristoneura fumiferana (Clemens)) are the subject of many population dynamics studies as a result of the extensive economic and aesthetic impacts that occur during outbreaks. As with any species, accurate estimates of population size hinge on proper sampling methods. Among some of the methods used for sampling lepidopteran populations are egg mass counts (Liebhold et al. 1994), canvas band and foliage sampling for larvae (Butler and Strazanac 2000a, 2000b), frass drop measurements for larvae (Liebhold and Elkinton 1988), pheromone- bait traps for adults (Allen et al. 1986; Shepard et al. 1985), and light traps for adults (MuirheadThomson 1991; Thomas and Thomas 1994). Although most of these techniques provide useful qualitative data, the accuracy of quantifying density for use in studying population dynamics varies greatly among techniques.

No method is without some inherent problems. For example, Lepidoptera collected from under canvas bands attached to tree trunks vary with time of day, stage of insect, and population density (Liebhold et al. 1986). Bait traps are influenced by wind intensity (Yela and Holyoak 1997), and light trap catches vary with temperature, wind, precipitation, cloud cover, and moon phase (Butler et al. 1999; Yela and Holyoak 1997). Absolute sampling methods include egg mass counts, frass drop measurements, and collection of larvae from foliage clippings. Egg mass surveys, which provide a number of egg masses per acre or hectare, are the most reliable and widely used estimates of gypsy moth density (Sharov et al. 1996); however, they are time consuming and costly 
(Liebhold et al. 1995), which may limit broad applicability. Frass drop measurements are useful in estimating larval gypsy moth populations (Liebhold and Elkinton 1988), but require characteristically shaped frass and high population densities. Foliage sampling yields the number of larvae per area of foliage and samples the principle habitat for defoliating Lepidoptera larvae. Although foliage may be the most logical sampling universe for determining larval abundance (Mason 1987), low numbers of larvae acquired from randomly selected foliage samples may introduce a sampling error that is too great to provide accurate data to study population dynamics.

Over 7 years, Lepidoptera were sampled using gypsy moth egg mass counts, canvas tree bands, foliage samples, and light traps in two forests of Central Appalachia. During the course of this study, data were collected on over 600 species of Lepidoptera (see Butler and Strazanac 2000a, 2000b; Butler et al. 2001). To relate the various techniques and evaluate their efficiency in measuring abundance, correlations were made of data collected from the various sampling methods using temporal series, spatial series, and mixed data (spatio-temporal) of the 10 most common Lepidoptera species, including the gypsy moth.

\section{Materials and Methods}

In 1995, 18 200- ha plots were established in the Monongahela National Forest (MNF), Pocahontas County, West Virginia, and in the George Washington National Forest (GWNF), Augusta County, Virginia to study potential non-target impacts of the gypsy moth pesticides, Bacillus thuringiensis kurstaki Berliner (B.t.k.) and NPV-

Gypchek $^{\circledR}$. In 1997 and 1998, six plots were treated with B.t.k. and six were treated with 
Gypchek $^{\circledR}$. Since B.t.k. reduces the abundance of non-target Lepidoptera larvae (Reardon and Wagner 1995), only the 12 plots that were not treated with B.t.k. were used for nongypsy moth species in the current study. The nuclear polyhedrosis virus, Gypchek ${ }^{\mathrm{TM}}$, is specific to gypsy moth, so only the 6 untreated plots were used for the comparison of gypsy moth collection techniques. Weekly collections of adults and larvae were made during a 15-week sampling period from May to August, 1995 through 2001.

Adults were collected from a single 12-watt black light trap hung within each plot at a height of approximately $1.5 \mathrm{~m}$. Traps were set once a week during the sampling period and opperated throughout one night with traps on all 12 plots operated simultaneously. Samples were collected from the traps the following day, chilled in coolers during transportation, and then placed in laboratory freezers until identified.

Larvae were collected from under canvas bands attached to tree trunks and from foliage clippings. On each plot, canvas bands were stapled around the circumference of each of 12 trees (average DBH $=27.83 \mathrm{~cm} \pm 10.38 \mathrm{std}, \min =7.17 \mathrm{~cm}, \max =69.75 \mathrm{~cm}$ ) to create a refuge for sheltering larvae. The top edge of the canvas bands was approximately $1.5 \mathrm{~m}$ above the ground. Each year on all plots the same 12 trees were banded, 10 of which were oaks (Quercus spp.), 1 was red maple (Acer rubrum L.), and 1 was a hickory (Carya spp.). A conscious effort was made to place half of the bands on trees at the upper elevations of the plot and half on the lower elevations. Larvae were collected from under the bands once a week, placed into plastic vials and refrigerated until they were identified.

Each week during the 15-week sampling periods larvae were also collected from foliage clippings. Foliage samples were taken from 2-3 designated sites within each plot 
that did not overlap with canvas band or light trap sites. Each week, five foliage samples were taken from each plot, each sample containing 21 branch tips of either white oak (Quercus alba L.), chestnut oak (Q. prinus L.), a mix of the red oak group (Quercus (Erythrobalanus) spp.), and sugar or red maple and 15 branch tips of mixed hickory species (Carya spp.). Branch tips consisted of the terminal 6-8 inches of the branch and were clipped from the mid- to lower canopy by pole pruners that were equipped with metal rings which held plastic bags. No more than 2 branch tips were pruned from the same tree each week. Bagged foliage samples were stored in a walk-in cooler $\left(4^{\circ} \mathrm{C}\right)$ until they were hand-gleaned within 3 days of collection. Larval abundance from foliage sampling was calculated as number of larvae per branch tip. All voucher specimens were deposited in the WVU Arthropod Collection.

Each year during winter months (December to March), the number of gypsy moth egg masses were counted in a 1/40- acre subplot at 28 grid points (Kolodny-Hirsch 1986). The number of egg masses per acre were then calculated.

Ten species representing five families were selected for this analysis based on relative abundance of the species in at least two or three sampling techniques (Table 1.1). Adults for most species were generally collected in large numbers and larvae were collected in sufficient numbers from either foliage samples or canvas bands. Only three species (L. dispar, Polia latex Guenée, and Catocala amica Hübner) were collected from both foliage clippings and from under canvas bands.

Pearson correlation coefficients were determined for all possible pair-wise comparisons of foliage samples, canvas bands, and light traps for non-gypsy moth Lepidoptera, and between foliage, canvas bands, and egg masses for gypsy moth. Gypsy 
moths captured in light traps were not included in the analyses because female gypsy moths are flightless and male gypsy moths are primarily diurnal. Therefore, gypsy moths collected in light traps are incidental and would not be considered a reliable census of the population. Comparisons were made using series of annual abundance (temporal comparisons), plot totals over the study period (spatial comparisons), and for each yearplot series (spatio-temporal). Abundance was Log- transformed prior to analyses to normalize the data.

Table 1.1. Study species and total number of individuals from each sampling method used for comparisons.

\begin{tabular}{llrrr}
\hline \hline \multicolumn{1}{c}{ Family } & \multicolumn{1}{c}{ Species } & C & F & \multicolumn{1}{c}{ L } \\
\hline Arctiidae & Hypoprepia fucosa Hübner & 350 & 0 & 14,537 \\
Notodontidae & Heterocampa guttivitta (Walker) & 0 & 281 & 4,341 \\
Geometridae & Hypagyrtis unipunctata (Haworth) & 0 & 268 & 3,839 \\
& Itame pustularia (Guenée) & 0 & 410 & 11,250 \\
Noctuidae & Phoberia atomaris Hübner & 538 & 0 & 82 \\
& Acronicta ovata Grote & 0 & 1,702 & 33,749 \\
& Catocala ilia (Cramer) & 113 & 0 & 97 \\
& Catocala amica (Hübner) & 175 & 52 & 1,293 \\
& Polia latex (Guenée) & 609 & 737 & 1,816 \\
Lymantriidae & Lymantria dispar (L.) & 2,572 & 1,511 & 209 \\
\hline
\end{tabular}

C, canvas bands; F, foliage clippings; L, light trap.

For the three species that were collected from both foliage and canvas band samples, the average weighted- weeks of collection were compared to determine if these two methods collected larvae at similar times of the season. For each species collected with each method, the average collection week weighted with larval counts was calculated for each year $(n=7)$ on each forest $(n=2)$, so that there was the potential of 14 independent observations for each species. The square-root transformation of week was 
used to normalize the data prior to calculating the weighted average. Two-way analysis of variance compared means for each species among methods, forests, and method*forest. Minimum and maximum temperatures and rainfall were measured twice each week at the light trap of each plot. The first reading was taken on the Monday of each week, the day that light traps were set up and canvas bands were checked. The second reading was taken the following day when light traps were dismantled and foliage samples were collected. Light trap catches were related to rainfall $\left(\mathrm{R}_{w}\right)$, minimum $\left(\mathrm{T}_{\text {wmin }}\right)$ and maximum temperatures ( $\left.\mathrm{T}_{w \max }\right)$ over a six day period (Tuesday through Monday), and sample night minimum temperature $\left(\mathrm{T}_{n \min }\right)$, rainfall $\left(\mathrm{R}_{n}\right)$, and moon phase $(\mathrm{M})$ on the night the traps were run. Since canvas band samples were collected on the day light traps were set up, the possible relationship between abundance of larvae collected from under canvas band was related with $\mathrm{T}_{w \min }, \mathrm{T}_{w \max }$, and $\mathrm{R}_{w}$. Foliage samples, which were collected the day light traps were taken down, were related to $\mathrm{T}_{n \min }, \mathrm{T}_{n \max }, \mathrm{T}_{w \min }, \mathrm{T}_{w \max }, \mathrm{R}_{w}$, and $\mathrm{R}_{n}$. Lepidoptera collected by each sampling method were related to environmental parameters by fitting the variables into a stepwise multiple regression equation. To account for spatial autocorrelation among the plots of each forest, the average environmental parameters and average pooled abundance of all Lepidoptera species from all plots within each forest for each week of the sampling period was used. All statistical analyses were performed using SAS software (SAS Institute 1999).

\section{Results}

Significant correlations between larval and adult collection methods were found for 6 of the 9 non-gypsy moth species (Table 1.2). The species with the highest 
correlations were those that were well represented by both adults and larvae. The species Itame pustularia (Guenée), Acronicta ovata Grote, P. latex, and Heterocampa guttivitta (Walker) were collected in relatively high abundance as both larvae and adults and had the strongest correlations using the temporal series $(r>0.93, \mathrm{p}<0.01)$. For A. ovata and H. guttivitta, correlation of light trap and foliage data was highly significant in all three data series, whereas $P$. latex had significant correlations in the temporal and mixed data sets but not the spatial data set (Figure 1.1). Itame pustularia and H. fucosa also had high temporal correlations and moderate correlations using mixed data, but did not have significant correlations using spatial data. For C. amica, both canvas band and foliage samples were significantly correlated with light trap samples. The species that did not have any significant correlations (Hypagyrtis unipunctata (Haworth), Phoberia atomaris Hübner, Catocala ilia (Cramer)) were those that were collected in relatively low numbers from one or all of the sampling methods. The lack of correlation in these species may be due to the proportionately higher sampling error due to small sample sizes. In general, correlations were weak or not significant using spatial data and were negative in some comparisons. The correlations made from mixed and spatial data, although significant in the well represented species, are not as high as correlations made using the temporal series.

Of the three species collected from both foliage clippings and from under canvas bands, $C$. amica had significant correlations of larval abundance collected from these two methods using all three data series. For L. dispar and P. latex, the abundance of larvae collected from foliage and from under canvas bands was only significant using mixed data (Table 1.2). The comparison of weighted mean week found that $L$. dispar and $P$. 
latex larvae were collected from foliage clippings earlier in the season than they were from under canvas bands $\left(\mathrm{F}_{\text {L.dispar }}=24.65 \mathrm{~F}_{\text {P.latex }}=20.84\right.$, d.f. $\left.=25, \mathrm{P}<0.001\right)$. Larval abundance of $C$. amica collected from canvas bands from both forests only differed significantly from foliage samples collected from the GWNF ( $\mathrm{F}=9.5$, d.f. $=13, \mathrm{P}<0.05$ ) (Figure 1.2). All three species were collected from both methods earlier on the GWNF than on the MNF, but these differences were not significant.

Table 1.2. Pearson correlation coefficients for method comparisons.

\begin{tabular}{lcccrcrc}
\hline & & \multicolumn{2}{c}{ Temporal } & \multicolumn{2}{c}{ Spatial } & \multicolumn{2}{c}{ Mixed } \\
\multicolumn{1}{c}{ Species } & Comparison & $\mathrm{r}$ & $\mathrm{P}$ & $\mathrm{r}$ & $\mathrm{P}$ & \multicolumn{1}{c}{$\mathrm{r}$} & $\mathrm{P}$ \\
\hline H. fucosa & $\mathrm{C}+\mathrm{L}$ & 0.925 & $* *$ & -0.037 & $\mathrm{~N} / \mathrm{S}$ & 0.553 & $* * *$ \\
H. guttivitta & $\mathrm{F}+\mathrm{L}$ & 0.938 & $* *$ & 0.657 & $*$ & 0.643 & $* * *$ \\
H. unipunctata & $\mathrm{F}+\mathrm{L}$ & 0.459 & $\mathrm{~N} / \mathrm{S}$ & -0.024 & $\mathrm{~N} / \mathrm{S}$ & -0.009 & $\mathrm{~N} / \mathrm{S}$ \\
I. pustularia & $\mathrm{F}+\mathrm{L}$ & 0.969 & $* * *$ & 0.237 & $\mathrm{~N} / \mathrm{S}$ & 0.501 & $* * *$ \\
P. atomaris & $\mathrm{C}+\mathrm{L}$ & -0.062 & $\mathrm{~N} / \mathrm{S}$ & -0.597 & $\mathrm{~N} / \mathrm{S}$ & -0.278 & $\mathrm{~N} / \mathrm{S}$ \\
A. ovata & $\mathrm{F}+\mathrm{L}$ & 0.958 & $* * *$ & 0.729 & $* *$ & 0.763 & $* * *$ \\
C. ilia & $\mathrm{C}+\mathrm{L}$ & 0.402 & $\mathrm{~N} / \mathrm{S}$ & 0.310 & $\mathrm{~N} / \mathrm{S}$ & 0.179 & $\mathrm{~N} / \mathrm{S}$ \\
C. amica & $\mathrm{C}+\mathrm{L}$ & 0.815 & $*$ & 0.803 & $* *$ & 0.716 & $* * *$ \\
& $\mathrm{~F}+\mathrm{L}$ & 0.642 & $\mathrm{~N} / \mathrm{S}$ & 0.859 & $* * *$ & 0.570 & $* * *$ \\
& $\mathrm{C}+\mathrm{F}$ & 0.881 & $* *$ & 0.769 & $* *$ & 0.624 & $* * *$ \\
P. latex & $\mathrm{C}+\mathrm{L}$ & 0.489 & $\mathrm{~N} / \mathrm{S}$ & -0.163 & $\mathrm{~N} / \mathrm{S}$ & 0.233 & $*$ \\
& $\mathrm{~F}+\mathrm{L}$ & 0.936 & $* *$ & 0.569 & $\mathrm{~N} / \mathrm{S}$ & 0.633 & $* * *$ \\
& $\mathrm{C}+\mathrm{F}$ & 0.691 & $\mathrm{~N} / \mathrm{S}$ & -0.212 & $\mathrm{~N} / \mathrm{S}$ & 0.276 & $*$ \\
L. dispar & $\mathrm{C}+\mathrm{E}$ & 0.653 & $\mathrm{~N} / \mathrm{S}$ & 0.498 & $\mathrm{~N} / \mathrm{S}$ & 0.560 & $* * *$ \\
& $\mathrm{~F}+\mathrm{E}$ & 0.842 & $*$ & -0.280 & $\mathrm{~N} / \mathrm{S}$ & 0.635 & $* * *$ \\
& $\mathrm{~F}+\mathrm{C}$ & 0.627 & $\mathrm{~N} / \mathrm{S}$ & 0.075 & $\mathrm{~N} / \mathrm{S}$ & 0.676 & $* * *$ \\
\hline C. canc
\end{tabular}

$\mathrm{C}$, canvas bands; $\mathrm{F}$, foliage clippings; $\mathrm{L}$, light trap; $\mathrm{E}$, egg mass survey. * $\mathrm{P}=0.05, * *$ $\mathrm{P}=0.01, * * * \mathrm{P}<0.001, \mathrm{~N} / \mathrm{S}$ not significant.

The number of gypsy moth egg masses counted were correlated with larval abundance collected from foliage clippings using temporal series and mixed data $(r>$ 0.635, $\mathrm{p}<0.05$; Table 1.2; Figure 1.3). Egg mass counts were correlated with larval abundance under canvas bands using mixed data only $(r=0.560, \mathrm{p}<0.001)$. 
In the best fit model of environmental factors and moths collected from light traps, all factors significantly influenced the number of moths collected with the exception of $\mathrm{R}_{w}$ and $\mathrm{R}_{n}$ (Table 1.3). The factors that had the strongest influence on the number of moths collected were $\mathrm{T}_{n \min }, \mathrm{T}_{w \max }$, and $\mathrm{M}$. Number of moths collected from light traps was greater at higher temperatures and decreased with an increase of moonlight (Figure 1.4.a). The number of larvae collected from both canvas bands and foliage samples decreased with increasing weekly temperatures, but did not share a strong relationship with rainfall or daily temperatures based on our model (Table 1.3; Figure 1.4.b). 
Table 1.3. Multiple regression table for the effects of environmental factors on the light traps, foliage samples, and canvas bands.

\begin{tabular}{|c|c|c|c|c|c|c|c|c|c|c|}
\hline \multirow{2}{*}{$\begin{array}{c}\text { Environmental } \\
\text { Factor }\end{array}$} & & \multicolumn{3}{|c|}{ Light Traps } & \multicolumn{3}{|c|}{ Foliage } & \multicolumn{3}{|c|}{ Canvas Bands } \\
\hline & & $F$ & $\mathrm{P}$ & $\mathrm{R}^{2}$ & $\mathrm{~F}$ & $P$ & $\mathrm{R}^{2}$ & $F$ & $P$ & $\mathrm{R}^{2}$ \\
\hline Weekly maximum temp & $\mathrm{T}_{\text {wmax }}$ & 25.60 & $<0.0001$ & 0.058 & 10.89 & 0.001 & 0.050 & 4.41 & 0.037 & 0.021 \\
\hline Weekly minimum temp & $\mathrm{T}_{w \min }$ & 11.69 & 0.0008 & 0.024 & 4.96 & 0.027 & 0.022 & & NS & \\
\hline Weekly rainfall & $\mathbf{R}_{w}$ & & NS & & & NS & & & NS & \\
\hline Night minimum temp & $\mathrm{T}_{\text {nmin }}$ & 188.60 & $<0.0001$ & 0.476 & & NS & & & & \\
\hline Night rainfall & $\mathrm{R}_{n}$ & & NS & & & NS & & & & \\
\hline Moonlight & M & 13.56 & 0.0003 & 0.029 & & & & & & \\
\hline
\end{tabular}

NS, not significant. Reported $\mathrm{R}^{2}$ values are partial $\mathrm{R}^{2}$ of the final regression model. 


\section{Discussion}

The number of moths collected weekly from light traps was related to daily temperature and moonlight, supporting the well documented conclusion that moth abundance collected from light traps is influenced by changes in daily environmental conditions (Butler et al. 1999; Holyoak et al. 1997; Morton et al. 1981; MuirheadThomson 1991; Yela and Holyoak 1997). Association of moth abundance with nightly temperature, precipitation, and moonphase indicate that changes in moth abundance in light traps are reflective of changes in nightly flight activity rather than changes in abundance. As a result, light traps have an inherently high sampling error for obtaining absolute population estimates (Holyoak et al. 1997). Conversely, there was no significant influence of daily temperature or rainfall on the abundance of larvae collected from foliage clippings detected during the study. Although larval feeding may vary with time of day and be disrupted by heavy wind or rain, the regression did not detect significant variability of foliage samples with immediate weather conditions. The abundance of larvae collected from foliage clippings was inversely related to weekly temperatures; however this relationship is most likely indicative of changes in larval abundance throughout the season rather than characteristic of the sampling method.

As a consequence of their daily variability, light traps are criticized as an inappropriate sampling method for studying moth population dynamics (Holyoak et al. 1997). However, the annual abundance of moths collected from light traps was strongly correlated with the annual abundance of larvae in well- represented species, indicating that daily environmental effects may be muted when weekly samples are pooled throughout the season. In this study, the annual abundance of well- represented moth 
species collected from light traps documented population behavior as accurately as the annual abundance of larvae collected from foliage samples. Since population dynamics hinge on changes in populations over time, light trap samples taken in the manner described here may be sufficient for studying moth population dynamics.

Holyoak et al. (1997) found that biased abundance estimates of moths collected by light traps were more likely in moth species with shorter flight periods. Of the three species that did not have significant correlations between adult and larval abundance, $P$. atomaris and C. ilia had relatively short flight periods as sampled during our field seasons ( $\leq 7$ weeks), as well as low abundances. Although pooled weekly abundance of moths collected in light traps may provide good estimates of population behavior in wellrepresented species, less abundant species that are only present for a few weeks of the season may still be subjected to high sample error using this method. Weekly collections require a great time and financial commitment that may not be feasible for some longterm studies. Many studies of population dynamics have used pre-existing light trap data sets (Hanski and Woiwod 1993; Miller and Epstein 1986; Taylor 1986) and weekly light trap collections that have been conducted for research purposes other than population dynamics may lend to reliable estimates of population behavior.

Development of accurate methods for measuring larval density would be invaluable for species such as gypsy moth (Liebhold and Elkinton 1988), whose populations are intensely monitored to assess potential damage caused by the larval stage. Most sampling for Lepidoptera larvae has been done using foliage samples (Butler and Strazanac 2000b), and beating foliage may be one of the more time efficient larval sampling methods (Wagner et al. 1997). Canvas, or burlap, tree bands have been used to 
study non-target impacts of pesticides (Butler and Kondo 1993; Wagner et al. 1996), Lepidoptera species richness (Butler et al. 1995, 2000a), life stage mortality (Campbell et al. 1977; Cook et al. 1994), and between-tree movement of gypsy moth (Liebhold et al. 1986), and is a viable sampling method for determining Lepidoptera larval diversity (Butler and Strazanac 2000a). Some caterpillars that feed on canopy foliage descend to the trunk of the tree and seek shelter under the bands during the day. Since not all caterpillars exhibit this behavior, canvas bands may be most useful to sample species such as tussock moths, tent caterpillars, underwing noctuids, and Lithosiinae arctiids (Wagner et al. 1997). However, with the exception of outbreak species, there may not be more than 2-4 larvae for every 10 bands examined (Wagner et al. 1997). Canvas bands collect larvae by providing an artificial resting site and protection against natural enemies. Since larvae congregate under these artificial resting sites (Liebhold et al. 1986), abundance data obtained from canvas bands are relative estimates and do not represent randomly selected areas of a tree trunk.

There was a significant correlation between the number of larvae collected from foliage clippings and from under canvas bands in C. amica using all three data series, but only weak to moderate correlations in L. dispar and P. latex using mixed data series. Comparison of weighted mean collection week of foliage and canvas bands found that the three species in our study were collected from foliage earlier in the season than from under canvas bands, indicating that foliage and canvas band sampling favor early and late instars, respectively. Since late instar larvae of some species, particularly gypsy moth, descend from the tree on which they were feeding and ascend a new tree to exploit the broader host plant range of later instars (Liebhold et al. 1986), this conclusion may be 
intuitive. Although the sample size of three species is hardly exhaustive, these results imply that the relative estimates obtained from canvas bands are only moderately correlated with the absolute abundance obtained from foliage samples, and that these two sampling methods sample different larval stages. In conclusion, caution should be exercised before quantitative data collected from canvas bands are combined with larvae collected from foliage samples to study population dynamics.

The comparison of methods for estimating gypsy moth populations was limited by small sample sizes $\left(\mathrm{N}_{\mathrm{plots}}=6\right)$ and low gypsy moth populations. During the course of the study, gypsy moth populations crashed in 1996 and remained low through 1998. Foliage and canvas band samples indicated an increase on all plots between $1999-2001$, whereas egg masses counted during this period were only found on 3 of the 6 plots, one of which contained almost $80 \%$ of all egg masses counted during that period and experienced visible defoliation in 2001. This difference may be due to either egg masses undetected during the survey or wind-blown dispersal of early instar larvae from plots with high egg mass densities to plots without egg masses counted. The maximum distance between plots that did not have egg masses detected and those that did was approximately $10 \mathrm{~km}$, a distance within the range of larval dispersal according to some authors (Mason and McManus 1981). Although egg mass surveys are the most commonly employed and most accurate estimate of medium to high gypsy moth populations (Sharov et al. 1996), a reliable method for estimating low larval populations on a small scale is still lacking. The correlation of egg mass counts and larval abundance collected from foliage sampling indicates that foliage samples may be adequate to 
estimate low-density gypsy moth larval populations when egg mass survey are either not applicable or do not detect low density egg masses.

For any population of scientific information, inferences are based on information obtained from a sample, and the sample is only as reliable as the method used to collect the data. Since most sampling methods contain variability, understanding their limitations is essential to making accurate evaluations and predictions. This study shows that the high daily variability of light trap samples can be overcome by pooling weekly samples taken throughout the season. Although gypsy moth egg mass counts are accurate estimators of population density, foliage sampling may also provide good estimates of gypsy moth larval density. This study has discussed some of the strengths and weaknesses of insect sampling methods with the goal of reducing sampling error in future population dynamics studies that focus on Lepidoptera.

\section{References Cited}

Allen, D. C., L. P. Abrahamson, D. A. Eggen, G. N. Lanier, S. R. Swier, R. S. Kelly, M. Auger. 1986. Monitoring spruce budworm (Lepidoptera: Tortricidae) populations with pheromone-bait traps. Environmental Entomology. 15: 152-165.

Butler, L. and V. Kondo. 1993. Impacts of Dimilin on non-target Lepidoptera: Results of an operational gypsy moth suppression program at Coopers Rock State Forest, West Virginia. WV Univ. Agric. For. Exp. Stn. Bull. 710.

Butler, L. and J. Strazanac. 2000a. Macrolepidopteran larvae sampled by tree bands in temperate mesic and xeric forests in eastern United States. Proceedings Entomological Society Washington. 102: 188-197.

Butler, L. and J. Strazanac. 2000b. Occurrence of Lepidoptera on selected host trees in two central Appalachian national forests. Annals Entomological Society America. 93: 500-511. 
Butler, L., G. Chrislip, and V. Kondo. 1995. Canopy arthropods at Fernow Experimental Forest in West Virginia's Allegheny mountain section: II. Macrolepidopterous larvae on foliage and under burlap bands. WV Univ. Agric. For. Exp. Stn. Bull. 713.

Butler, L., V. Kondo, E. M. Barrows, and E. C. Townsend. 1999. Effects of weather conditions and trap types on sampling for richness and abundance of forest macrolepidoptera. Environmental Entomology. 28: 795 - 805.

Butler, L., V. Kondo, and J. Strazanac. 2001. Light trap catches of Lepidoptera in two central Appalachian forests. Proceedings Entomological Society Washington. 103: 879 902.

Campbell, R. W., R. J. Sloan, C. E. Biazak. 1977. Sources of mortality among late instar gypsy moth larvae in sparse populations. Environmental Entomology. 6: 865-871.

Cook, S. P., F. P. Hain, and H. R. Smith. 1994. Oviposition and pupal survival of gypsy moth (Lepidoptera: Lymantriidae) in Virginia and North Carolina pine-hardwood forests. Environmental Entomology. 23: 360-366.

Hanski, I. and J. P. Woiwod. 1993. Spatial synchrony in the dynamics of moth and aphid populations. Journal Animal Ecology 62: 656-668.

Holyoak, M., V. Jarosik, and I. Novak. 1997. Weather-induced changes in moth activity bias measurements of long-term population dynamics form light trap samples.

Entomologia Experimentalis et Applicata. 83: 329-335.

Kolodny-Hirsch, D. M. 1986. Evaluation of methods for sampling gypsy moth (Lepidoptera: Lymantriidae) egg mass populations and development of sequential sampling plans. Environmental Entomology. 15: 122-127.

Liebhold, A. M. and J. S. Elkinton. 1988. Techniques for estimating the density of lateinstar gypsy moth, Lymantria dispar (Lepidoptera: Lymantriidae), populations using frass drop and frass production measurements. Environmental Entomology. 17: 381-384.

Liebhold, A.M., J.S. Elkinton and W.E. Wallner. 1986. Effect of burlap bands on between-tree movement of late instar gypsy moth, Lymantria dispar (Lepidoptera: Lymantriidae). Environmental Entomology. 15: 373-379.

Liebhold, A., K. Thorpe, J. Ghent, and D. B. Lyons. 1994. Gypsy moth egg mass sampling for decision-making: A user's guide. U.S. Dept. Agric. For. Ser. FHP NA-TP04-94.

Liebhold, A. M., J. S. Elkinton, G. Zhou, M. E. Hohn, R. E. Rossi, G. H. Boettner, C. W. Boettner, C. Burnham, and M. L. McManus. 1995. Regional correlation of gypsy moth (Lepidoptera: Lymantriidae) defoliation with counts of egg masses, pupae, and male moths. Environmental Entomology. 24: 193-203. 
Mason, R. R. 1987. Nonoutbreak species of forest Lepidoptera, pp. 31-57. In P. Barbosa and J. C. Schultz (eds.), Insect Outbreaks. Academic Press. San Diego, CA.

Mason, C. J. and M. L. McManus. 1981. Larval dispersal of the gypsy moth. In The gypsy moth: Research toward integrated pest management. U.S. Dept. Agric. For. Ser. Tech. Bull. 1584.

Miller, W. E. and M. E. Epstein. 1986. Synchronous population fluctuations among moth species (Lepidoptera). Environmental Entomology. 15: 443-447.

Morton, R., L. D. Tuart, K. G. Wardhaugh. 1981. The analysis and standardization of light- trap catches of Heliothis armigera (Hubner) and H. punctiger (Wallengren) (Lepidoptera: Noctuidae). Bulletin Entomological Research. 71: 205-225.

Muirhead- Thomson, R. C. 1991. Trap Responses of Flying Insects. Academic Press, London.

Reardon, R. and D.L. Wagner. 1995. Impact of Bacillus thuringiensis on nontarget lepidopteran species in broad-leaved forests. In. ACS Symposium Series. F.R. Hall and J.W. Barry (Eds.). 283-292. USDA FHTET-97-05.

Royama, T. 1992. Analytical Population Dynamics. Chapman \& Hall. London.

SAS Institute. 1999. SAS OnlineDoc, version 7-1. SAS Institute. Cary, NC.

Sharov, A. A., A. M. Liebhold, and E. A. Roberts. 1996. Spatial variation among counts of gypsy moth (Lepidoptera: Lymantriidae) in pheromone-baited traps at expanding population fronts. Environmental Entomology. 25:1312-1320.

Shepard, R. F, T. G. Gray, R. J. Chroney, G. E. Daterman. 1985. Pest management of Douglas-fir tussock moth, Orgyia pseudotsugata (Lepidoptera: Lymantriidae): monitoring endemic populations with pheromone traps to detect incipient outbreaks. Canadian Entomologist. 117: 839-847.

Taylor, L. R. 1986. Synoptic dynamics, migration and the Rothamsted Insect Survey. Journal Animal Ecology. 55: 1-38.

Thomas, A. W. and G. M. Thomas. 1994. Sampling strategies for estimating moth species diversity using a light trap in a northeastern softwood forest. Journal Lepidopterists' Society. 48: 85-105.

Wagner, D. L., Peacock, J. L. Carter, and S. E. Talley. 1996. Field assessment of Bacillus thuringiensis on nontarget Lepidoptera. Environmental Entomology. 25: 1444-1454. 
Wagner, D. L., V. Giles, R. C. Reardon, and M. L. McManus. 1997. Caterpillars of Eastern Forests. U.S. Department of Agriculture, Forest Service, FHTET-96-34. 113 pp.

Yela, J. L. and M. Holyoak. 1997. Effects of moonlight and meteorological factors on light and bait trap catches of noctuid moths (Lepidoptera: Noctuidae). Environmental Entomology. 26: $1283-1290$. 
Figure 1.1. Correlations of A. ovata, P. latex, and H. guttivitta using ${ }^{\mathrm{a}}$ temporal series, ${ }^{\mathrm{b}}$ spatial series, and ${ }^{\mathrm{c}}$ mixed data. 

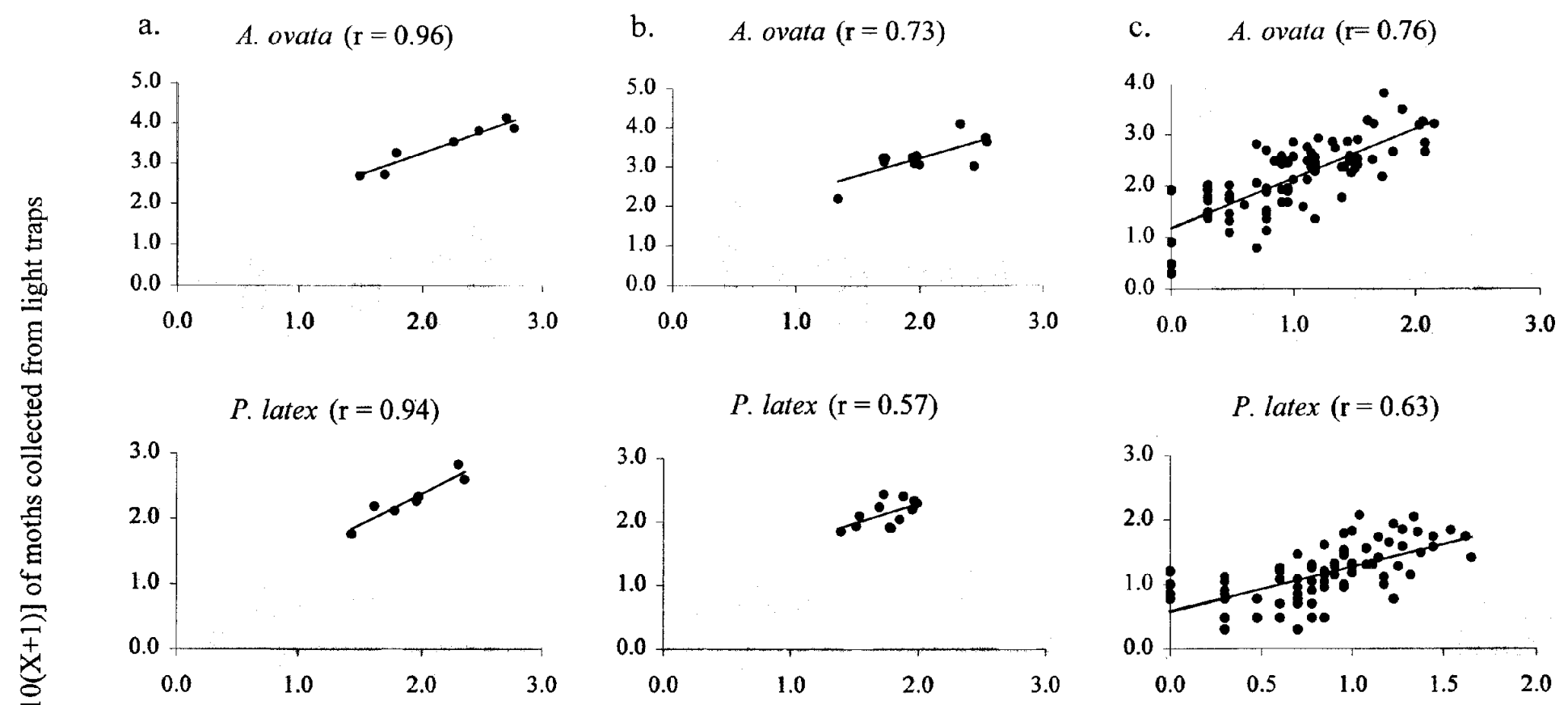

H. guttivitta $(\mathrm{r}=0.94)$

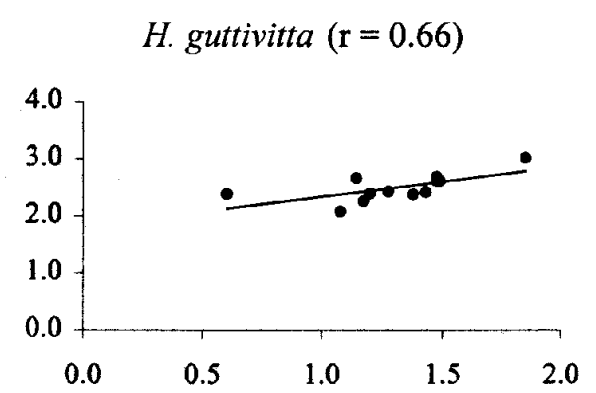

H. guttivitta $(\mathrm{r}=0.64)$

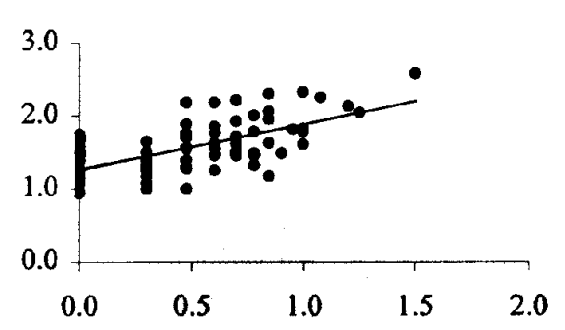

Abundance $[\log 10(\mathrm{X}+1)]$ of caterpillars collected from foliage clippings 
Figure 1.2. Weighted average collection week of larvae collected from foliage clippings and from under canvas bands on the GWNF and MNF. The blocks represent the weighted mean week that larvae were collected \pm the range of weeks larvae were collected throughout the study period. The vertical axis identifies the sampling method $(\mathrm{C}=$ canvas bands, $\mathrm{F}=$ foliage samples $)$ and forest $(\mathrm{G}=$ George Washington, $\mathrm{M}=$ Monongahela $)$. Similar superscripts on sampling method/forest indicate similar groups $(\mathrm{p}<0.05)$. 


\section{L. dispar}

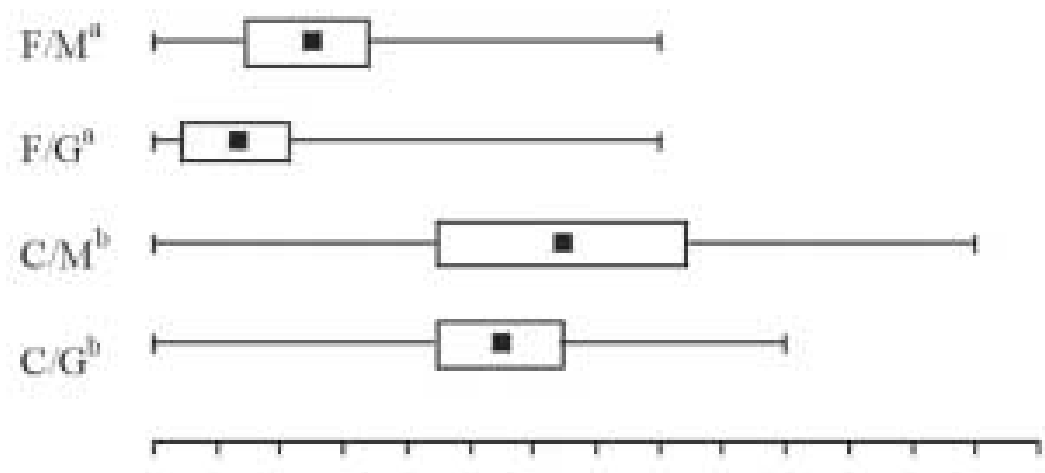

\section{P. latex}
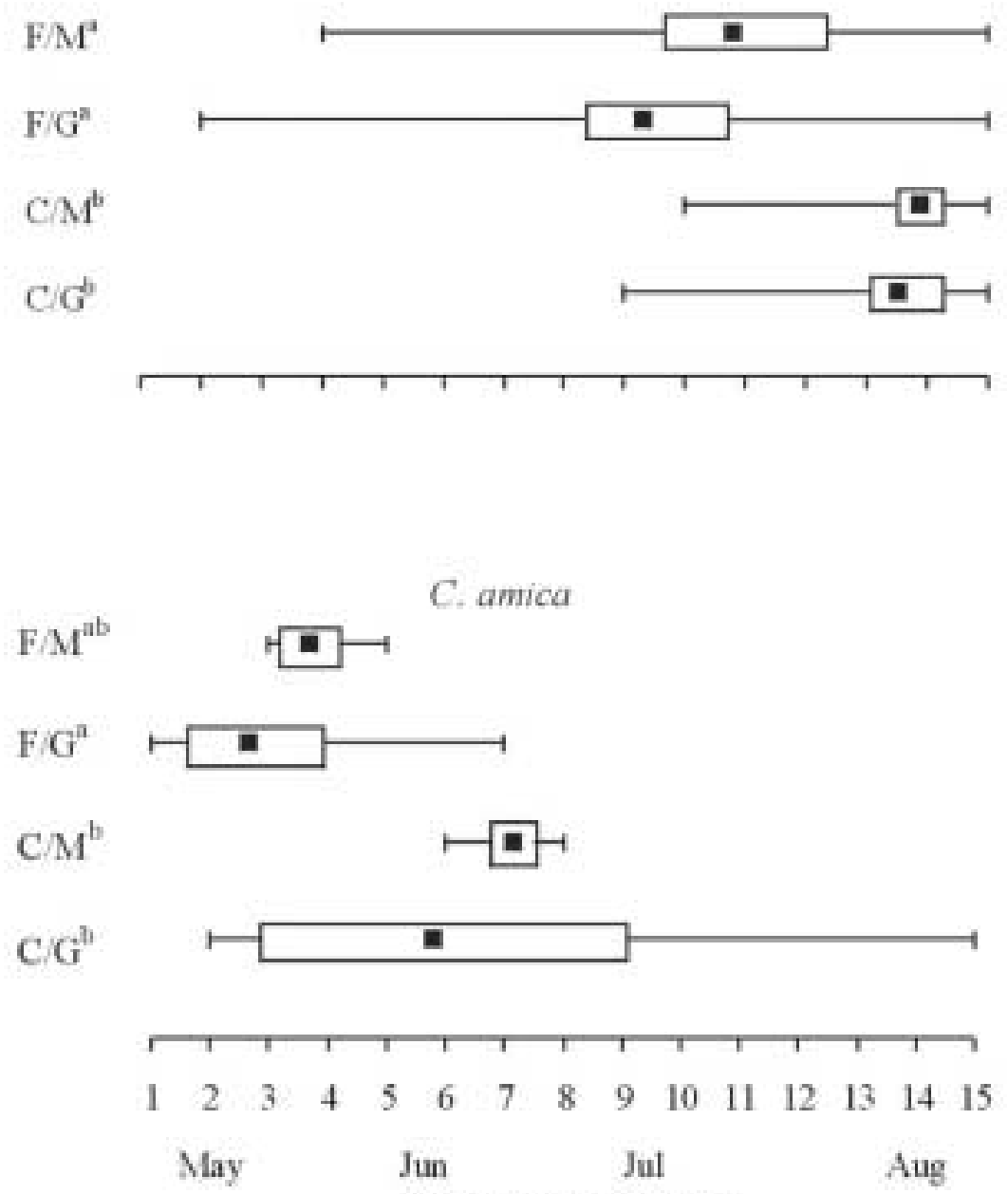

Project Week/Month 
Figure 1.3. Time series of yearly counts for gypsy moth collection methods. $\mathrm{C}=$ canvas bands, $\mathrm{F}=$ foliage, $\mathrm{E}=$ egg mass surveys. Foliage samples were correlated with egg mass counts $(r=0.842, \mathrm{p}<0.05)$. Canvas band samples were not correlated with either foliage or egg mass counts. 


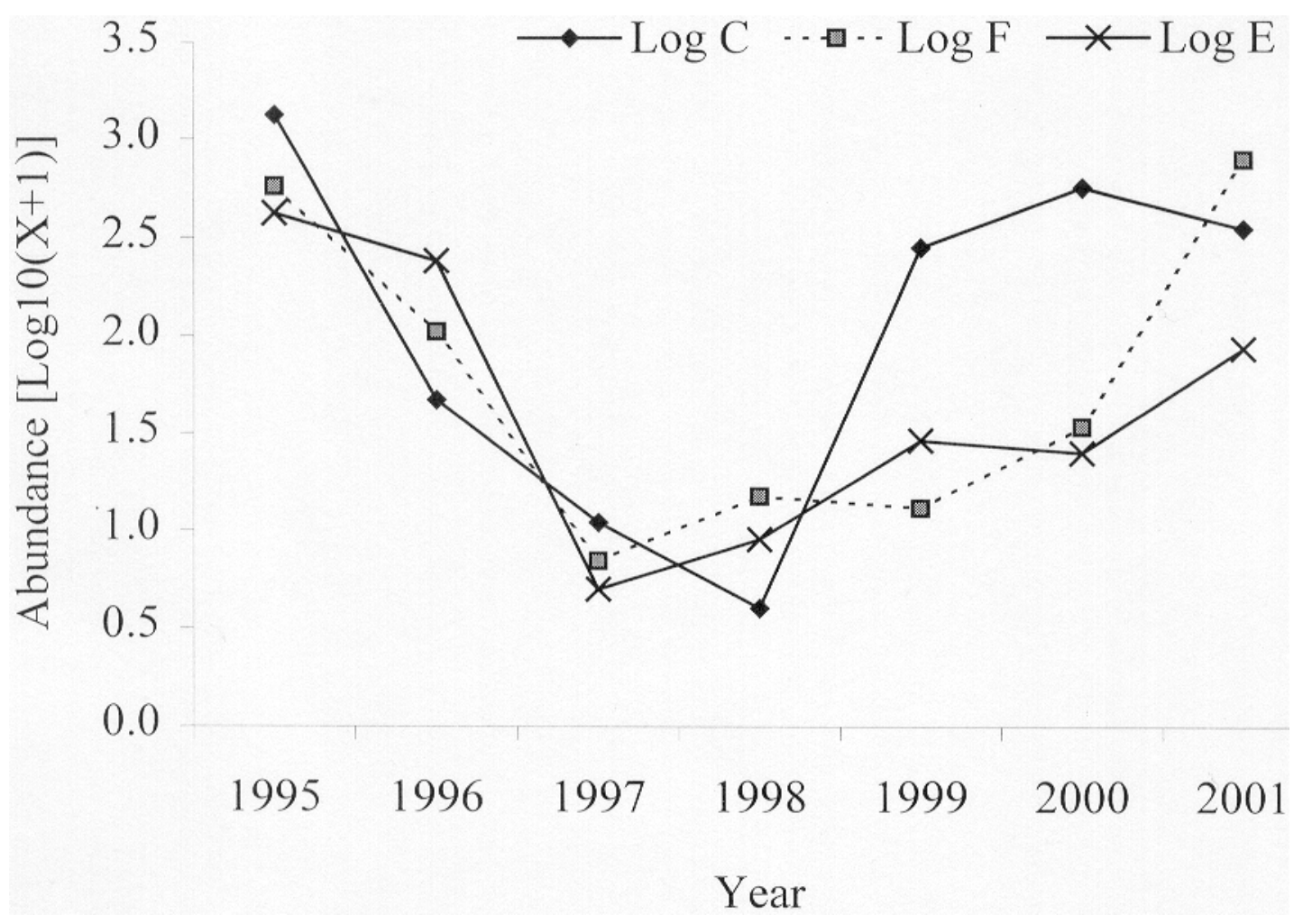


Figure 1.4. (a.) Average abundance of moths collected by light traps compared with $\mathrm{T}_{w \min }, \mathrm{T}_{w \max }, \mathrm{T}_{\text {nmin }}$, and Moonlight. (b.) Average abundance of larvae collected from foliage clippings and from under canvas bands compared with $\mathrm{T}_{\text {wmin }}, \mathrm{T}_{\text {wmax }}$. Graphs represent the average of all plots on both forests in 2001. Abundance is measured as $\log 10(x+1)$, where $x$ is the total number of individuals collected from light traps, foliage clippings, and under canvas bands. 


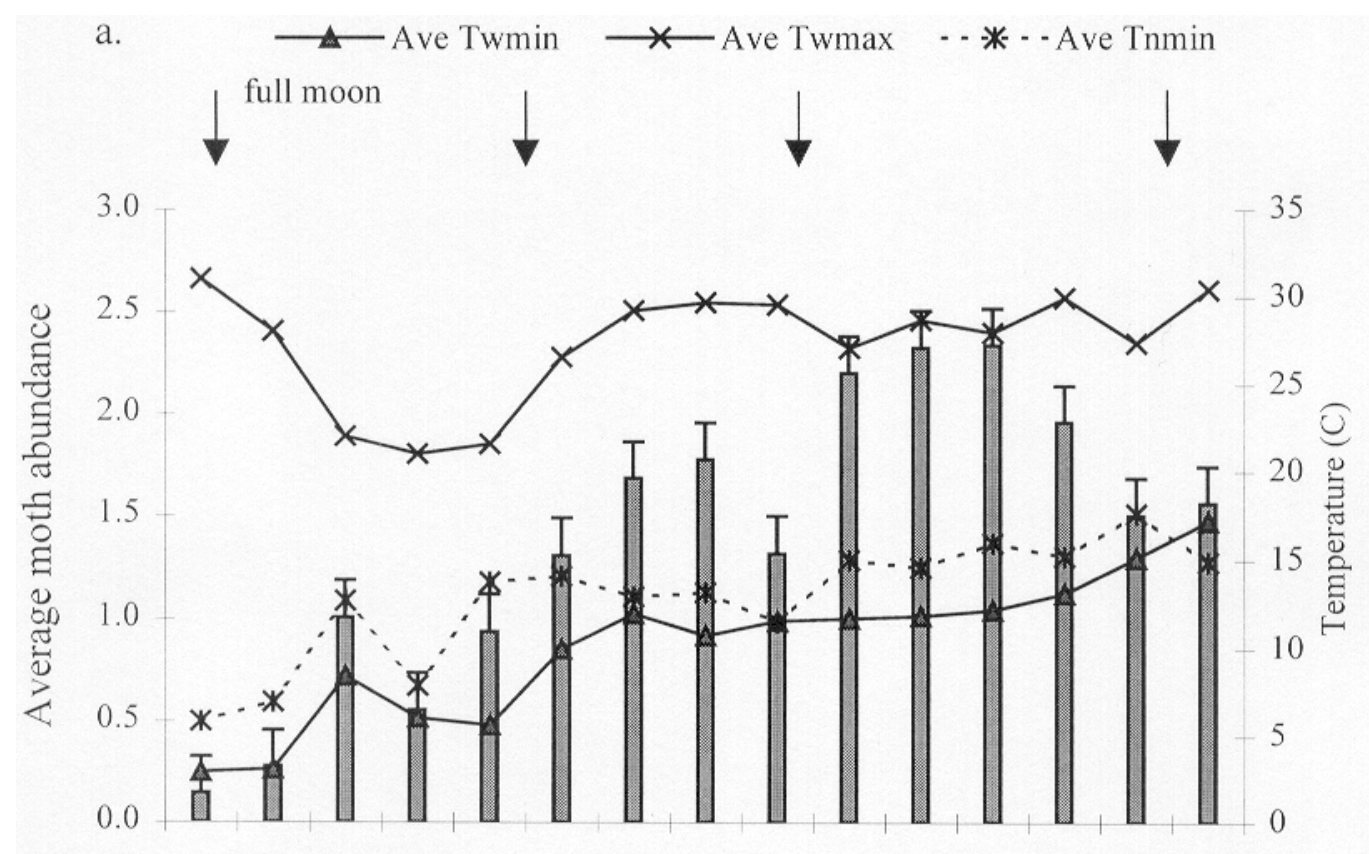

b.

$\square$ Canvas bands $\square$ Foliage $\longrightarrow$ Twmax $\cdots *$ - - Twmin

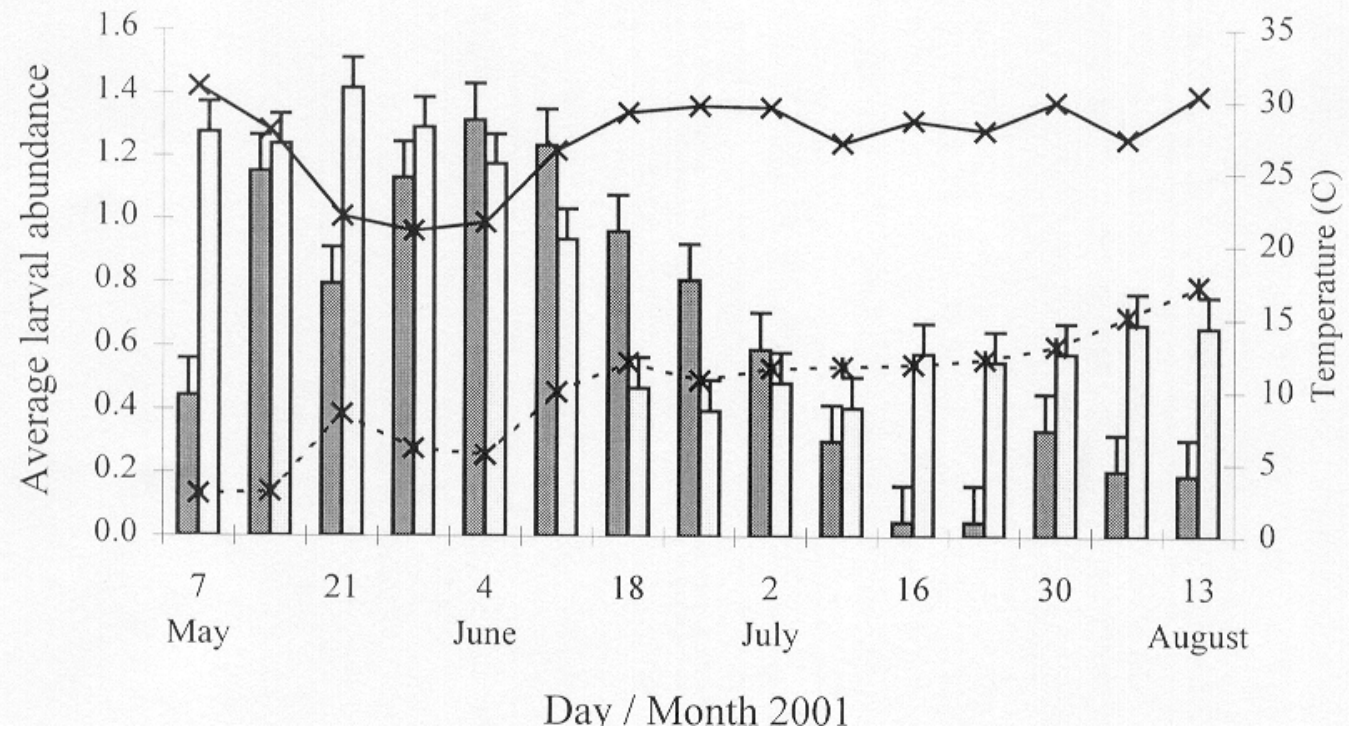




\section{Addendum}

After completion of this study, the species list for the remaining population dynamics studies was revised to include only species that were well represented in light trap samples. Species that were collected in low numbers by light traps (Alsophila pometaria (Harris), Catocala ilia (Cramer), Catocala amica (Hübner), and Phoberia atomaris Hübner) were replaced with those that were relatively well represented (Melanolophia canadaria (Guenée), Besma endropiaria (Grote \& Robinson), Zale minerea (Guenée), and Catocala micronympha Guenée). Revising the species list in this way allowed me to use species data that were collected by one standardized method. Contrary to foliage samples that were collected from various pruning sites from week to week and season to season, light traps were placed in the same locations every week during the entire sampling period, providing an exact geographic location for every sample taken. The revised list of species and descriptions of their natural history can be found in Appendix I. 


\title{
Chapter 2
}

\section{Effects of Bacillus thuringiensis kurstaki on the \\ Population Dynamics of Selected Non-target Lepidoptera}

\begin{abstract}
The microbial pesticide, Bacillus thuringiensis kurstaki (B.t.k.), is frequently applied at the landscape scale to control forest-defoliating Lepidoptera, and the reduction of non-target Lepidoptera where B.t.k. is applied is well documented. This study examined the impact of B.t.k. on the population dynamics of selected Lepidoptera species using a 7- year times series, which included two consecutive years of B.t.k. application, in an effort to detect potentially long-term implications of B.t.k. treatments. The effect of B.t.k. on the population dynamics of 11 non-target Lepidoptera species and gypsy moth was assessed by comparing annual abundance, population growth rate, coefficient of variation, and correlation of time series among plots treated with B.t., the nuclear polyhedrosis virus product Gypchek ${ }^{\circledR}$, and reference plots. There were no differences in abundance or population growth rate among treatment plots for any year of the study and average time series of all treatments were highly correlated. Coefficient of variation was significantly higher on B.t.k. plots for 2 species, but was also significantly lower on B.t.k. plots for 2 species. Long- term ecological impacts of B.t.k. on the focal species in this study are unlikely based on the population parameters measured.
\end{abstract}

Keywords: Bacillus thuringiensis, population dynamics, Lepidoptera 


\section{Introduction}

Since its introduction to Massachusetts in 1869 , the range of the gypsy moth [Lymantria dispar (L.)] has expanded north to Nova Scotia, south to North Carolina, and west to Michigan (U.S.D.A Forest Service 1998). Despite early efforts for its eradication, the gypsy moth has become a ubiquitous feature of northern hardwood forests within its range, particularly in stands dominated by oaks (Quercus spp.), the preferred host of gypsy moth larvae. During years of high gypsy moth densities, larval feeding can completely defoliate host trees; between 1981 and 2001, over 22.5 million hectares of hardwood forests were defoliated by gypsy moth (Gypsy Moth News 2002), and 240 million hectares are considered susceptible to defoliation in the eastern United States (Reardon and Wagner 1995).

Management to slow the spread of gypsy moth and prevent exorbitant economic loss to timber usually employs large scale aerial applications (up to 300,000-ha in 1992) of the microbial pesticide, Bacillus thuringiensis kurstaki Berliner (B.t.k.) (Gypsy Moth News 1992). Although B.t.k. is among the more environmentally benign control agents, it causes a decrease in the number of non-target Lepidoptera where it is applied (Miller 1990a; Reardon and Wagner 1995; Sample et al. 1996; Wagner et al. 1996). Identifying a reduction in caterpillar numbers following pesticide applications is the critical first step in assessing the impact of gypsy moth management. Miller (1990b) proposed that a reduced abundance of non-target Lepidoptera larvae may place species at an "ecological risk" in large-scale management areas. To determine the extent of such risk, non-target impact studies must be expanded to examine the effect of treatment on population dynamics of non-target species. 
The short time frame (less than 3 years) of previous studies of B.t.k. impacts limit the potential to examine long-term ecological effects of pesticide applications. An investigation of the impact of B.t.k. on Lepidoptera population dynamics, which includes effects on population growth rate and population fluctuations, would help discover if the reduction of larvae following B.t.k. applications in successive years is extensive enough to affect the long-term stability of the defoliating feeding guild.

The objective of this study was to examine several population parameters (population abundance, population growth rate, coefficient of variation, and time series analysis) of 12 Lepidoptera species in two gypsy moth management areas. Results of these analyses will help elucidate potential long-term impacts on the population dynamics of native Lepidoptera where B.t.k. is applied for suppression of forest defoliators.

\section{Methods}

\section{$\underline{\text { Treatments }}$}

Within each forest, three plots were randomly designated to be treated with B.t.k., three were treated with the nuclear polyhedrosis virus product Gypchek ${ }^{\circledR}$ (Gyp), and three received no treatment and were established as reference sites (Ref). Treatments were applied in the spring of 1997 and 1998 when white oak leaves had expanded to approximately one-fourth their full length $(1-3 \mathrm{~cm})$. Plot designation and treatment dates are shown in Table 2.1. Aerial applications of B.t.k. (Foray 48F) were administered at a dosage rate of 40 billion international units / ha. Applications of Gyp were at a rate of 8 X $10^{10}$ polyhedral inclusion body / ha. Applications were made to the MNF plots via fixwinged aircraft and to the GWNF plots by helicopters. 
Table 2.1. Treatment - plot designations and treatment dates.

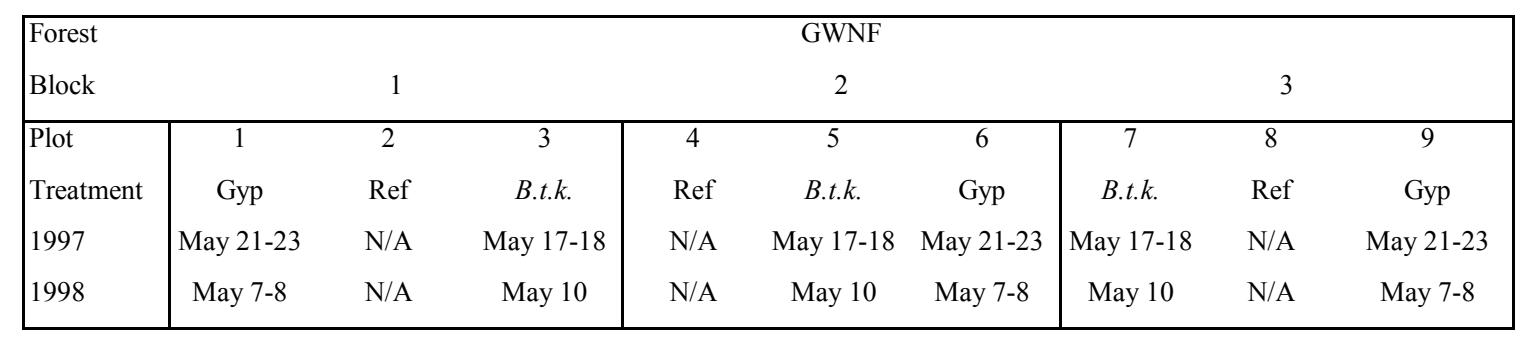

\begin{tabular}{|l|ccc|ccc|ccc|}
\hline \multicolumn{9}{|c|}{ Forest } \\
Block & \multicolumn{9}{c|}{ MON } \\
\hline Plot & 10 & 11 & 12 & 13 & 14 & 15 & 16 & 17 & 18 \\
Treatment & Gyp & B.t.k. & Ref & Gyp & Ref & B.t.k. & Ref & Gyp & B.t.k. \\
1997 & May 23 & May 28-29 & N/A & May 23 & N/A & May 28-29 & N/A & May 23 & May 28-29 \\
1998 & May 13-14 & May 15 & N/A & May 13-14 & N/A & May 15 & N/A & May 13-14 & May 15 \\
\hline
\end{tabular}

$\underline{\text { Statistical Analyses }}$

For each species, potential effects of B.t.k. were determined using four analyses: Analysis of Variance (ANOVA) for species abundance, ANOVA for population growth rate, Wilcoxon sign-test for Coefficient of Variation (CV) among treatment populations, and Pearson correlation of treatment time series. Because the latter three analyses compared characteristics of population behavior, only adult data for non-gypsy moth species and gypsy moth collected from foliage were used for these analyses (Chapter 1). Since B.t.k. directly affects the larval stage, both adult and larval data were used in the ANOVA comparing abundance among treatments. Except where noted, annual abundance of each species was determined as the total number collected throughout the 15- week sampling period.

Analysis of Variance of abundance. Mixed model ANOVAs were performed on log-transformed species abundance data among treatment groups for adults of all species and larvae of species that were sufficiently collected by larval methods (Chapter 1). 
Separate analyses were performed for adults and larvae and two ANOVA models were run for each larval and adult abundance. The first model was performed using only data collected during treatment years and did not include individuals collected during the weeks prior to treatment applications. The second model included data collected from all sampling weeks for all years and was conducted to determine if differences existed among treatments in years prior to and following treatments. All years were included in one model to reduce the probability of type I errors that would result from performing separate ANOVAs for each year. Although treatment years were included in the second model, the first model would be more sensitive to a decrease in abundance following treatment because only individuals collected after the treatments were applied were included in the analysis.

All ANOVA models tested the null hypothesis that there were no differences in abundance among treatment groups and were performed using SAS procedure MIXED (SAS Institute 1990). For all ANOVA models, treatment, year, and treatment*year were the fixed effects and plot nested within forest was the random effect.

Population growth rate. For each species, population growth rate, $r$, was calculated for the generations following treatment (1997-1998, 1998-1999) using the equation $r=\log \left(\mathrm{N}_{\mathrm{t}+1} / \mathrm{N}_{\mathrm{t}}\right)$ where $\mathrm{N}_{\mathrm{t}}$ is the abundance of individuals collected in either 1997 or 1998 and $N_{t+1}$ is the abundance of individuals collected the following year. Mixed model ANOVAs were run similarly to the above analysis where treatment, year, and treatment*year were fixed effects and plot nested within forest was the random effect. Gypsy moth was not used in any of the above ANOVA models because 
populations crashed in 1996 from interactions with the pathogenic fungus Entomophaga maimaiga Humber, Shimauzu, and Soper.

Coefficient of Variation. For each species, coefficient of variation (CV) was calculated for each time series for each plot. Comparing CVs among treatments allowed for the analysis of actual (untransformed) abundance data (Sokal and Rohlf 1995). Wilcoxon sign test compared CVs of all treatment pairs (B.t.k. vs. Ref, B.t.k. vs. Gyp, Gyp vs. Ref). If applications of B.t.k. increased the variability of the populations, B.t.k.treated populations would be expected to have higher CVs than untreated populations with a greater frequency than would be expected by chance. This analysis tested the null hypothesis that populations from all treatments were equally variable.

Correlation of time series. The average log-transformed annual abundance for each treatment was used to generate the average time series of each treatment. Pearson correlation coefficients were calculated for each treatment pair to determine if the fluctuations of populations on B.t.k.- treated plots were correlated with those on Gyp and Ref plots. Since the time series of plots within a forest are spatially autocorrelated, a high level of correlation would be expected. Therefore, little or no correlation of populations on B.t.k.- treated plots with other treatment plots may indicate altered dynamics of these populations.

\section{Results}

In general, very few significant differences were found among treatment plots. The times series of adult abundance of all species depicts the data used for all analyses of this chapter and is shown in Figure 2.1. 
Analysis of Variance. Analysis of variance did not indicate any differences in abundance of larvae collected from treatment plots for any species during the treatment years (Table 2.2). Significant treatment effects were detected for adults of $H$. unipunctata (d.f. $=15, F=4.15, p<0.05$ ), however, differences of least squares means revealed that this difference was due to higher abundance on Gyp plots compared with B.t.k. and Ref plots (Figure 2.1.c). The ANOVA model that included all seven years of data did not indicate any significant differences among treatments in either the pre-treatment or posttreatment years. Analysis of variance also failed to detect significant differences of population growth rates among treatments.

Coefficient of Variation. Significantly higher CVs were found for B.t.k.- treated populations of $H$. unipunctata (B.t.k./Ref: $\mathrm{T}=151, \mathrm{Z}=2.86, \mathrm{p}<0.005 ;$ B.t.k./Gyp: $\mathrm{T}=44$, $\mathrm{Z}=4.54, \mathrm{p}<0.001$ ) and I. pustularia (B.t.k./Ref: $\mathrm{T}=31, \mathrm{Z}=4.74, \mathrm{p}<0.001 ;$ B.t.k./Gyp: $\mathrm{T}=$ $170, Z=2.56, p<0.01$ ) (Figure 2.2.c \& d). Significantly higher CVs were also found for Gyp-treated populations of B. endropiaria (Gyp/Ref: $T=88, Z=3.85, \mathrm{p}<0.001$; Gyp/B.t.k.: $\mathrm{T}=116, \mathrm{Z}=3.41, \mathrm{p}<0.001)$ and $Z$. minerea $($ Gyp/Ref: $\mathrm{T}=126, \mathrm{Z}=3.25, \mathrm{p}<$ 0.005; Gyp/B.t.k.: $\mathrm{T}=170, \mathrm{Z}=2.56, \mathrm{p}<0.01$ ) (Figure 2.2. $\mathrm{f} \& \mathrm{~g}$ ). Significantly lower CVs were found for B.t.k.-treated populations of $H$. guttivitta (B.t.k. $/ \operatorname{Ref}: \mathrm{T}=106, \mathrm{Z}=3.57, \mathrm{p}<$ 0.001; B.t.k./Gyp: $\mathrm{T}=72, \mathrm{Z}=4.1, \mathrm{p}<0.001$ ) and P. latex (B.t.k. $/$ Ref: $\mathrm{T}=105, \mathrm{Z}=3.58, \mathrm{p}<$ 0.001; B.t.k./Gyp: $\mathrm{T}=149, \mathrm{Z}=2.89, \mathrm{p}<0.005$ ) (Figure 2.2. $\mathrm{b} \& \mathrm{k}$ ).

Correlation of treatment time series. For most species, all treatment pairs were highly correlated (Table 2.3). Exceptions were for M. canadaria, in which reference plots were not correlated with either B.t.k. or Gyp time series, which were correlated with each 
other (Figure 2.1.e). Other treatment pairs that were not correlated were B.t.k. / Gyp time series for H. unipunctata and Gyp / Ref time series of Z. minerea (Figure 2.1.c \& g).

Table 2.2. Results of mixed model ANOVA $($ d.f. $=15)$ of treatment effects on larval and adult abundance during treatment years.

\begin{tabular}{|c|c|c|c|c|c|c|c|c|}
\hline \multirow[b]{3}{*}{ Species } & \multicolumn{4}{|c|}{ Larvae } & \multicolumn{4}{|c|}{ Adults } \\
\hline & \multicolumn{2}{|c|}{ Treatment } & \multicolumn{2}{|c|}{ Treatment*year } & \multicolumn{2}{|c|}{ Treatment } & \multicolumn{2}{|c|}{ Treatment*year } \\
\hline & $\mathrm{F}$ & $\mathrm{P}$ & $\mathrm{F}$ & $\mathrm{P}$ & $\mathrm{F}$ & $\mathrm{P}$ & $\mathrm{F}$ & $P$ \\
\hline Hypoprepia fucosa & 0.22 & 0.80 & 1.03 & 0.38 & 0.50 & 0.62 & 0.12 & 0.89 \\
\hline Heterocampa guttivitta & 2.02 & 0.17 & 0.31 & 0.74 & 0.67 & 0.52 & 1.18 & 0.33 \\
\hline Hypagyrtis unipunctata & 0.28 & 0.76 & 0.12 & 0.89 & 4.15 & 0.03 & 0.37 & 0.69 \\
\hline Itame pustularia & 3.30 & 0.07 & 1.43 & 0.27 & 1.76 & 0.21 & 0.27 & 0.77 \\
\hline Melanolophia canadaria & N/A & N/A & N/A & N/A & 0.02 & 0.98 & 0.83 & 0.45 \\
\hline Besma endropiaria & N/A & N/A & N/A & N/A & 0.03 & 0.97 & 1.06 & 0.37 \\
\hline Zale minerea & N/A & N/A & $\mathrm{N} / \mathrm{A}$ & N/A & 0.04 & 0.96 & 0.97 & 0.40 \\
\hline Catocala micronympha & N/A & N/A & N/A & N/A & 1.58 & 0.24 & 1.14 & 0.34 \\
\hline Catocala amica & N/A & N/A & N/A & N/A & 0.08 & 0.92 & 0.27 & 0.76 \\
\hline Acronicta ovata & 0.18 & 0.84 & 2.56 & 0.11 & 1.03 & 0.38 & 0.94 & 0.41 \\
\hline Polia latex & 0.10 & 0.90 & 0.14 & 0.87 & 0.95 & 0.41 & 1.04 & 0.38 \\
\hline
\end{tabular}

Table 2.3. Pearson correlation coefficients for treatment time series of each species.

\begin{tabular}{lccccccc}
\hline \multirow{2}{*}{\multicolumn{1}{c}{ Species }} & \multicolumn{7}{c}{ Treatment Pair } \\
\cline { 2 - 9 } & \multicolumn{2}{c}{ B.t.k./ Ref } & & \multicolumn{2}{c}{ B.t.k. / Gyp } & \multicolumn{2}{c}{ Gyp / Ref } \\
Hypoprepia fucosa & 0.94 & $*$ & 0.94 & $*$ & 0.97 & $*$ \\
Heterocampa guttivitta & 0.85 & $*$ & 0.94 & $*$ & 0.91 & $*$ \\
Hypagyrtis unipunctata & 0.88 & $*$ & 0.62 & & 0.85 & $*$ \\
Itame pustularia & 0.92 & $*$ & 0.94 & $*$ & 0.99 & $*$ \\
Melanolophia canadaria & 0.65 & & 0.80 & $*$ & 0.75 & \\
Besma endropiaria & 0.96 & $*$ & 0.98 & $*$ & 0.95 & $*$ \\
Zale minerea & 0.82 & $*$ & 0.87 & $*$ & 0.64 & \\
Catocala micronympha & 0.99 & $*$ & 0.96 & $*$ & 0.96 & $*$ \\
Catocala amica & 0.97 & $*$ & 0.94 & $*$ & 0.96 & $*$ \\
Acronicta ovata & 0.97 & $*$ & 0.99 & $*$ & 0.98 & $*$ \\
Polia latex & 0.97 & $*$ & 0.97 & $*$ & 0.97 & $*$ \\
Lymantria dispar & 0.97 & $*$ & 0.98 & $*$ & 0.97 & $*$ \\
\hline
\end{tabular}




\section{Discussion}

Although very few significant differences were found among treatments for the species in this study, previous analyses of these data have shown a significant decrease in larval abundance on B.t.k.- treated plots following application (Marshall et al. 2002; Rastall 1999). Whereas this study examined abundance of individual species, Marshall et al. (2002) compared the total number of all larvae collected from foliage. Their analysis, therefore, contained considerably larger samples for each treatment, allowing treatment effects to be more easily detected by their model. Rastall (1999) also used these data to determine B.t.k. treatment effects for individual species and found significantly lower counts of Heterocampa guttivitta larvae on B.t.k. plots compared to Gyp and Ref plots. Although Rastall (1999) used the same data as the current analysis, the inconsistency in results is most likely due to differences in the statistical model used in his analysis and the current study. No significant effects were noted for gypsy moth because populations of all plots crashed in 1996 and remained low during the treatment years.

The current study examined only 11 non-gypsy moth species selected on the basis of the abundance of moths in light traps that was great enough to study population dynamics. As a consequence of the selectivity of the study species, a comprehensive survey of the spring defoliating feeding guild is not adequately represented. Although the majority of the species used in this study are larvae in the spring when treatments are applied, H. guttivitta, B. endropiaria, A. ovata and P. latex overwinter as pupae (or late instar larvae) and were pupae or adults at the time treatments were administered. Hypoprepia fucosa feeds on lichens and mosses and would have had limited exposure to 
B.t.k. spores. Therefore, of the 11 selected species, at least 5 were unlikely candidates for treatment effects.

Of the analyses performed in this study, only comparisons of CVs yielded significant differences among treatments. The two species that exhibited higher CVs on B.t.k. plots were geometrids whose larvae were present at the time of applications. Conversely, the two species that exhibited lower CV on B.t.k. plots were H. guttivitta and P. latex, which were primarily adults at the time of treatment.

The population dynamics of the selected species were studied using the adult census. Although B.t.k. directly affects the larval stage, it is just one of many mortality factors acting on early instar larvae. The adult population size, which is ultimately responsible for recruiting the next generation, is a factor of all the mortality agents acting on all other life stages. Therefore, the degree that B.t.k. affects the adult population may be dependent on the relative impact of treatments compared with other larval mortality factors, as well as the variability of species survivorship curves during treatment years (Gotelli 2001). For example, a late spring freeze occurred on both forests in 1997 and 1998, contributing to low populations of several spring defoliating species on all plots. Extreme weather conditions may have had more of an effect on the population dynamics of the study species than B.t.k. treatment.

Identifying reduced larval abundance is the first step in determining if pesticides affect native species, but does not lend to any indication of long-term ecological consequences. Since Lepidoptera larvae are an integral part of the forest foodweb, a primary concern surrounding B.t.k.- reduced Lepidoptera abundance is how predator populations will respond to a reduction of Lepidoptera (Miller 1990). Predators have 
demonstrated altered behavior as a result of pesticide-reduced abundance of Lepidoptera larvae. Among the documented impacts are delayed nest initiation of Red-eyed Vireos (Vireo olivaceus L.) (Marshall et al. 2002), increased hunting time and decreased brood time of Tennessee warblers (Vermivora peregrina Wilson) (Holmes 1998), reduced nest attempts by Black-throated Blue Warblers (Dendroica caerulescens Gmelin) (Rodenhouse and Holmes 1992), prey switching in songbirds (Sample et al. 1995) and female masked shrews (Sorex cinereus Kerr), and emigration from treated areas by male masked shrews (Bellocq et al. 1992). Indications that predators are affected by pesticideinduced Lepidoptera reductions leads to concern that there are larger ecological implications to B.t.k. treatments and warrants the necessity to study the population dynamics of non-target Lepidoptera.

Studying the population dynamics of Lepidoptera species may help to uncover if B.t.k. impacts are short or long-term. The population parameters examined in this study provide a good assessment of how B.t.k. may impact Lepidoptera populations. The results of this study indicate that the dynamics of the study species experienced very little adverse effects from B.t.k. applications. These results are far from conclusive due to the low number and selectivity of the study species; however, the parameters measured here, population abundance, population growth rate, coefficient of variation, and treatment time series, may be helpful to further studies assessing treatment effects on population dynamics. 


\section{References Cited}

Bellocq, M.I., J. F. Bendell, and B. L. Cadogan. 1992. Effects of the insecticide Bacillus thuringiensis on Sorex cinereus (masked shrew) populations, diet, and prey selection in a jack pine plantation in northern Ontario.

Gotelli, N. J. 2001. A Primer of Ecology. Sinauer Associates, Inc. Sunderland, MA.

Gypsy Moth News. 1992. U.S.D.A. Forest Service Publication. 29. Radnor PA.

Gypsy Moth News. 2001. http://fhpr8.srs.fs.fed.us/wv/gmdigest/gmdigest.html

Holmes, S. B. 1998. Reproduction and nest behaviour of Tennessee warblers Vermivora peregrina in forests treated with Lepidoptera-specific insecticides. Journal of Applied Ecology. 35: 185-194.

Marshall, M. R., R. J. Cooper, J. A. DeCecco, J. Strazanac, and L. Butler. 2002. Effects of experimentally reduced prey abundance on the breeding ecology of the Red-eyed Vireo. Ecological Applications. 12: 261-280.

Miller, J. C. 1990a. Effects of a microbial insecticide, Bacillus thuringiensis kurstaki, on nontarget Lepidoptera in a spruce budworm-infested forest. Journal of Research on the Lepidoptera. 29: 267-276.

Miller, J. C. 1990b. Field assessment of the effects of a microbial pest control agent on nontarget Lepidoptera. American Entomologist. 36: 135-139.

Rastall, K. E. 1999. Potential lethal and sublethal effects of gypsy moth biological treatments on non-target Lepidopterans in two Appalachian forests. Ph.D. Dissertation. West Virginia University. Morgantown, WV.

Reardon, R. C. and D. L. Wagner. 1995. Impact of Bacillus thuringiensis on nontarget Lepidopteran species in broad-leaved forests. In. Biorational Pest Control Agents. F. R. Hall and J. W. Berry (Eds.). ASC Symposium Series 595. pp. 284-292.

Rodenhouse, N. L. and R. T. Holmes. 1992. Results of experimental and natural food reductions for breeding Black-throated Blue Warblers. Ecology. 73: 357-372.

Sample, B. E., R. J. Cooper, and R. C. Whitmore. 1995. Dietary shifts among songbirds from a diflubenzuron-treated forest. The Condor. 95: 616-624.

Sample, B. E., L. Butler, C. Zivkovich, R. C. Whitmore, and R. Reardon. 1996. Effects of Bacillus thuringiensis var. kurstaki and defoliation by the gypsy moth [Lymantria dispar (L.) (Lepidoptera: Lymantriidae)] on native arthropods in West Virginia. The Canadian Entomologist. 128: 575-592. 
SAS Institute. 1990. SAS procedure guide, version 6, third ed. SAS Institute, Cary, North Carolina.

Sokal, R. R. and F. J. Rohlf. 1995. Biometry: the principles and practice of statistics in biological research. $3^{\text {rd }}$ ed. W.H. Freeman and Company. New York.

U.S.D.A. Forest Service. 1998. Online document.

http://www.fs.fed.us/ne/morgantown/4557/gmoth/spread/

Wagner, D. L., Peacock, J. L. Carter, and S. E. Talley. 1996. Field assessment of Bacillus thuringiensis on nontarget Lepidoptera. Environmental Entomology. 25: 1444-1454. 
Figure 2.1 a-c. Treatment time series of H. fucosa, H. guttivitta, and H. unipunctata. 


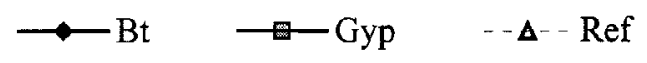

a. Hypoprepia fucosa
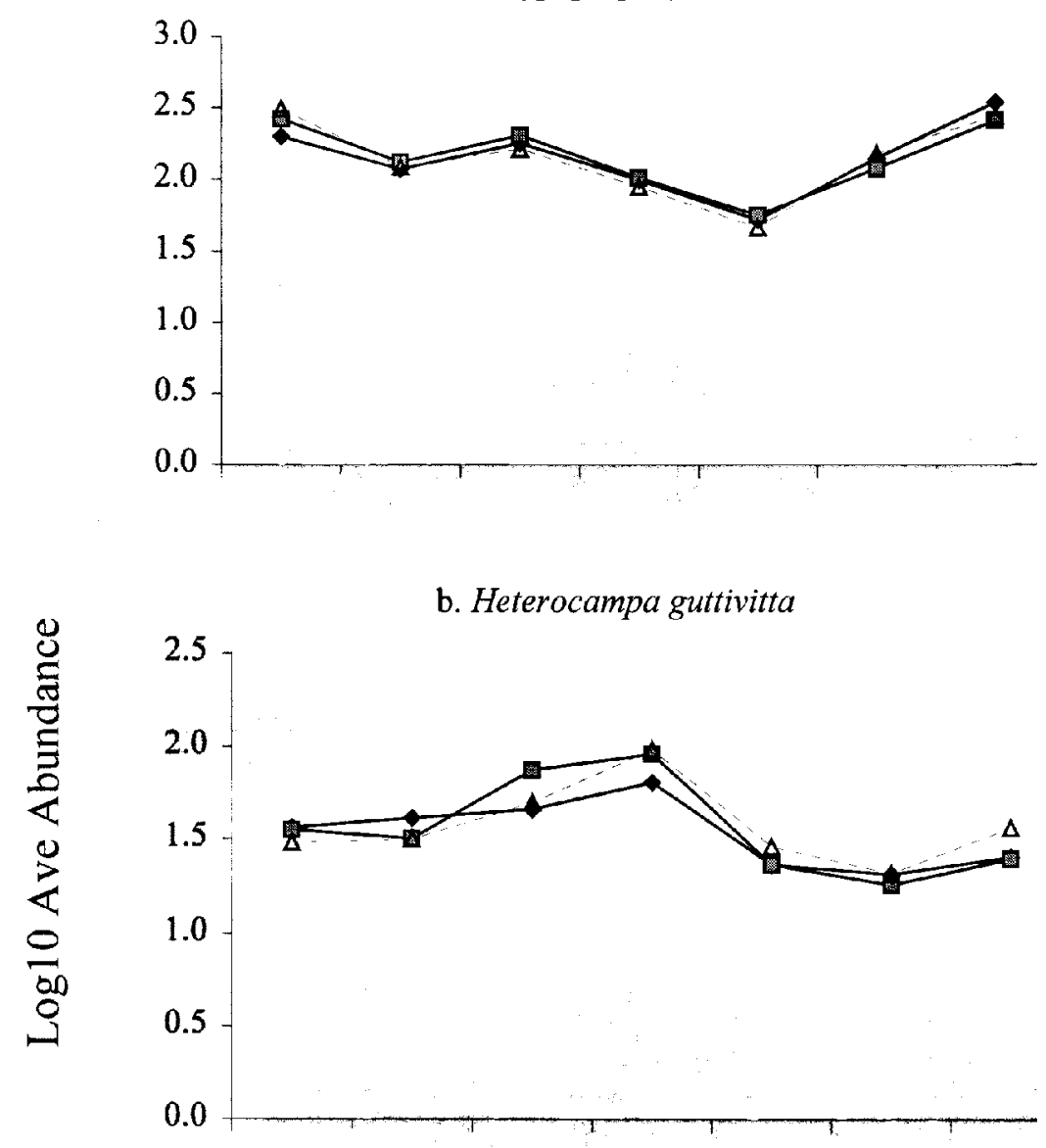

c. Hypagyrtis unipunctata

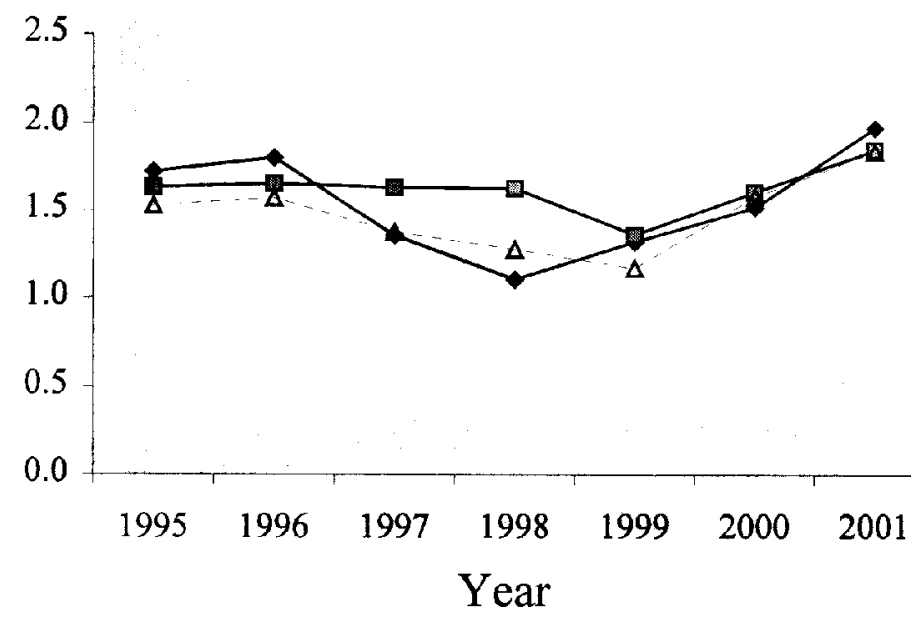


Figure 2.1 d-f. Treatment time series for I. pustularia, M. canadaria, and B. endropiaria. 

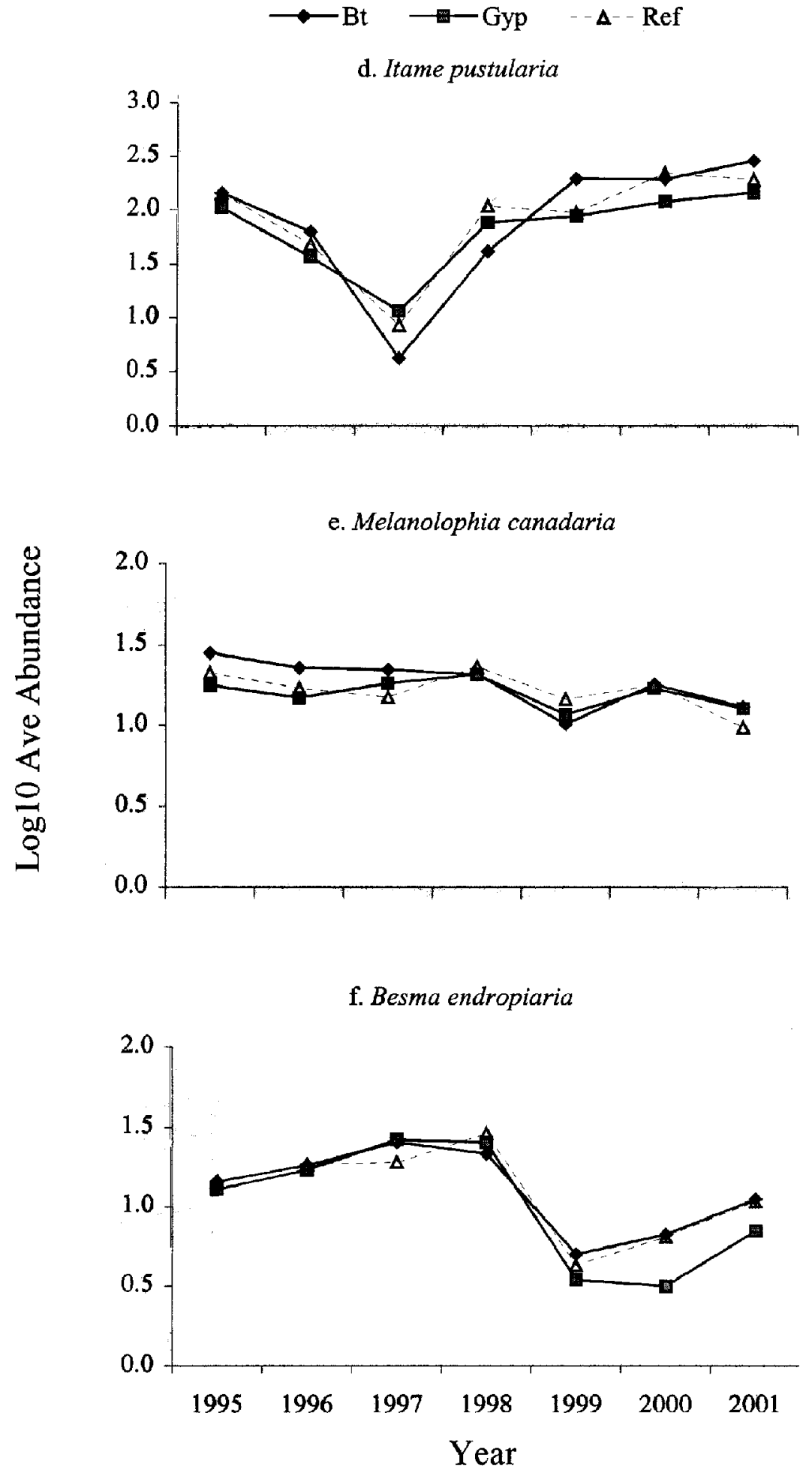
Figure 2.1 g-i. Treatment time series for Z. minerea, C. micronympha, and C. amica. 


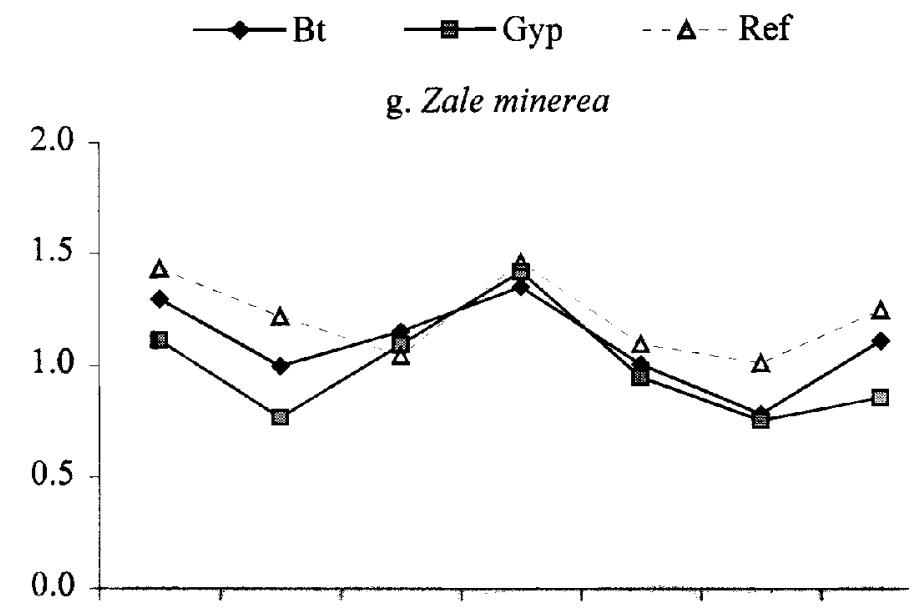

h. Catocala micronympha

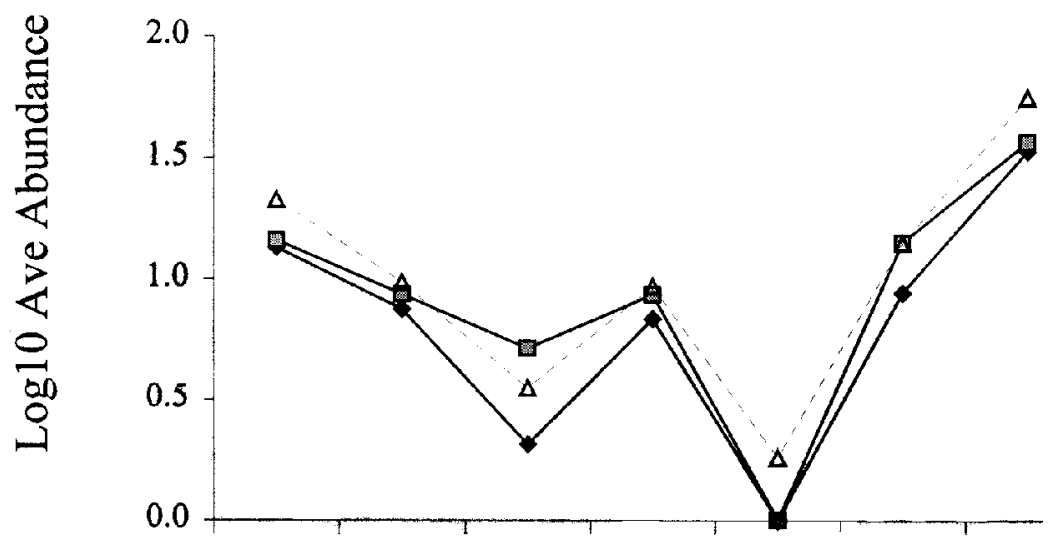

i. Catocala amica

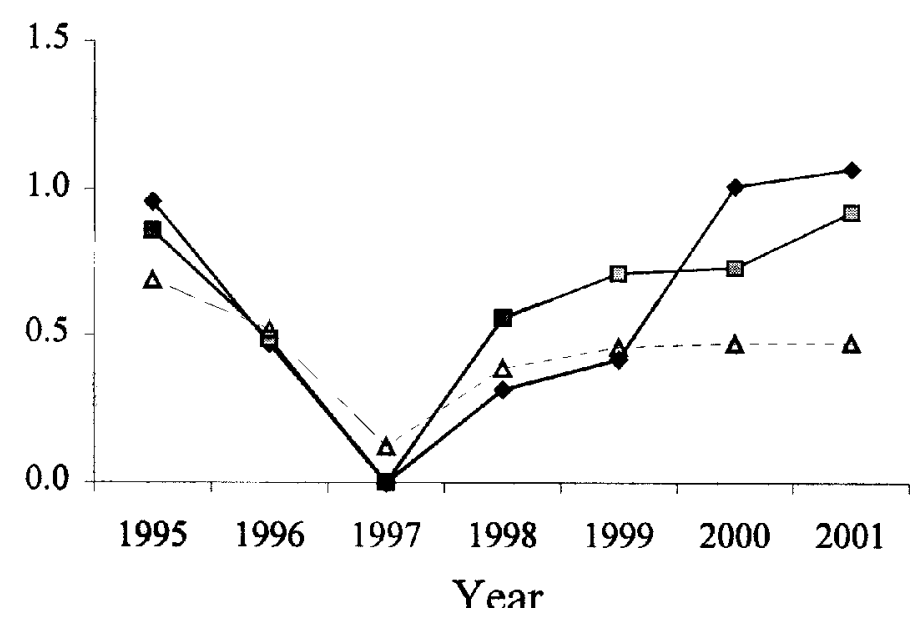


Figure $2.1 \mathrm{j}-1$. Treatment time series for A. ovata, P. latex, and L. dispar. 

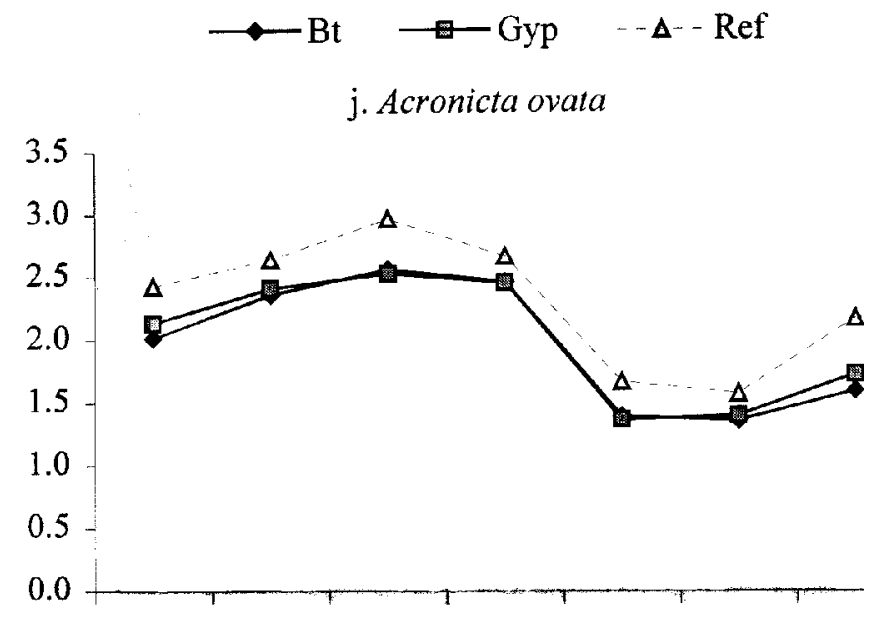

k. Polia latex

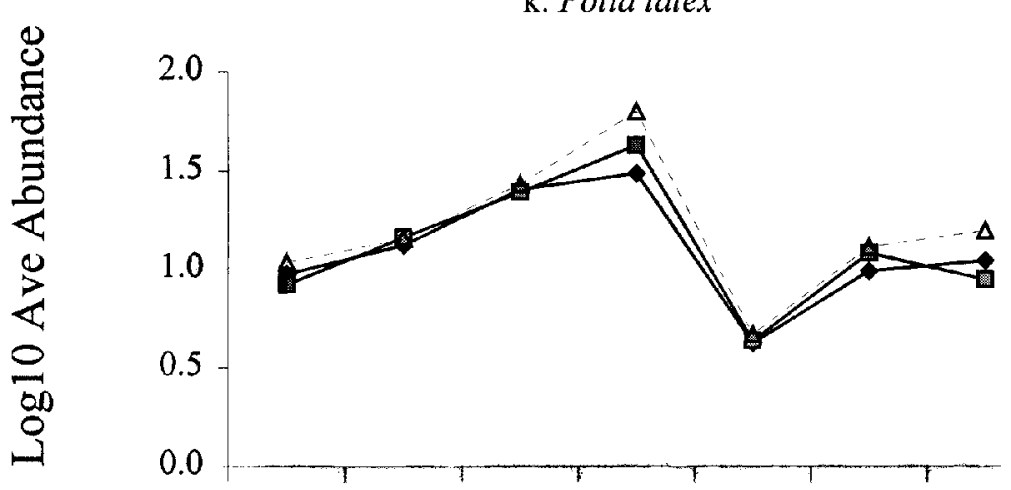

1. Lymantria dispar

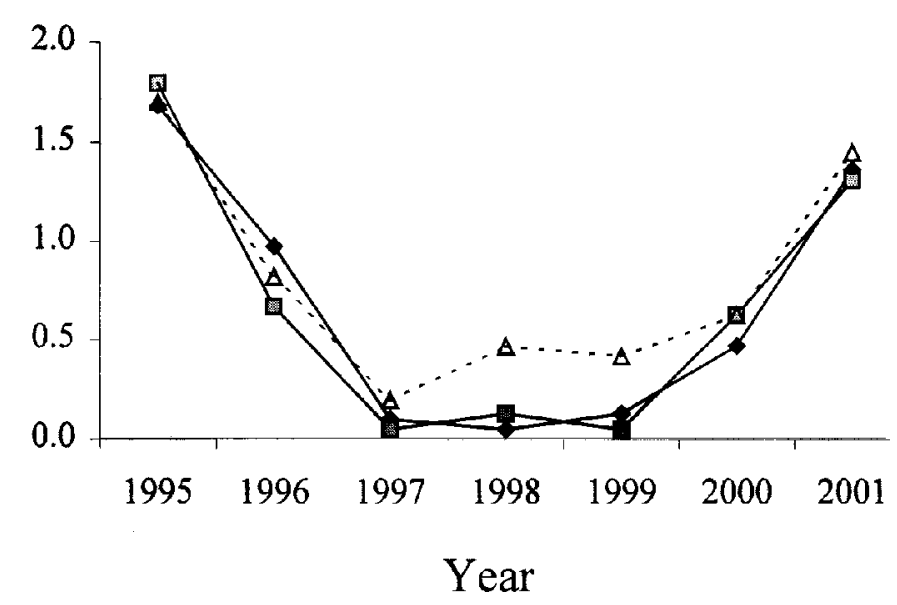


Figure 2.2. Coefficient of variation among treatments for each species. Treatments that were significantly different are indicated by the asterisk (Wilcoxon sign test, $\mathrm{p}<0.05$ ). 

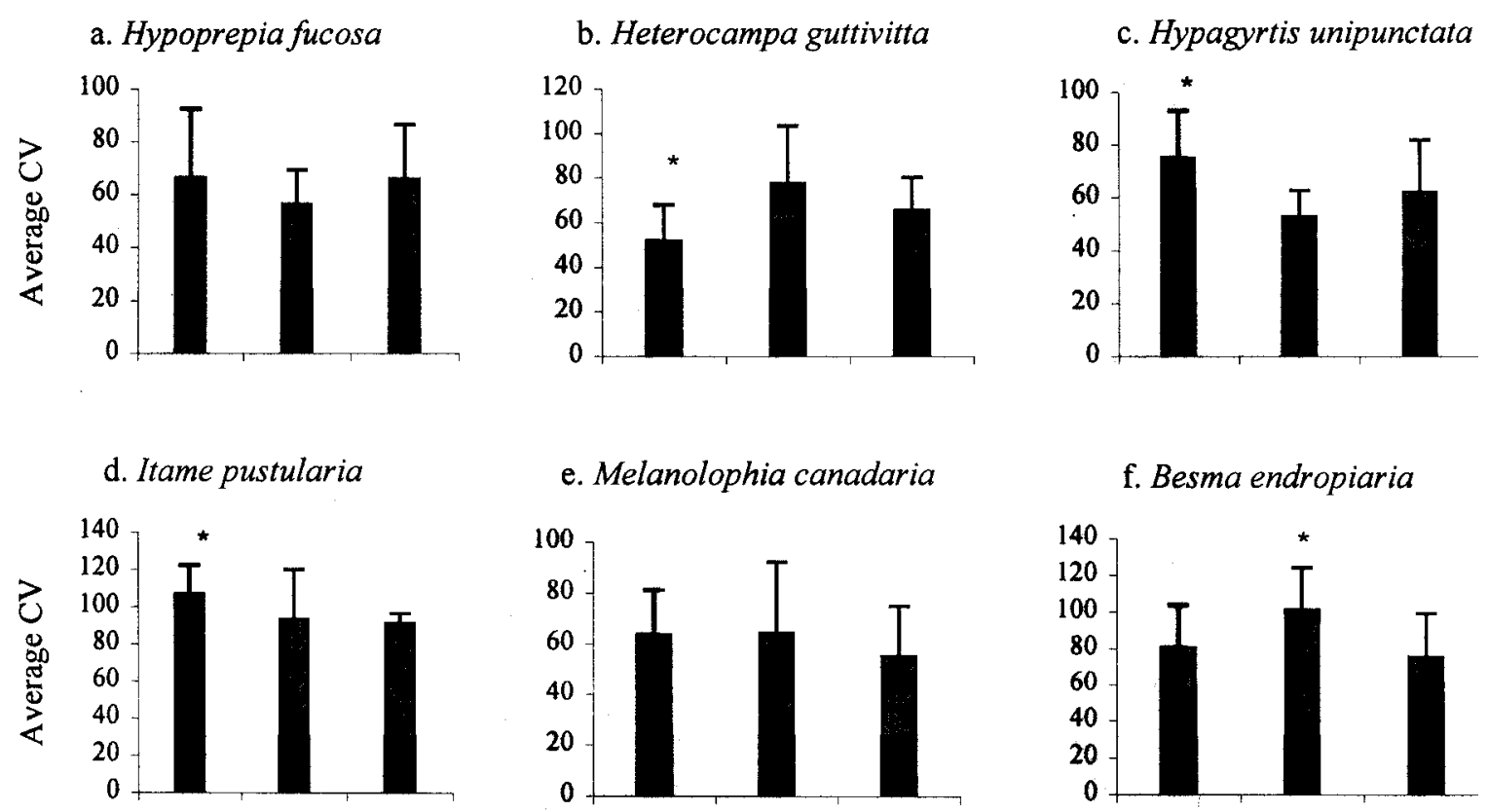

e. Melanolophia canadaria

f. Besma endropiaria
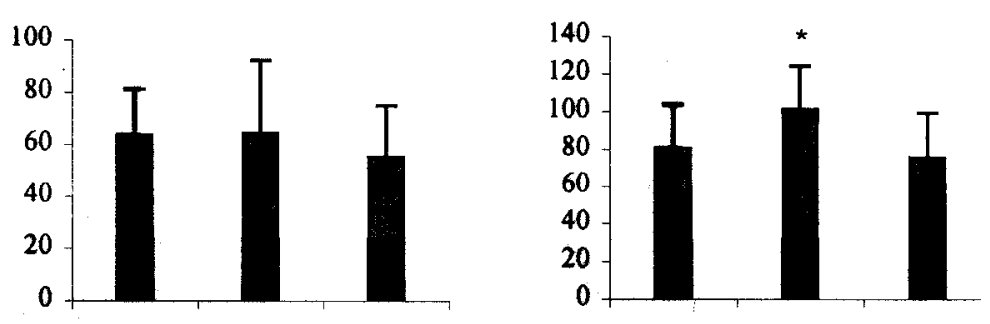

g. Zale minerea

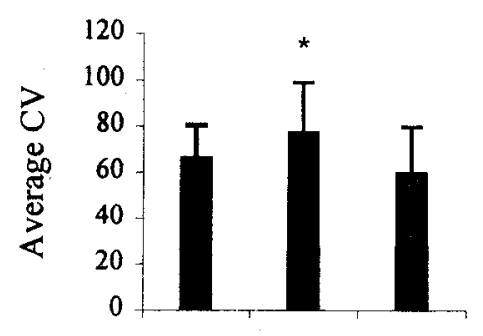

h. Catocala micronympha

i. Catocala amica
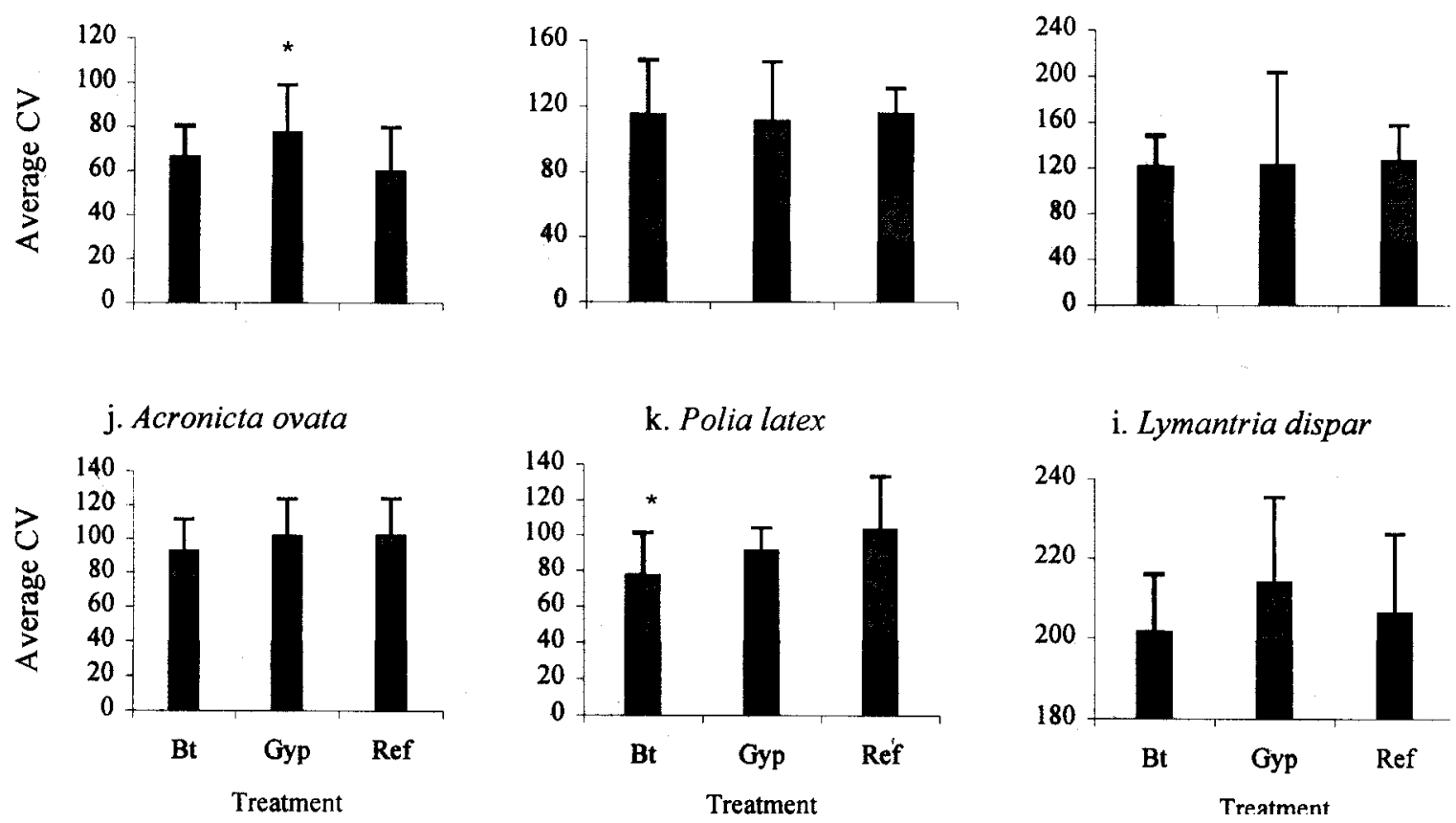

i. Lymantria dispar

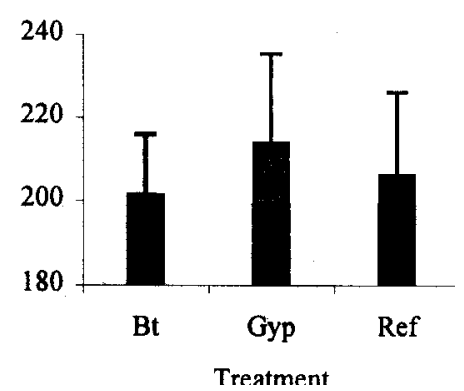




\title{
Chapter 3
}

\section{Spatial Synchrony Within and Among Native Lepidoptera Species: Patterns of Synchrony with Relation to Climate, Phylogeny, Phenology, and Upper-Story Canopy}

\begin{abstract}
Spatial synchrony of Lepidoptera populations from 12 sites was measured using region-wide cross-correlation functions and the pattern of synchrony was determined by regressing the correlation coefficient of local populations against the distance separating each pair of populations. Based on both the pattern of synchrony and the region-wide cross-correlation coefficients, 8 of 10 Lepidoptera species appear to be synchronized, at least in part, by local climatic conditions. Interspecific region-wide cross-correlations were calculated for all species pairs and patterns of interspecific synchrony were related to phylogeny, larval phenology, geographic distribution based on canopy vegetation, and climate. Interspecific synchrony was highest among species whose larvae were present during the same time of the season, but there was no relationship between interspecific synchrony and family classification or geographic distribution. The climate variable representing minimum temperatures was correlated with both members of the majority $(90 \%)$ of synchronous species pairs and is indicated as a potential mechanism involved in synchronizing populations of different species.
\end{abstract}

Key Words: Spatial synchrony, interspecific synchrony, region-wide cross-correlation, climate 


\section{Introduction}

Central to the study of insect population dynamics are species that cause exorbitant economic damage, either as exotic species lacking a natural enemy complex and/or through cyclic outbreaks. Despite numerous studies on the population dynamics of outbreaking species, little research has been conducted on the dynamics of nonoutbreaking, native species. However, the dynamics of outbreak species are likely influenced by the non-outbreak species that feed on the same foliage (Faeth 1987; Mason 1987), particularly in non-outbreak years, and the progress of understanding outbreak dynamics may be facilitated by studying associated species (Cappuccino 1995). The overwhelming majority of non-outbreaking species (generally $>90 \%$ of defoliating feeding guild, Markin 1982) impresses the importance of incorporating their population dynamics where outbreak species are intensely studied.

Gypsy moth (Lymantria dispar L.) is an eruptive species that causes severe damage to timber throughout eastern North America during years of high larval densities. Gypsy moth population dynamics have been extensively studied (for review, Elkinton and Liebhold 1990), yet only recently have the native Lepidoptera species associated with gypsy moth been identified in central Appalachia (Butler and Strazanac 2000a, b; Butler et al. 2001). This is the first study to explore the population dynamics of these native species in an effort to provide a fuller understanding of the lepidopteran community in which gypsy moth has become naturalized.

In the past decade, there has been increasing interest in characterizing spatial patterns of animal abundance through time and identifying processes that cause these patterns. A critical issue in the evolution of spatial dynamics is the pattern of spatial 
synchrony of local populations (Lande et al. 1999; Paradis et al. 2000), measured as the correlation of temporal fluctuations among localities. The intensity and spatial extent of population synchrony has been used to characterize dynamics of insects (Hanski and Woiwod 1993; Miller and Epstein 1986; Pollard 1991; Sutcliffe et al. 1996; Williams and Liebhold 2000), fish (Ranta et al. 1995a), birds (Koenig 2001; Lindström et al. 1996; Paradis et al. 2000; Ranta et al. 1995a,b), mammals (Ranta et al. 1995a; Ranta et al. 1997; Steen et al. 1996), and diseases (Bjørnstad 2000). Synchronous population fluctuations are attributed to density-dependent dispersal, regional stochasticity ("Moran effect”), and community process/ trophic interactions (Bjornstad et al. 1999), although the relative roles of these factors most likely vary among species and spatial scale. As theoretical research continues to expand and establish spatial synchrony as a viable tool of spatial dynamics, studies are needed to bridge the gap between theory and empiricism. Few studies have attempted to span this gap and fewer have applied the theories of spatial synchrony to describe patterns in population and community ecology. This study puts the theories of spatial synchrony to practice in an attempt to describe the dynamics of native Lepidoptera in the forests of central Appalachia.

Intraspecific and interspecific synchrony of 10 Lepidoptera species native to central Appalachia were studied with three primary objectives. The first is to describe the intraspecific spatial synchrony of local native lepidopteran populations and quantify the correlation of climate and local populations. The second objective is to measure the interspecific synchrony within the lepidopteran "community" and identify patterns of synchrony and phylogeny, larval phenology, and geographic association based on vegetation. Interspecific synchrony may also result from populations of several species 
responding similarly to climatic trends if their dynamics are correlated with the environment (Post and Forchhammer 2002). From this hypothesis, the third objective is synthesized from the first two, to determine if species exhibiting interspecific synchrony are those that are entrained by correlation with the environment.

\section{Methods}

Measure of Region-wide Synchrony

Intraspecific synchrony among local (plot) populations was first measured using the zero-lag cross-correlation coefficient between time series of log-transformed abundance from 12 locations (Bjornstad et al. 1999). This method computes the regionwide synchrony from the average pairwise cross-correlations of the population growth rates in the time series as:

$$
\operatorname{average}\left(\rho_{i j}\right)=2 / N(N-1) \sum_{i=1}^{N} \sum_{j=i+1}^{N} \rho_{i j}
$$

The total number of local populations $i$ and $j$ is given by $N$, and $\rho_{i j}$ is the cross-correlation coefficient of the two populations measured by:

$$
\rho_{i j}=\operatorname{cov}(i, j) / \delta_{i} \delta_{j}
$$

Because population growth rates are interdependent, a confidence interval for the mean synchrony was obtained by bootstrapping (1000 iterations) with replacement among the populations with subsequent recalculations of coefficients and averages (Bjornstad et al. 
1999). To obtain interspecific region-wide synchrony for each species pair, equation 3.1 was modified to:

$$
\operatorname{average}\left(\rho_{i k}\right)=2 / N(N-1) \sum_{j=1}^{N} \sum_{l=1}^{N} \rho i_{j} k_{l}
$$

where $i_{j}$ is species $i$ at location $j$ and $k_{l}$ is species $k$ at location $l$.

\section{Synchrony of Lepidoptera Species and Climate}

The 'Moran theorem' states that under identical dynamics, correlation of local populations is equal to the correlation of the environment (Moran 1953). Under this assumption, the pattern of regional correlation in the environment has the potential to provide the functional form of synchrony of local population dynamics (Bjornstad and Bolker 2000). Two approaches were used to identify the synchronization of climate and Lepidoptera species abundance: 1) region-wide correlation of local population abundance and climate, and 2) correlation of the pattern of synchrony, identified by the intensity and spatial extent of synchrony, among climate and species abundance.

The data consisted of 12 environmental variables (average minimum and maximum temperature and total rainfall for May through August) from which three principle components (Climate 1-3) accounting for $66 \%$ of the variation of the original variables, were extracted. Principle components were calculated for each year-plot combination, hence 12 seven-year time series were generated for each Climate variable. Regional synchrony of each Climate variable was calculated using equation 3.1 and correlation of each Climate variable with each species was determined from equation 3.3. 
Patterns of spatial synchrony were determined by calculating Pearson correlation coefficients of all possible locality pairs of intraspecific (or intra-Climate) time series and then regressing the correlation against the Euclidean distance between pairs of locations (Buonaccorsi et al. 2001). The pattern of synchrony of each Climate variable was related to the pattern of synchrony of each species by plotting the correlation coefficients of Climate against species in a linear model.

\section{Interspecific Synchrony}

Region-wide interspecific correlation coefficients (equation 3.3) were compared among Lepidoptera families (Noctuidae/ Geometridae) and larval phenology (early season / late (mid-late season) / all season). The family analysis compared interspecific synchrony within and among families to test the hypothesis that species within a family are more synchronized than species in different families. Since the families Notodontidae and Arctiidae were only represented by 1 species each in the selected 10 species, these families were excluded from this analysis. Similarly, larval phenology comparisons were made by comparing interspecific correlation of species present in the same season (ie. early vs. early), different seasons (early vs. late), or overlapping seasons (early vs. all, late vs. all). Family comparisons were made using the two sample Mann-Whitney U-test and categories of larval phenology were compared with the Kruskal- Wallace rank sum test.

Since the 10 species in this study do not represent a single feeding guild (e.g., oak-feeding spring defoliating) in the strictest sense and distribution of species may vary based on plot vegetation, Canonical Correspondence Analysis (CCA) was used to 
describe how the insect species covaried in abundance with canopy vegetation. This analysis identified the lepidopteran species that are geographically associated with each other in areas of similar vegetation. CCA was chosen over other multivariate analyses because it works well with few environmental variables and is an appropriate test for count data (James and McCulloch 1990). The significance of the ordination was determined through Monte Carlo testing, which randomized the distribution of the environmental data among samples (1000 iterations) (Pc-ord 1999). Since CCA does not account for temporal variability, only the first two years data were used for the analysis. For each species, the total abundance of the first two years was correlated with the total basal area of oaks, maples, hickories, pines, other vegetation, and elevation for each plot (Franklin et al. in press). Interspecific region-wide correlations were then compared to the relative distances of the respective species pairs.

\section{Results}

\section{Synchrony of Lepidoptera Species and Climate}

Region-wide cross-correlations were considered significant if the confidence interval did not include zero. All intraspecific cross-correlations were significant, ranging in values from 0.20 to 0.88 (Table 3.1).

Climate 1 explained $31 \%$ of the environmental variation and reflects all precipitation variables except June. Climate 2 is positively related to minimum temperatures of every month and June precipitation and contributed to $20 \%$ of the total environmental variation. Climate 3 , representing $15 \%$ of environmental variation, was a linear representation of minimum temperature and precipitation in May, June, and 
August, and maximum temperature in May. All Climate variables showed significant region-wide synchrony throughout the study area. Of the 30 Climate/Species comparisons, 18 (60\%) showed significant, region-wide synchrony (Table 3.2).

Regression of Pearson correlation coefficients and distance showed a significant decrease in synchrony with increasing distance for all species, which was expected $a$ priori from this well- documented pattern of spatial dynamics (Figure 3.1). Climate variables also showed a decrease in synchrony with distance, although the slope of this decrease was not as strong for Climate variables as it was for the species, indicating that Climate is highly correlated over larger distances than were most Lepidoptera species (Figure 3.1). Particularly, Climate 1 showed a very slight decrease in synchrony with distance and was highly synchronized across the entire study area. The pattern of synchrony of Climate 1 was only correlated with that of 3 species (Z. minerea, A. ovata, and $P$. latex), whereas patterns of Climate 2 and 3 where significantly correlated with all species except Z. minerea (Figure 3.2). 
Table 3.1. a Average region-wide cross-correlation coefficients for intraspecific and interspecific comparisons in the upper portion of the table. The + and - symbols in the lower portion of the table indicate the direction of significant correlations. ${ }^{\text {b5 }} \%$ Confidence interval for region-wide cross-correlations. Correlations are significant if the confidence interval does not include 0.

\begin{tabular}{|c|c|c|c|c|c|c|c|c|c|c|}
\hline Correlations & I. pustularia & M. canadaria & $H$ unipunctata & $B$ endroniaria & $H$ outtivitta & $H$ fucos $a$ & 7 minerea & $C$ micronymnha & 4 ovata & $P$ later \\
\hline I. pustularia & 0.65 & -0.06 & 0.20 & -0.37 & -0.32 & 0.05 & 0.01 & 0.33 & -0.51 & -0.25 \\
\hline M. canadaria & & 0.20 & -0.09 & 0.18 & 0.17 & -0.02 & 0.16 & -0.03 & 0.18 & 0.23 \\
\hline H. unipunctata & & & 0.42 & 0.07 & -0.08 & 0.43 & -0.09 & 0.53 & 0.03 & 0.04 \\
\hline B. endropiaria & - & + & & 0.66 & 0.54 & 0.22 & 0.26 & 0.14 & 0.74 & 0.54 \\
\hline H. guttivitta & - & & & + & 0.60 & 0.02 & 0.35 & -0.02 & 0.60 & 0.54 \\
\hline H. fucosa & & & + & + & & 0.73 & 0.01 & 0.58 & 0.28 & 0.07 \\
\hline Z. minerea & & + & & + & + & & 0.35 & 0.02 & 0.27 & 0.27 \\
\hline C. micronympha & + & & + & & & + & & 0.74 & 0.08 & 0.14 \\
\hline A. ovata & - & + & & + & + & + & + & & 0.88 & 0.53 \\
\hline P. latex & - & + & & + & + & & + & & + & 0.65 \\
\hline \multicolumn{11}{|l|}{ b. } \\
\hline Lower \Upper & I. pustularia & M. canadaria & H. unipunctata & B. endropiaria & H. guttivitta & H. fucosa & Z. minerea & C. micronympha & A. ovata & P. latex \\
\hline I. pustularia & $0.57 \backslash 0.73$ & 0.13 & 0.44 & -0.19 & -0.14 & 0.26 & 0.21 & 0.49 & -0.35 & -0.11 \\
\hline M. canadaria & -0.24 & $0.10 \backslash 0.32$ & 0.14 & 0.33 & 0.36 & 0.25 & 0.31 & 0.24 & 0.34 & 0.37 \\
\hline H. unipunctata & -0.04 & -0.30 & $0.31 \backslash 0.55$ & 0.26 & 0.11 & 0.56 & 0.09 & 0.65 & 0.26 & 0.24 \\
\hline B. endropiaria & -0.50 & 0.03 & -0.13 & $0.59 \backslash 0.73$ & 0.69 & 0.39 & 0.45 & 0.29 & 0.81 & 0.63 \\
\hline H. guttivitta & -0.47 & -0.03 & -0.26 & 0.37 & $0.51 \backslash 0.70$ & 0.19 & 0.50 & 0.16 & 0.75 & 0.63 \\
\hline H. fucosa & -0.17 & -0.32 & 0.29 & 0.04 & -0.15 & $0.66 \backslash 0.80$ & 0.19 & 0.69 & 0.45 & 0.30 \\
\hline Z. minerea & -0.17 & 0.04 & -0.28 & 0.09 & 0.18 & -0.17 & $0.25 \backslash 0.47$ & 0.26 & 0.46 & 0.44 \\
\hline C. micronympha & 0.18 & -0.29 & 0.42 & 0.00 & -0.19 & 0.47 & -0.19 & $0.64 \backslash 0.83$ & 0.17 & 0.36 \\
\hline A. ovata & -0.66 & 0.02 & -0.18 & 0.67 & 0.41 & 0.11 & 0.07 & -0.02 & $0.86 \backslash 0.90$ & 0.62 \\
\hline P. latex & -0.37 & 0.08 & -0.17 & 0.43 & 0.43 & -0.21 & 0.10 & -0.09 & 0.44 & $0.58 \backslash 0.71$ \\
\hline
\end{tabular}


Table 3.2. Region-wide cross- correlation of Climate variables and Lepidoptera species abundance. Correlation coefficients in bold are significant at the 0.05 level and $\mathrm{CI}$ is the $95 \%$ confidence interval.

\begin{tabular}{lcccccc}
\hline \multicolumn{1}{c}{ Species } & \multicolumn{2}{c}{ Climate 1 } & \multicolumn{2}{c}{ Climate 2 } & \multicolumn{2}{c}{ Climate 3 } \\
& $\rho$ & CI & $\rho$ & CI & $\rho$ & CI \\
\hline I. pustularia & -0.256 & $(-0.375,-0.117)$ & -0.014 & $(-0.173,0.152)$ & $\mathbf{0 . 2 8 7}$ & $(0.148,0.417)$ \\
M. canadaria & -0.096 & $(-0.241,0.065)$ & $\mathbf{0 . 2 2 4}$ & $(0.082,0.360)$ & $\mathbf{0 . 1 6 9}$ & $(0.066,0.273)$ \\
H. unipunctata & $\mathbf{0 . 3 5 4}$ & $(0.133,0.522)$ & -0.104 & $(-0.261,0.047)$ & 0.157 & $(-0.025,0.349)$ \\
B. endropiaria & $\mathbf{0 . 2 2 5}$ & $(0.044,0.394)$ & $\mathbf{0 . 2 3 4}$ & $(0.059,0.416)$ & $\mathbf{0 . 1 9 2}$ & $(0.055,0.310)$ \\
H. guttivitta & -0.004 & $(-0.166,0.144)$ & $\mathbf{0 . 2 9 5}$ & $(0.192,0.391)$ & 0.053 & $(-0.112,0.218)$ \\
H. fucosa & $\mathbf{0 . 2 6 9}$ & $(0.170,0.368)$ & $\mathbf{0 . 2 9 1}$ & $(0.168,0.416)$ & -0.076 & $(-0.230,0.096)$ \\
Z. minerea & -0.309 & $(-0.476,-0.125)$ & $\mathbf{0 . 4 0 3}$ & $(0.328,0.491)$ & 0.120 & $(-0.013,0.268)$ \\
C. micronympha & $\mathbf{0 . 3 1 1}$ & $(0.206,0.423)$ & 0.052 & $(-0.083,0.171)$ & $\mathbf{0 . 2 5 7}$ & $(0.111,0.402)$ \\
A. ovata & $\mathbf{0 . 2 1 0}$ & $(0.069,0.349)$ & $\mathbf{0 . 3 3 6}$ & $(0.235,0.442)$ & 0.076 & $(-0.040,0.188)$ \\
P. latex & $\mathbf{0 . 2 2 7}$ & $(0.065,0.387)$ & $\mathbf{0 . 1 5 5}$ & $(0.037,0.276)$ & $\mathbf{0 . 2 1 5}$ & $(0.082,0.335)$ \\
& & & & & & \\
Climate 1 & $\mathbf{0 . 6 5 1}$ & $(0.567,0.733)$ & -0.055 & $(-0.242,0.12)$ & 0.195 & $(-0.054,0.433)$ \\
Climate 2 & & & $\mathbf{0 . 2 0 2}$ & $(0.081,0.313)$ & -0.087 & $(-0.297,0.115)$ \\
Climate 3 & & & & & $\mathbf{0 . 4 2 5}$ & $(0.300,0.558)$ \\
\hline
\end{tabular}


$\underline{\text { Interspecific Synchrony }}$

Significant region-wide interspecific synchrony was found for 20 species pairs (44\% of 45 pair-wise combinations) (Table 3.1). Interspecific spatio-temporal synchrony is graphically presented in Figure 3.3. Family classification and designation of larval phenology categories are listed in Table 3.3. There was no significant difference in the interspecific cross-correlation of species within or among families (1-tailed, $\mathrm{T}=165$, $\mathrm{p}=0.05$ ). However, interspecific correlations were significantly higher among species whose larvae were present during the same season (average $\rho=0.37 \pm 0.28, \mathrm{n}=12$ ) than species pairs whose larvae were present during different (average $\rho=-0.042 \pm 0.25$, $\mathrm{n}=12)$ or overlapping (average $\rho=0.15 \pm 0.17, \mathrm{n}=21)$ seasons $(\mathrm{T}=9.715$, d.f. $=2, \mathrm{p}<0.01)$ (Figure 3.4).

Table 3.3. Species family classification and designation into categories of larval phenology. Phenology categories designate the time of the season when larvae are present.

\begin{tabular}{llc}
\hline \multicolumn{1}{c}{ Species } & Family & Phenology \\
\hline I. pustularia & Geometridae & early \\
M. canadaria & Geometridae & all \\
H. unipunctata & Geometridae & all \\
B. endropiaria & Geometridae & late \\
H. guttivitta & Notodontidae & mid-late \\
H. fucosa & Arctiidae & early \\
Z. minerea & Noctuidae & all \\
C. micronympha & Noctuidae & early \\
A. ovata & Noctuidae & mid-late \\
P. latex & Noctuidae & mid-late \\
\hline
\end{tabular}

Canonical Correspondence Analysis identified associations among Lepidoptera species based on three eigenvalues (axes) that described $72.8 \%$ of the total variability in 
canopy vegetation ( $61.8 \%$ for axis $1,4.7 \%$ for axis 2 , and $3.5 \%$ for axis 3$)$. Figure 3.5 shows species associations plotted on axis 1 and 2 in which species are clustered according to their overall similarity. Results of the Monte Carlo testing showed that only axis 1 was significantly correlated with canopy composition (data correlation $=0.944$, average correlation $=0.65, \mathrm{CI}=(0.36,0.94), \mathrm{p}=0.001)$. Since axis 2 described less then $5 \%$ of species variability and had a random relationship with insect abundance $(\mathrm{p}=0.48)$, insect associations were reduced to a linear relationship based on axis 1 (Figure 3.6). A correlation of the distance on axis 1 that separated each species pair with the region-wide interspecific cross-correlation did not show a significant relationship between the geographic distribution of insect species and interspecific synchrony $(r=0.166, p=0.22)$ (Figure 3.7).

\section{Interspecific Synchrony and Climate}

The species pairs with significant interspecific region-wide synchrony were compared with the region-wide cross-correlations of each species and Climate variable. Table 3.4 shows each species pair and significant correlations with each Climate variable. In all species pairs, both members were significantly correlated with at least one Climate variable. For sixteen species pairs $(80 \%)$, both species were significantly correlated with Climate 2. Climates 1 and 3 were synchronous with both pair members for only 8 and 4 pairs, respectively. 
Table 3.4. Species pairs with significant interspecific region-wide cross-correlations and significant correlation with Climate variables. The correlation column refers to the interspecific cross-correlation. Letters under the Climate variables indicate which species of the pair, A or B, were significantly correlated with that Climate variable. 'AB' in the Climate column indicates that both species are correlated with that Climate variable.

\begin{tabular}{|c|c|c|c|c|c|}
\hline Species A & Species B & Correlation & Climate 1 & Climate 2 & Climate 3 \\
\hline I. pustularia & C. micronympha & 0.33 & B & & $\mathbf{A B}$ \\
\hline M. canadaria & B. endropiaria & 0.18 & B & $\mathbf{A B}$ & $\mathbf{A B}$ \\
\hline M. canadaria & Z. minerea & 0.16 & & $\mathbf{A B}$ & A \\
\hline M. canadaria & A. ovata & 0.18 & B & AB & A \\
\hline M. canadaria & P. latex & 0.23 & B & $\mathbf{A B}$ & $\mathbf{A B}$ \\
\hline H. unipunctata & H. fucosa & 0.43 & $\mathbf{A B}$ & B & \\
\hline H. unipunctata & C. micronympha & 0.53 & $\mathbf{A B}$ & & B \\
\hline B. endropiaria & H. guttivitta & 0.54 & A & $\mathbf{A B}$ & A \\
\hline B. endropiaria & H. fucosa & 0.22 & $\mathbf{A B}$ & $\mathbf{A B}$ & A \\
\hline B. endropiaria & Z. minerea & 0.26 & A & $\mathbf{A B}$ & A \\
\hline B. endropiaria & A. ovata & 0.74 & $\mathbf{A B}$ & $\mathbf{A B}$ & A \\
\hline B. endropiaria & P. latex & 0.54 & AB & AB & AB \\
\hline H. guttivitta & Z. minerea & 0.35 & & $\mathbf{A B}$ & \\
\hline H. guttivitta & A. ovata & 0.60 & B & AB & \\
\hline H. guttivitta & P. latex & 0.54 & B & $\mathbf{A B}$ & B \\
\hline H. fucosa & C. micronympha & 0.58 & $\mathbf{A B}$ & A & B \\
\hline H. fucosa & A. ovata & 0.28 & AB & AB & \\
\hline Z. minerea & A. ovata & 0.27 & B & $\mathbf{A B}$ & \\
\hline Z. minerea & P. latex & 0.27 & B & $\mathbf{A B}$ & B \\
\hline A. ovata & P. latex & 0.53 & AB & $\mathbf{A B}$ & B \\
\hline
\end{tabular}




\section{Discussion}

Relating spatial synchrony of population fluctuations with environmental factors is difficult and often problematic (Ranta et al. 1999). Not only are local populations spatially autocorrelated (Koenig 1999), but synchronizing mechanisms may operate simultaneously (Bjornstad et al. 1999), and differentiating the relative role of dispersal, trophic interaction, and climate is often ambiguous (Ranta et al. 1995a). Relating the pattern of spatial autocorrelation in environmental factors, such as temperature and rainfall, to the pattern of spatial autocorrelation in populations would presumably determine the role of climate in synchronizing local populations (Moran 1953; Koenig 1999). However, analysis requires that environmental parameters are measured in the same sites as species are collected. Consequently, few studies have been able to quantify

the relationship between the patterns of environmental and population synchrony (Koenig 1999). Although dispersal rates and the role of trophic interactions were not obtainable in this study, these data did provide an opportunity to identify the potential role of climate in the spatial synchrony of lepidopteran populations.

Reduction of the 12 original climate measurements into 3 principle components compressed the environmental variation into three primary Climate variables; the first variable reflected precipitation, the second represented minimum temperatures, and the third represented a combination of precipitation and temperature variables. Comparing populations with these principle components avoided the problem of determining which environmental measurements were meaningful and reduced the number of spurious correlations that would result from comparing populations with 12 variables of raw data. 
Principle components were also useful in representing a combined effect of monthly variables for a more adequate representation of annual climate.

Based on the high frequency of correlations among the patterns of Climate and population synchrony, the spatial synchrony of Lepidoptera in this study appear to follow the prediction of the Moran theorem. However, correlation in "the decay in synchrony" implies a similarity in the intensity of correlation among local sites and the decrease of that intensity with increasing distance. Patterns of spatial synchrony do not indicate correlation of spatio-temporal fluctuations among Climate and populations. Therefore, for the conditions of the Moran theorem to be met, populations should not only show positive correlation in the pattern of synchrony, but also in the region-wide correlation of local population and Climate time series.

The decay in synchrony of all species was correlated with that of at least one Climate variable; however, there were inconsistencies among the correlation of patterns of synchrony and region-wide cross-correlations. Climate 1 was highly synchronous across the entire study area and demonstrated very little decay in synchrony with distance. This pattern of synchrony was correlated with only 3 Lepidoptera species $(Z$. minerea, A. ovata, and P. latex). Region-wide cross-correlation coefficients showed that the spatio-temporal dynamics of Climate 1 was correlated with 6 species, only 2 of which (A. ovata and P. latex) shared similar patterns in the decay of synchrony. Similar inconsistencies were seen with Climates 2 and 3 , in which patterns of synchrony were correlated with all but one species, but the region-wide cross-correlations were only significant for 7 and 5 species, respectively. Given the requirement of both a significant correlation of the patterns of synchrony and region-wide cross-correlations, spatial 
synchrony of 8 species appear to be attributed, at least in part, to correlation with climate. The remaining 2 species demonstrated a significant region-wide cross-correlation of a Climate variable but were not associated with any correlation in the pattern of synchrony. In these cases, the decay in synchrony of populations occurred over shorter distances than the decay in synchrony of Climate, and may represent situations where other mechanisms, such as dispersal, trophic interactions, and/or geographic variation in local population dynamics, cause synchrony to decline with distance at a faster rate than the correlation in the environment.

Previous studies examining the role of climate on population synchrony have been either theoretical (Heino et al. 1997; Kendall et al. 2000; Ranta et al. 1995a; Ranta et al. 1997; Ripa 2000) or utilized crude climate data collected from landscape-scale weather stations and do not represent the local conditions of the population census (Hawkins and Holyoak 1998; Lindström et al. 1996; Peltonen et al. 2002; Post and Forchhammer 2002). Many of these studies merge on the conclusion that dispersal is an important synchronizing agent at local scales, whereas environmental influences, although present at all scales, is a more dominant synchronizing agent at landscape scales. In this study, the distance between local populations $(<65 \mathrm{~km})$ represents a local scale relative to the spatial scale of previous studies and climate appears to be a strong synchronizing mechanism for at least 8 of the 10 species studied here. Despite these findings, dispersal and community processes should not be overlooked as an important synchronizing mechanism, nor should the potential interactions among them (Kendall et al. 2000). 
Patterns of interspecific synchrony are far less studied than the synchrony of conspecific populations. Since local populations of different species are not linked by dispersal, correlation with environmental factors (Hawkins and Holyoak 1998; Heino et al. 1997; Ranta et al. 1995b) and shared predation pressures (Ims and Steen 1990; Marcström et al. 1988; Norrdahl and Korpimäki 1996; Ydenberg 1987) have been the mechanisms associated with synchrony in previous studies. Koenig (2001) expanded the research on interspecific synchrony to include bottom-up factors and found that there was only a weak relationship between interspecific synchrony and diet of boreal birds throughout North America. With the study of interspecific synchrony still in its infancy, this study explored the possible relationship of interspecific synchrony and phylogeny, geographic association based on vegetation, larval phenology, and climate.

The comparison of interspecific synchrony and phylogenic association is based on the assumption that species within a family have more closely related life histories, which are directly related to population dynamics (Price 1997). Therefore, species within a family will have more similar dynamics than species among families. Since individual dynamics and degree of density dependence may influence synchrony in conspecific populations (Kendall et al. 2000), higher synchrony may be seen among species within a family than among families. This study did not detect higher interspecific synchrony within families and was unable to find an association between interspecific synchrony and species in the families Noctuidae and Geometridae.

The species selected for this study exhibited a diversity of food preferences and it was not statistically possible to compare within and among larval food plant preferences due to low sample sizes. Assuming that Lepidoptera distribution would be reflective of 
larval food plant preference, interspecific synchrony was compared to geographic association based on local canopy vegetation in an attempt to explore potential bottom-up factors or geographic influences that may affect interspecific synchrony. Similarly to the phylogenic analysis, there was no detectable relationship among interspecific synchrony and relative geographic distribution based on canopy distribution.

This study did, however, detect a significant relationship among the intensity of interspecific synchrony and larval phenology. Based on the 10 species in this study, species whose larvae were present during the same season of the year exhibited highly synchronized fluctuations relative to species whose larvae were present in different seasons. Species whose larvae were present during overlapping seasons generally exhibited moderate interspecific synchrony. Of the originally proposed mechanism of interspecific synchrony (climate and shared predators), shared generalist predators of Lepidoptera larvae, such as birds and small mammals, are present throughout the season and may not explain the pattern of interspecific synchrony observed here. Patterns of interspecific synchrony associated with larval phenology may be attributed to climate, which changes throughout the seasons and may act differently on early and late season larvae. Host plant quality changes throughout the season influence Lepidoptera dynamics (Price 1997); however several species pairs that were highly synchronized feed on different plant groups. For example, H. fucosa and C. micronympha are spring caterpillars with a relatively high interspecific region-wide correlation $(0.58)$ and feed on different plant groups (H. fucosa - lichens and mosses, C. micronympha-oaks). Therefore, changes in the quality of specific host plants are not a likely candidate to explain the within-season synchrony of different species. 
The majority (90\%) of synchronized species pairs showed significant correlation with Climate 2 for both species. Climate 2, representing minimum temperatures, appears to be a common denominator of interspecific synchrony. The two species pairs that did not have correlations of both species and Climate 2 were the species pairs of spring larvae (I. pustularia/ C. micronympha, H. fucosa/ C. micronympha). These pairs were, however, significantly correlated with Climate 1 or 3 , both of which include precipitation variables within the principle component. These data suggest that climate may have a synchronizing effect on species whose larvae are present at similar times of the season, and different climatic variables may influence caterpillars present in the early, late or entire season.

A complicated step in bridging the gap between theoretical and empirical spatial dynamics is the empirical testing of possible causal mechanisms (Bjornstad et al. 1999). Identifying cause and effect relationships in highly complex ecosystems such as the eastern deciduous forests realistically may be impossible. However, patterns of spatial covariance among Lepidoptera species abundance, climate, site vegetation, larval phenology, and phylogeny were demonstrated. Eight of the 10 species in this study possessed spatial patterns that would be expected under the influence of the spatially autocorrelated climatic effects, although the relative roles of climate, dispersal, and trophic interactions could not be distinguished. Interspecific synchrony of several species pairs also shared synchronous dynamics with climate and were positively associated with larval phenology, impressing the potential of climate and seasonality on interspecific synchrony of moth populations in central Appalachia. 
Autoecological factors (ie. temperature, precipitation) and between and within trophic interactions likely interact to influence insect population dynamics, including the occurrence of outbreaks (Faeth 1987). Studies have outlined complex vertical (trophic) interactions of gypsy moth (Elkinton et al. 1996), yet quantitative analyses of coexisting Lepidoptera are lacking (Mason 1987). This study represents the first step in studying the population dynamics of native species in effort to elucidate lateral interactions of the Lepidoptera community. Although gypsy moth was not collected in numbers large enough to include in this study, interspecific synchrony of gypsy moth with native Lepidoptera species is probable, particularly in non-outbreak years. Results of this study identify some of the factors which may synchronize forest Lepidoptera and identify community associations that exist in central Appalachia.

\section{References Cited}

Bjørnstad, O. N., R. A. Ims, and X. Lambin. 1999. Spatial population dynamics: analyzing patterns and processes of population synchrony. Trends in Ecology and Evolution. 14: 427-431.

Bjørnstad, O. N. 2000. Cycles and synchrony: two historical 'experiments' and one experience. Journal of Animal Ecology. 69: 869-873.

Bjørnstad, O. N. and B. Bolker. 2000. Canonical functions for dispersal-induced synchrony. Proceedings of the Royal Society of London: Series B. 267: 1787- 94.

Buonaccorsi, J. P., J. S. Elkinton, S. R. Evans, and A. M. Liebhold. 2001. Measuring and testing for spatial synchrony. Ecology. 82: 1668-1679.

Butler, L. and J. Strazanac. 2000a. Macrolepidopteran larvae sampled by tree bands in temperate mesic and xeric forests in eastern United States. Proceedings Entomological Society Washington. 102: 188-197.

Butler, L. and J. Strazanac. 2000b. Occurrence of Lepidoptera on selected host trees in two central Appalachian national forests. Annals Entomological Society America. 93: 500-511. 
Butler, L., V. Kondo, and J. Strazanac. 2001. Light trap catches of Lepidoptera in two central Appalachian forests. Proceedings Entomological Society Washington. 103: 879902.

Cappuccino, N. 1995. Novel approaches to the study of population dynamics. In Population Dynamics: New Approaches and Synthesis. N. Cappuccino and P. W. Price (Eds.). 429pp.

Elkinton, J. S. and A. M. Liebhold. 1990. Population dynamics of gypsy moth in North America. Annual Review of Entomology. 35: 571-596.

Elkinton, J. S., w. M. Healy, J. P. Buonaccorsi, G. H. Boettner, A. M. Hazzard, H. R. Smith, A. M. Liebhold. 1996. Interactions among gypsy moths, white footed mouse, and acorns. Ecology. 77: 2332-2342.

Faeth, S. H. 1987. Community structure and folivorous insect outbreaks: The roles of vertical and horizontal interactions. In Insect Outbreaks. P. Barbosa and J. C. Schultz (Eds.). Academic Press. San Diego, CA.

Franklin, A. J. A. M. Liebhold, K. Murray, and C. Donahue. in press. Canopy herbivore community structure: large-scale geographical variation and relation to forest composition. Ecological Entomology.

Hanski, I., and I. P. Woiwod. 1993. Spatial synchrony in the dynamics of moth and aphid populations. Journal of Animal Ecology. 62. 656-668.

Hawkins, B. A. and M. Holyoak. 1998. Transcontinental crashes of insect populations? The American Naturalist. 152: 480-484.

Heino, M., V. Kaitala, E. Ranta, and J. Lindström. 1997. Synchronous dynamics and rates of extinction in spatially structured populations. Proceedings of the Royal Society of London. Series B. 264: 481-486.

Ims, R. A. and H. Steen. 1990. Geographical synchrony in microtine population cycles: A theoretical evaluation of the role of nomadic avian predators. Oikos. 57: 381-387.

James, F. C. and C. E. McCulloch. 1990. Multivariate analysis in ecology and systematics: Panacea or Pandora's box? Annual Review Ecological Systems. 21: 129-66.

Kendall, B. E., O. N. Bjørnstad, J. Bascompte, T. H. Keitt, and W. F. Fagan. 2000. Dispersal, environmental correlation, and spatial synchrony in population dynamics. American Naturalist. 155: 628-636.

Koenig, W. D. 1999. Spatial autocorrelation of ecological phenomena. TREE. 14: 22-26. 
Koenig, W. D. 2001. Synchrony and periodicity of eruptions by boreal birds. The Condor. 103:725-735.

Lande, R., S. Engen, and B. Sæther. 1999. Spatial scale of population synchrony: Environmental correlation versus dispersal and density regulation. The American Naturalist. 154: 271-281.

Lindström, J., E. Ranta, and H. Linden. 1996. Large-scale synchrony in the dynamics of capercaillie, black grouse and hazel grouse populations in Finland. Oikos. 76: 221-227.

Markin, G. P. 1982. Abundance and life cycles of Lepidoptera associated with an outbreak of the western spruce budworm Choristoneura occidentalis (Lepidoptera: Torticidae) in southeastern Idaho. Journal of the Kansas Entomological Society. 55: 365372.

Marcström, V., R. E. Kenward, and E. Engren. 1988. The impact of predation on boreal tetraonids during vole cycles: an experimental study. Journal Animal Ecology. 57: 859872.

Mason, R. R. 1987. Nonoutbreak species of forest Lepidoptera. In Insect Outbreaks. P. Barbosa and J. C. Schultz (Eds.). Academic Press. San Diego, CA.

Miller, W. E. and M. E. Epstein. 1986. Synchronous population fluctuations among moth species (Lepidoptera). Environmental Entomology. 15: 443-447.

Moran, P.A.P. 1953. The statistical analysis of the Canadian lynx cycle. II. Synchronization and meteorology. Australian Journal of Zoology. 1: 291-298.

Norrdahl, K. and E. Korpimäki. 1996. Do nomadic avian predators synchronize population fluctuations of small mammals? A field experiment. Oecologia. 107: 478-483.

Paradis, E., S.R. Baillie, W. J. Sutherland, and R. D. Gregory. 2000. Spatial synchrony in populations of birds: Effects of habitat, population trend, and spatial scale. Ecology. 81: 2112-2125.

Pc-ord. 1999. Pc-ord Version 4: Multivariate Analysis of Ecological Data User's Guide. MJM software design. Gleneden Beach, OR. 237pp.

Peltonen, M., A. M. Liebhold, O. N. Bjornstad, D. W. Williams. 2002. Spatial synchrony in forest insect outbreaks: roles of regional stochasticity and dispersal. Ecology. 83: 3120-3129.

Pollard, E. 1991. Synchrony of population fluctuations: The dominant influence of widespread factors on local butterfly populations. Oikos. 60: 7-10. 
Post, E. and M. C. Forchhammer. 2002. Synchronization of animal population dynamics by large-scale climate. Nature. 420: 168-171.

Price, P. 1997. Insect Ecology. $3^{\text {rd }}$ ed. Wiley and Sons, Inc. New York, NY.

Ranta, E., V. Kaitala, J. Lindström, and H. Linden. 1995a. Synchrony in population dynamics. Proceedings of the Royal Society of London: Series B. 262: 113-118.

Ranta, E., J. Lindström, and H. Linden. 1995b. Synchrony in tetraonid populations dynamics. Journal of Animal Ecology. 64: 767-776.

Ranta, E., V. Kaitala, J. Lindström, and E. Helle. 1997. The Moran effect and synchrony in population dynamics. Oikos. 78.136-142.

Ranta, E., V. Kaitala, and J. Lindström. 1999. Spatially autocorrelated disturbances and patterns in population synchrony. Proceedings Royal Society London. Series B. 266: 1851-1856.

Ripa, J. 2000. Analysing the Moran effect and dispersal: their significance and interaction in synchronous population dynamics. Oikos. 90: 175-187.

Steen, H., R. A. Ims, G., and A. Sonerud. 1996. Spatial and temporal patterns of smallrodent population dynamics at a regional scale. Ecology. 77: 2365-2372.

Sutcliffe, O. L., C. D. Thomas, and D. Moss. 1996. Spatial synchrony and asynchrony in butterfly population dynamics. Journal of Animal Ecology. 65: 85-95.

Williams, D. W. and A. M. Liebhold. 2000. Spatial synchrony of spruce budworm outbreaks in eastern North America. Ecology. 81: 2753-2766.

Ydenberg, R. C. 1987. Nomadic predators and geographical synchrony in microtine population cycles. Oikos. 50: 270-272. 
Figure 3.1. Spatial synchrony (cross-correlation) of conspecific populations and Climate variables against distance between populations in central Appalachia. 

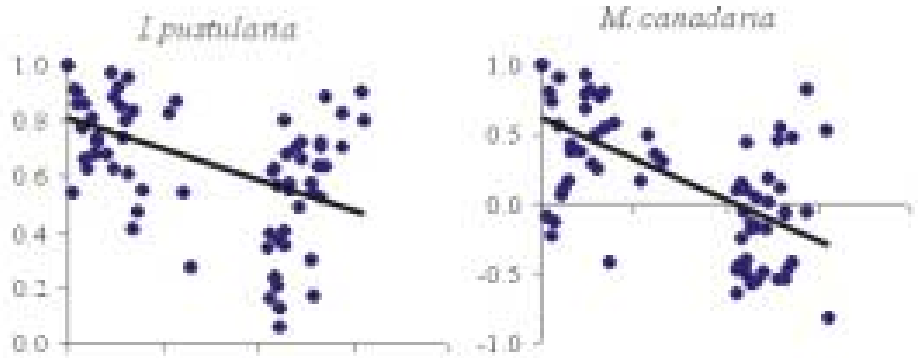

A. Tupunctata

\section{B. endropiana}
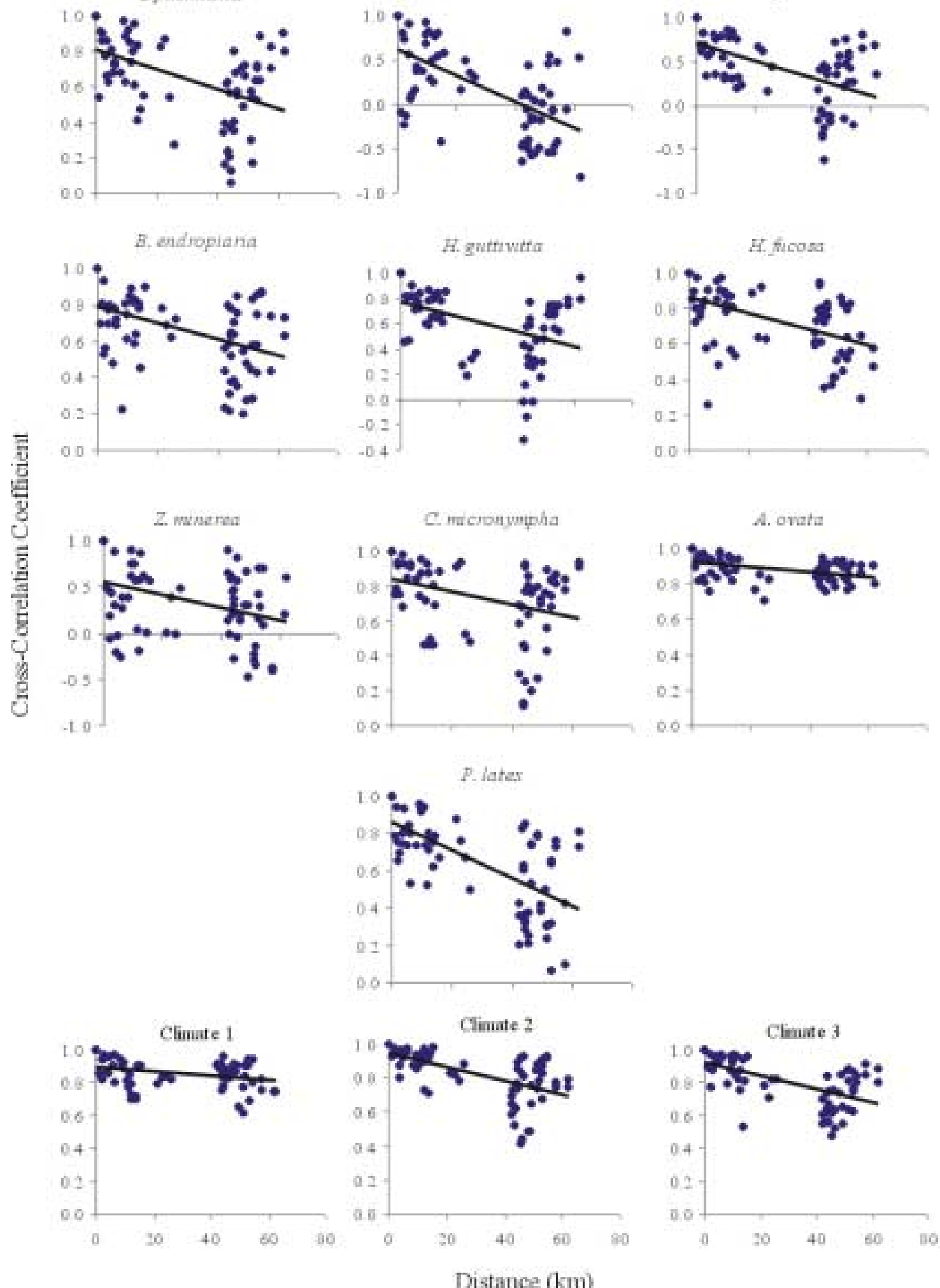
Figure 3.2a . Relationship between the spatial synchrony of Lepidoptera populations and Climate 1. Asterisks next to the species name identifies significant species/ Climate associations. 

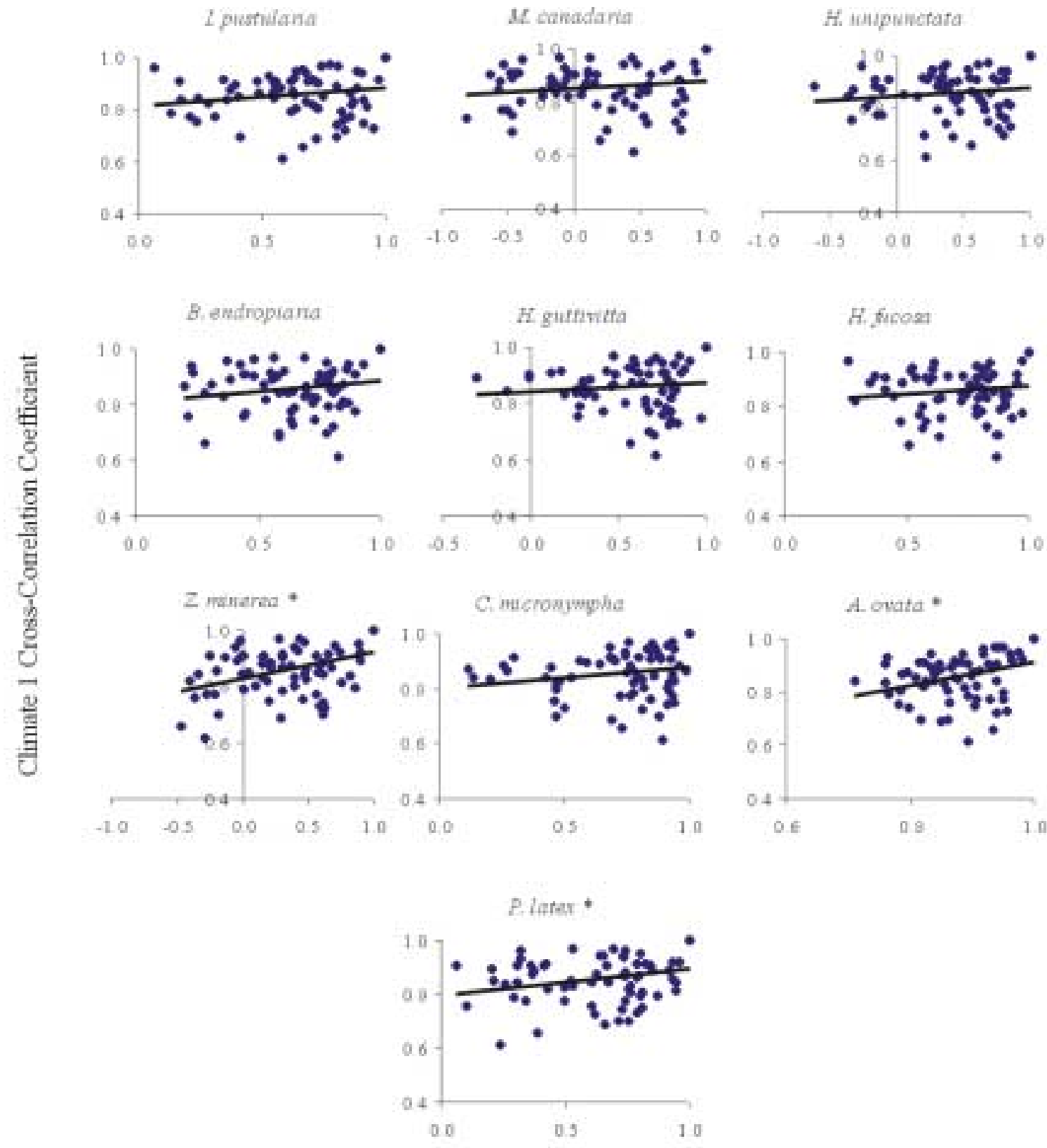

Lepidoptera Cross-Correlation Coefficient 
Figure $3.2 \mathrm{~b}$. Relationship between the spatial synchrony of Lepidoptera populations and Climate 2. Asterisks next to the species name identifies significant species/ Climate associations. 

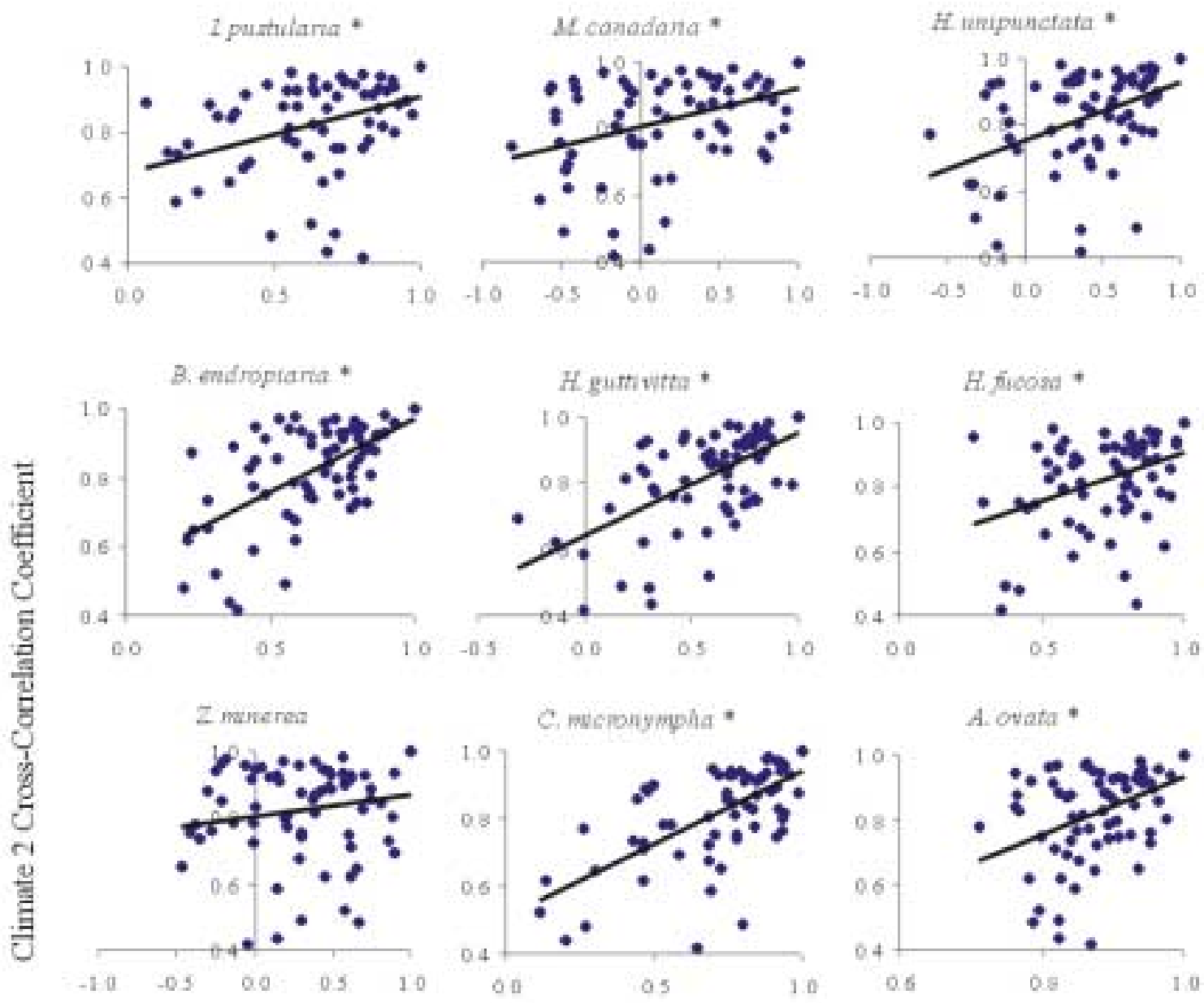

P. Jatex *

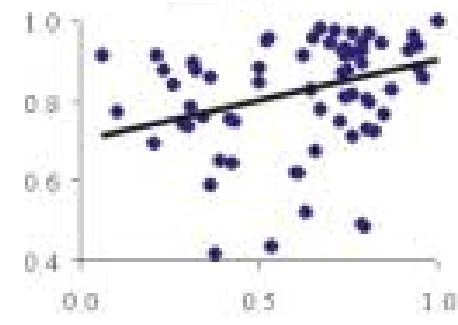

Lepidoptera Cross-Correlation Coefficient 
Figure 3.2c. Relationship between the spatial synchrony of Lepidoptera populations and Climate 3. Asterisks next to the species name identifies significant species/Climate associations. 

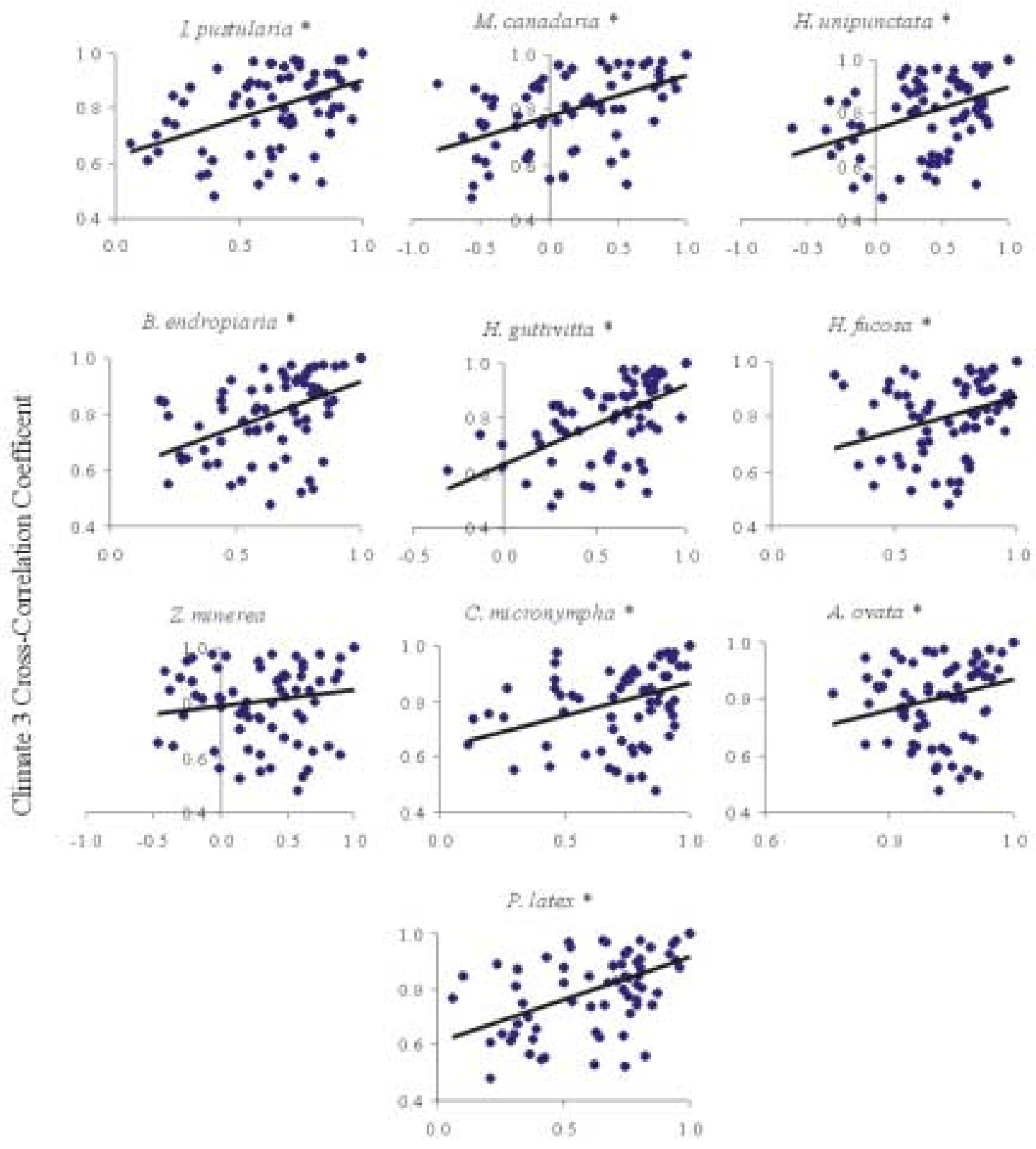

Lepidoptera Cross-Correlation Coefficient 
Figure 3.3a. Graphical representations of spatio-temporal interspecific synchrony of Itame pustularia. The $\mathrm{x}$-axis is plot, the $\mathrm{y}$-axis is year, and the $\mathrm{z}$-axis represents species abundance. 


\section{1. pustularia}

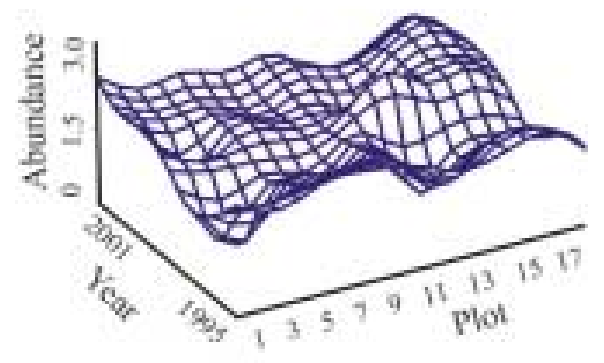

\section{C. micronympha}

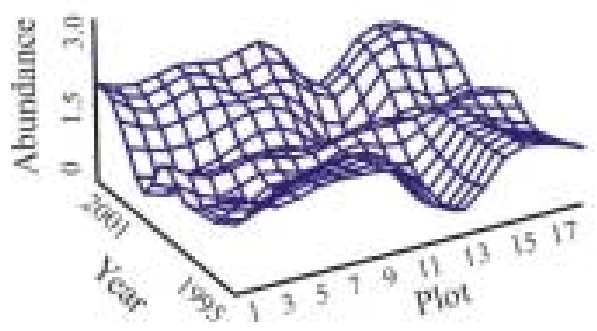


Figure 3.3b. Graphical representations of spatio-temporal interspecific synchrony of Melanolophia canadaria. The $\mathrm{x}$-axis is plot, the $\mathrm{y}$-axis is year, and the $\mathrm{z}$-axis represents species abundance. 


\section{M. canadaria}

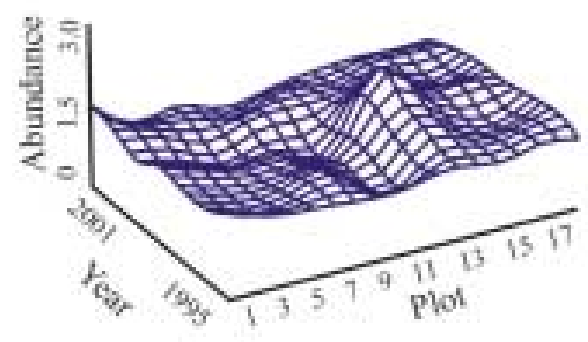

B. endropiaria

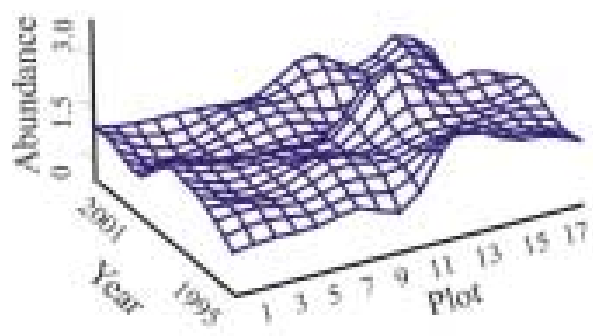

A. ovata

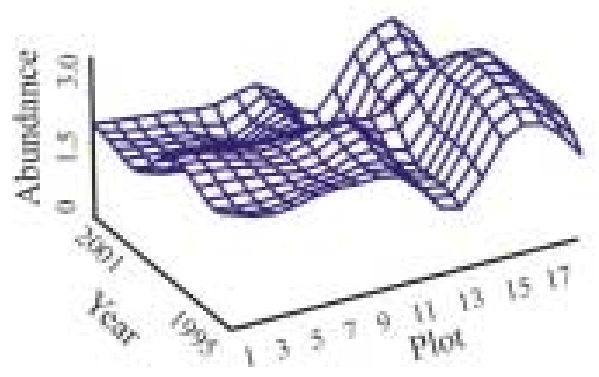

Z. minerea

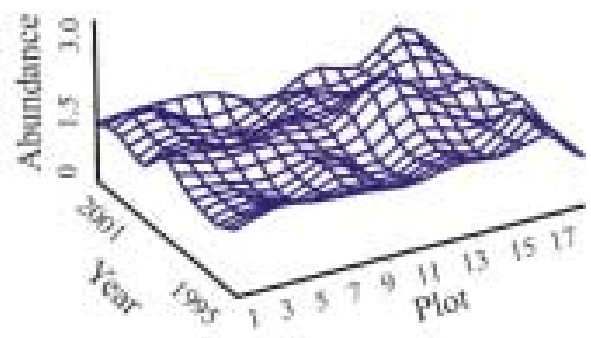

P. latex

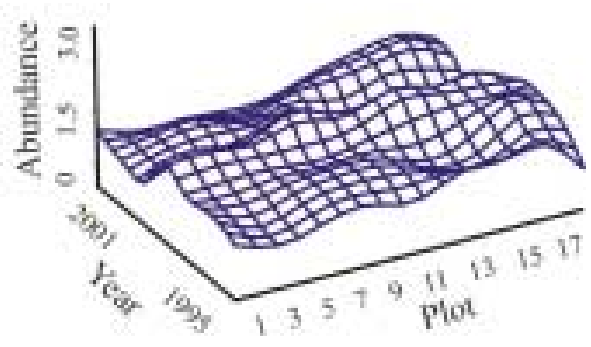


Figure 3.3c. Graphical representations of spatio-temporal interspecific synchrony of Hypagyrtis unipunctata. The $\mathrm{x}$-axis is plot, the $\mathrm{y}$-axis is year, and the $\mathrm{z}$-axis represents species abundance. 


\section{H. unipunctata}

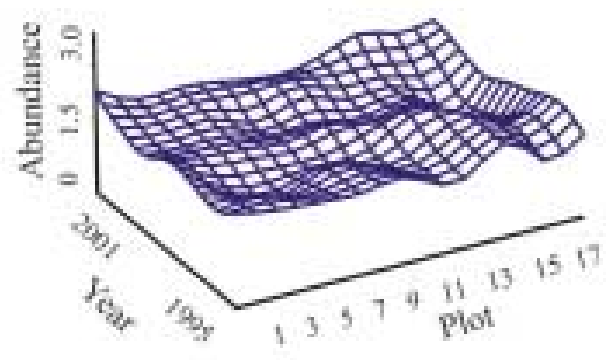

\section{C. micromympha}

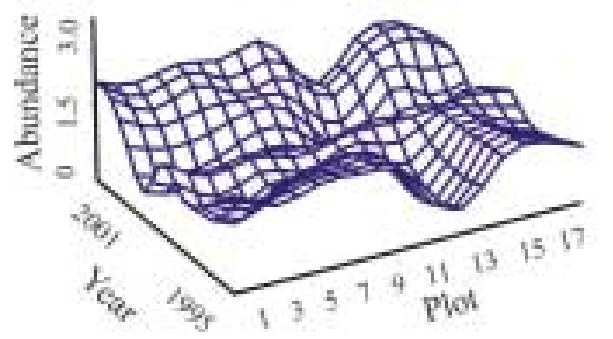

H. fucosa

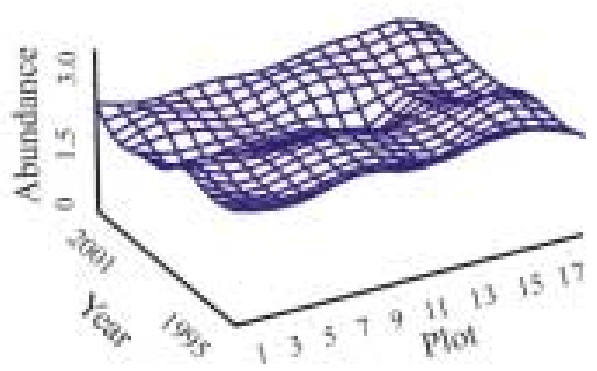


Figure 3.3d. Graphical representations of spatio-temporal interspecific synchrony of Besma endropiaria. The $\mathrm{x}$-axis is plot, the $\mathrm{y}$-axis is year, and the $\mathrm{z}$-axis represents species abundance. 


\section{B. endropiaria}

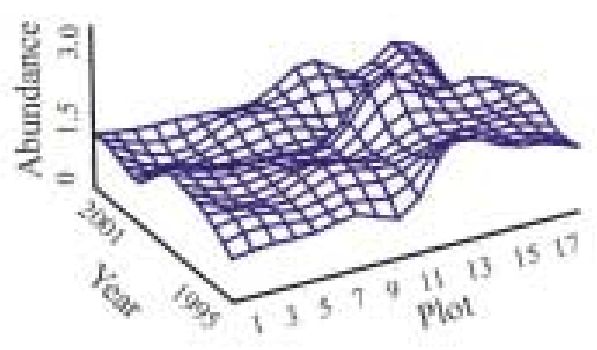

\section{M. canadaria}

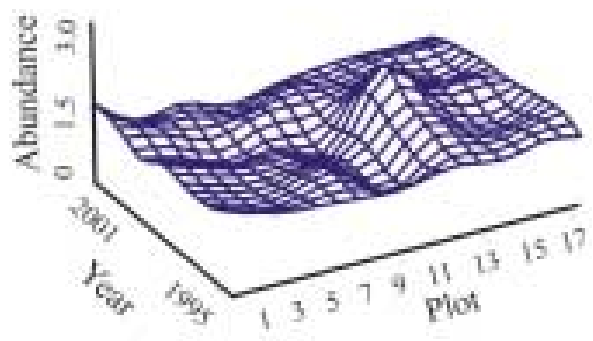

H. fucosa

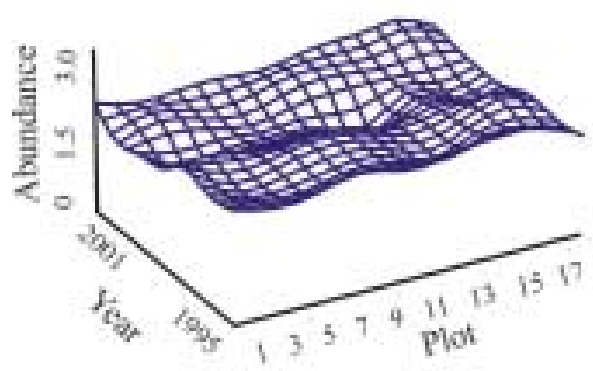

A. ovata

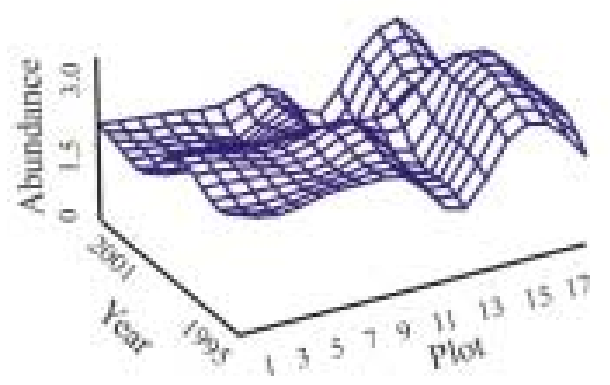

H. guttivitta

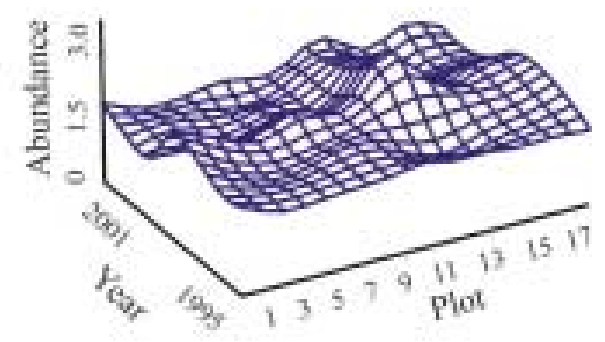

Z. minerea

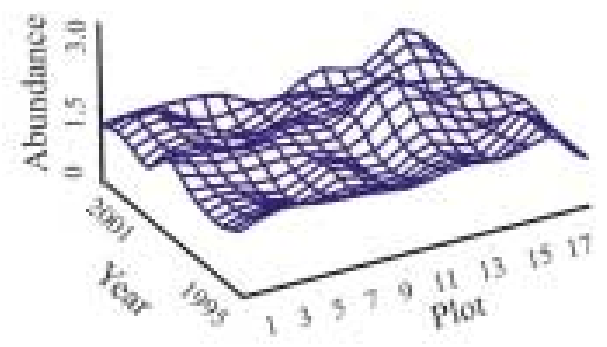

P. latex

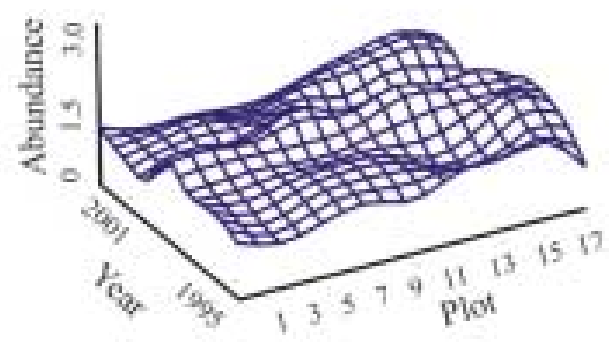


Figure 3.3e. Graphical representations of spatio-temporal interspecific synchrony of Heterocampa guttivitta. The $\mathrm{x}$-axis is plot, the $\mathrm{y}$-axis is year, and the $\mathrm{z}$-axis represents species abundance. 


\section{H. guttivitha}

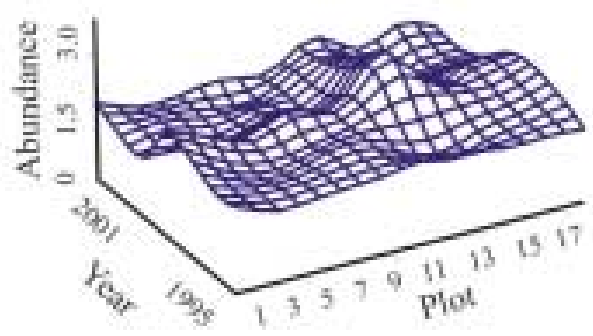

B. endropiaria

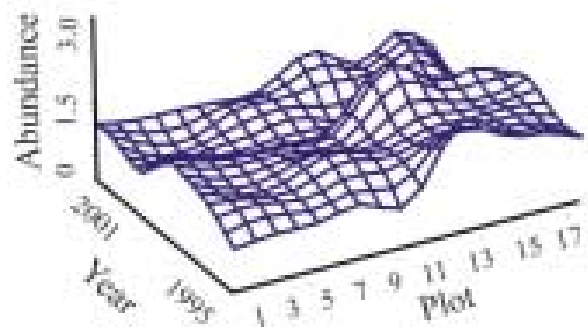

A. ovata

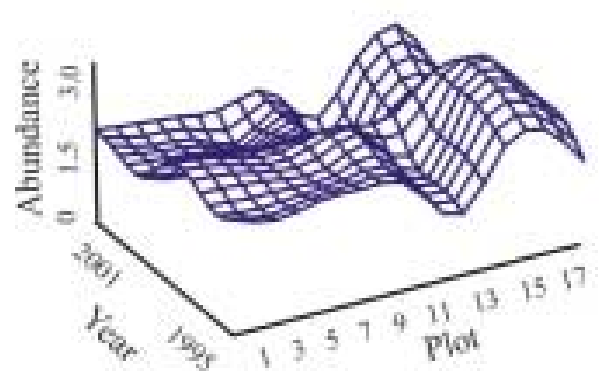

Z. minerea

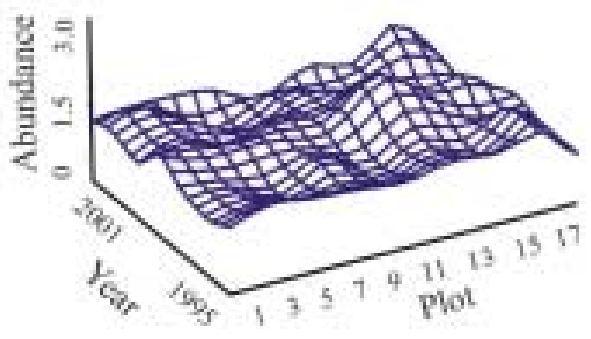

P. latex

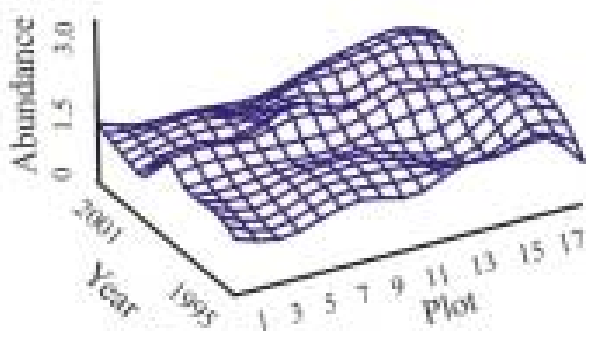


Figure 3.3f. Graphical representations of spatio-temporal interspecific synchrony of Hypoprepia fucosa. The $\mathrm{x}$-axis is plot, the $\mathrm{y}$-axis is year, and the z-axis represents species abundance. 


\section{H. fucosa}

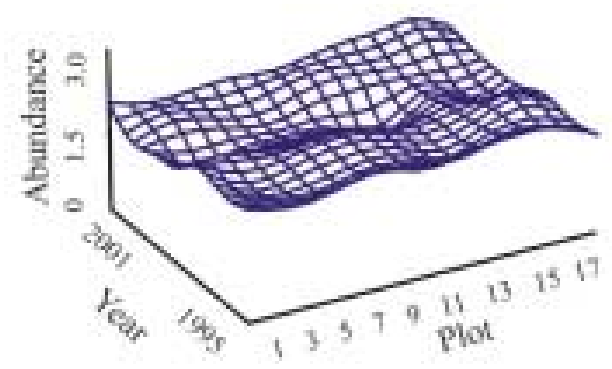

H. wipunctata

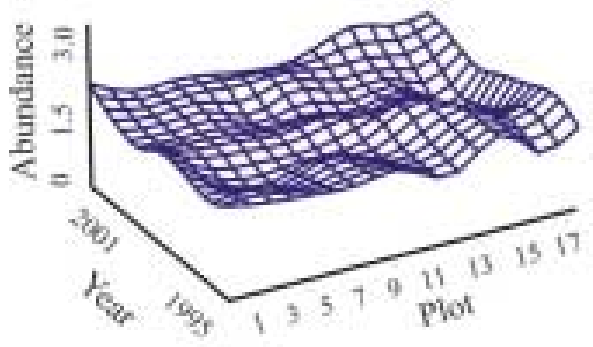

B. endropiaria

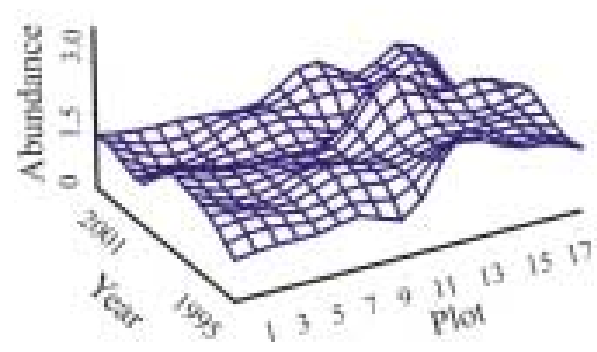

C. micromympha

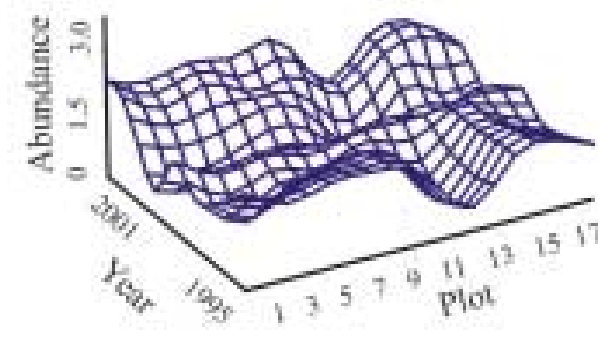

A. ovata

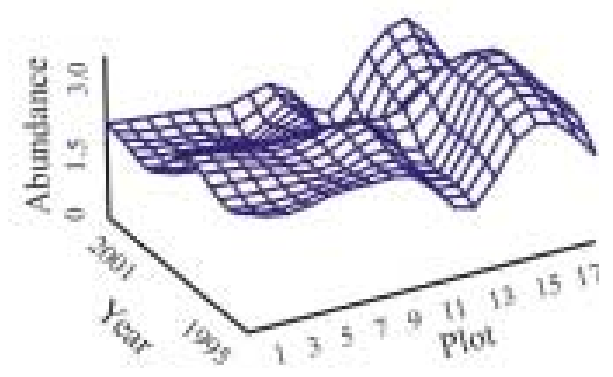


Figure 3.3g. Graphical representations of spatio-temporal interspecific synchrony of Zale minerea. The $\mathrm{x}$-axis is plot, the $\mathrm{y}$-axis is year, and the z-axis represents species abundance. 


\section{Z. minerea}

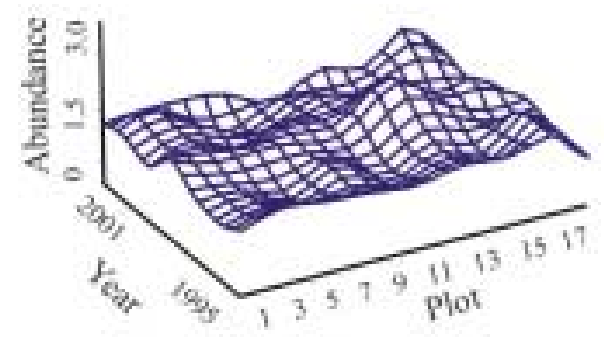

M. canadaria

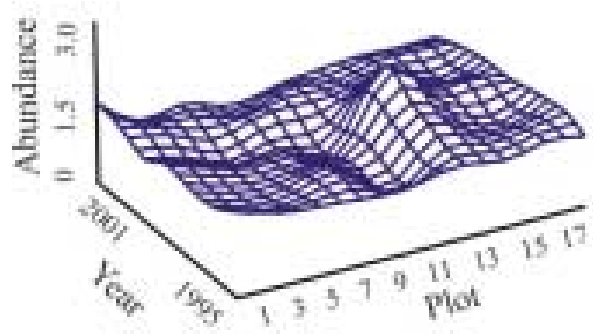

H. gutivitha

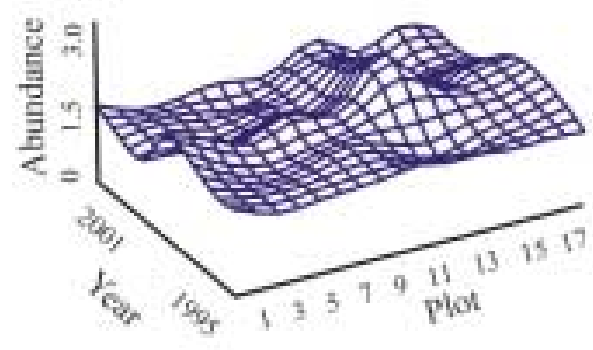

P. latex

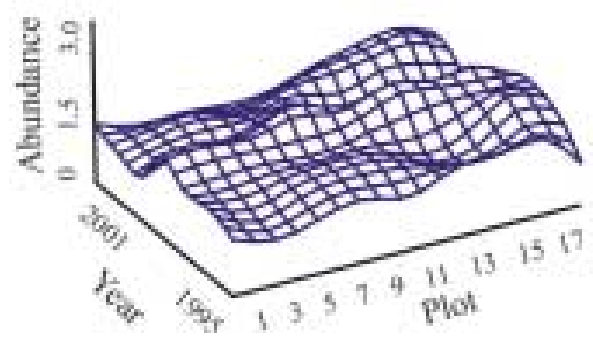

B. endropiaria

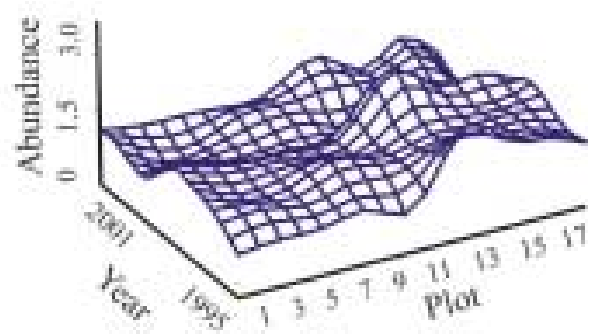

A. ovara

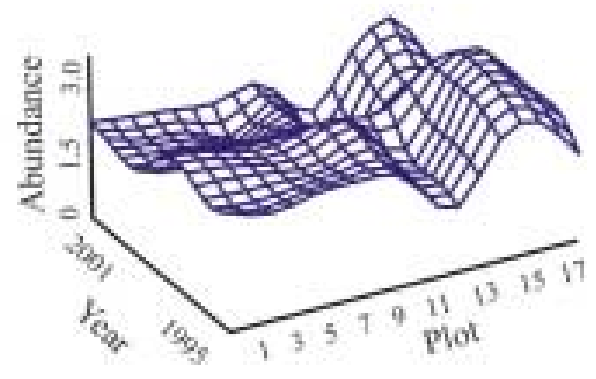


Figure 3.3h. Graphical representations of spatio-temporal interspecific synchrony of Catocala micronympha. The $\mathrm{x}$-axis is plot, the $\mathrm{y}$-axis is year, and the $\mathrm{z}$-axis represents species abundance. 


\section{C. micromympha}

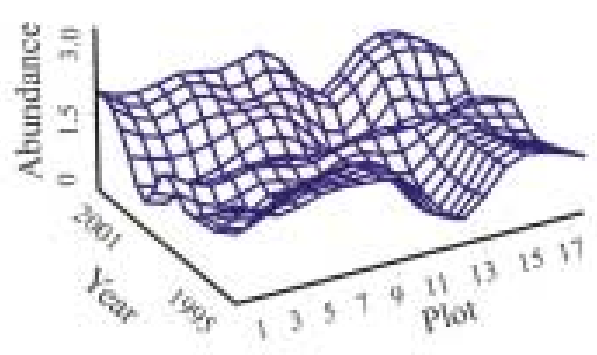

H. fucosa

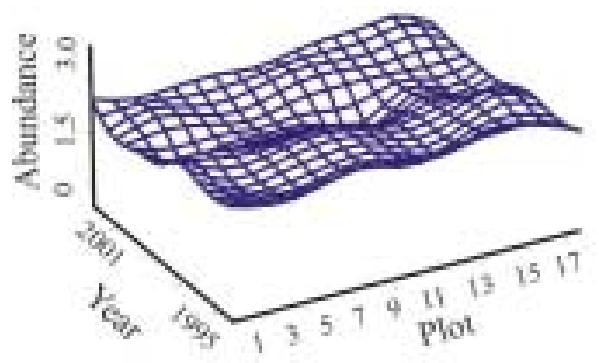

H. unipunctata

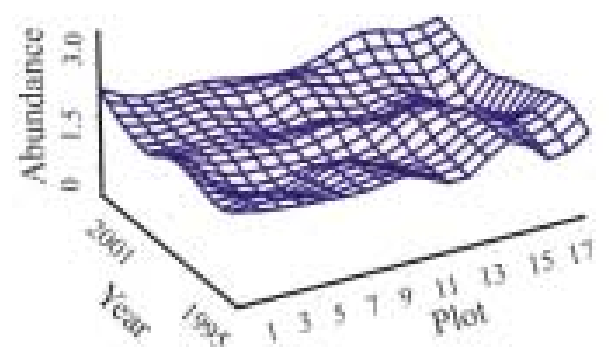

1. pustularia

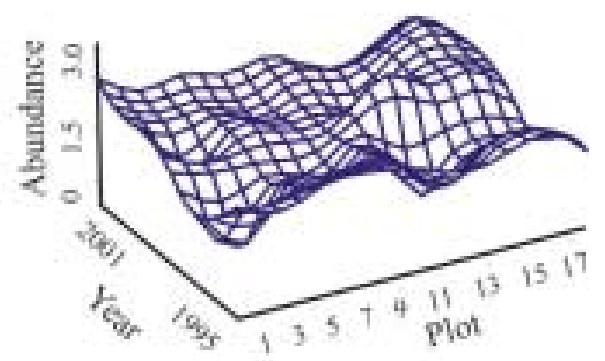


Figure 3.3i. Graphical representations of spatio-temporal interspecific synchrony of Acronicta ovata. The $\mathrm{x}$-axis is plot, the $\mathrm{y}$-axis is year, and the $\mathrm{z}$-axis represents species abundance. 


\section{A. ovata}

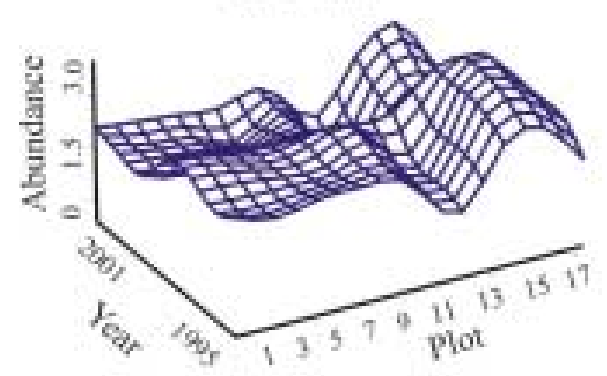

M. canadaria

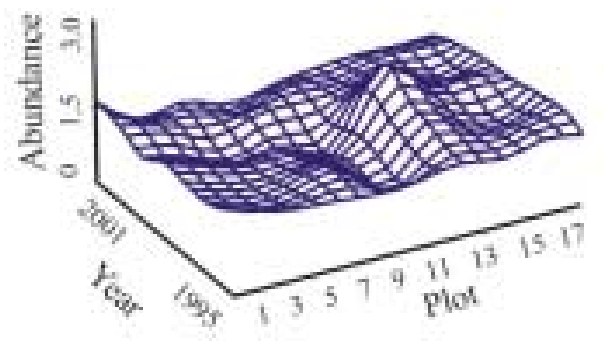

H. gutivitta

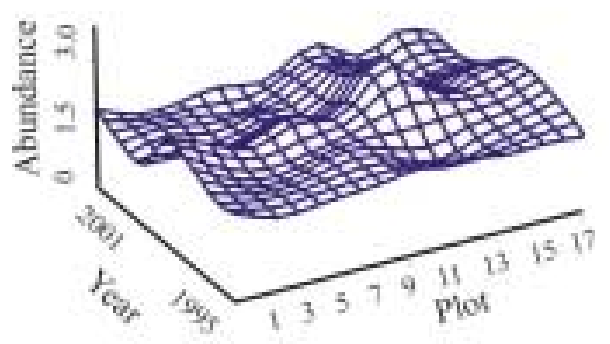

Z. minerea

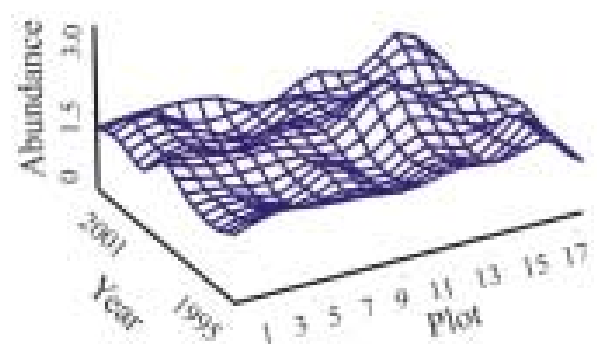

B. endropiaria

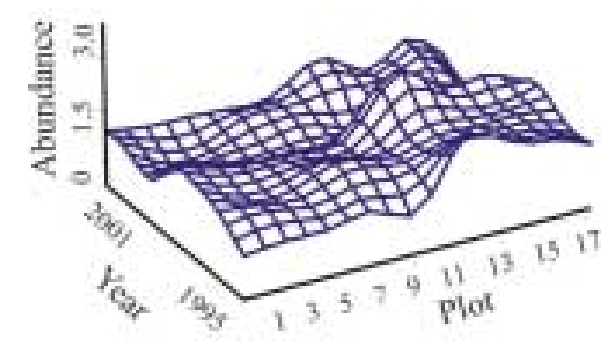

H. fucosa

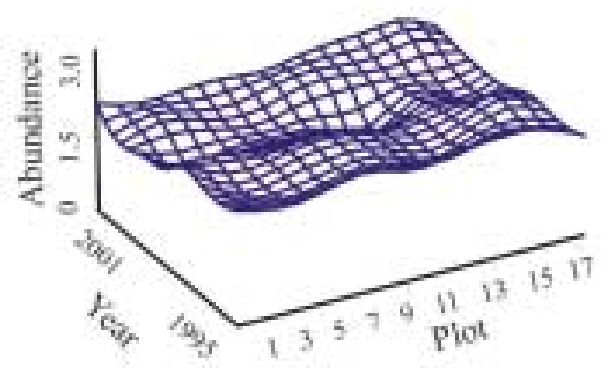

P. latex

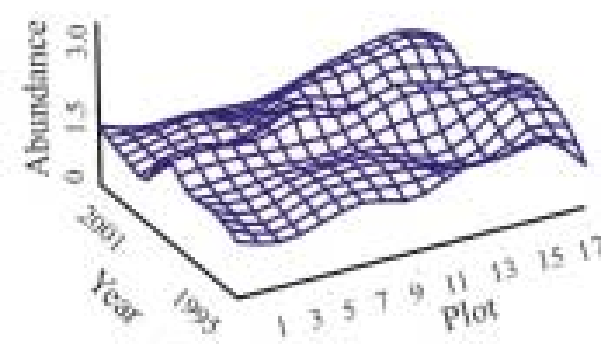


Figure 3.3j. Graphical representations of spatio-temporal interspecific synchrony of Polia latex. The $\mathrm{x}$-axis is plot, the $\mathrm{y}$-axis is year, and the $\mathrm{z}$-axis represents species abundance. 


\section{P. latex}

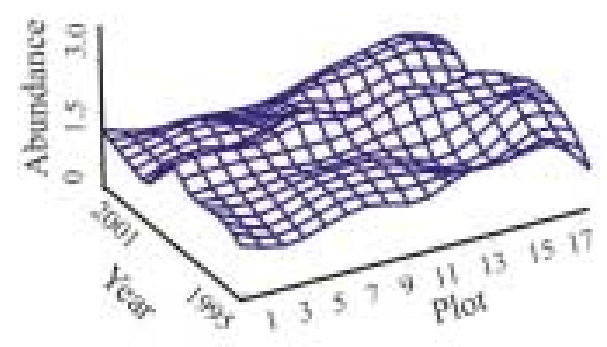

M. canadaria

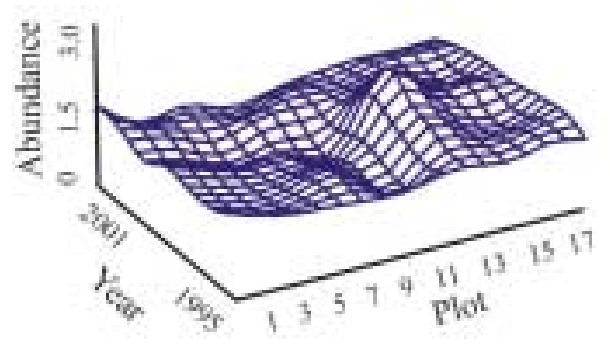

H. guttivitta

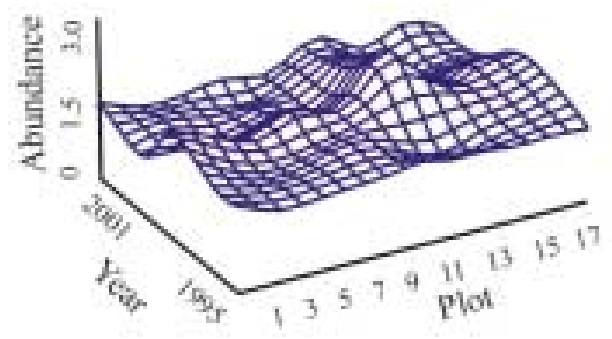

A. ovata

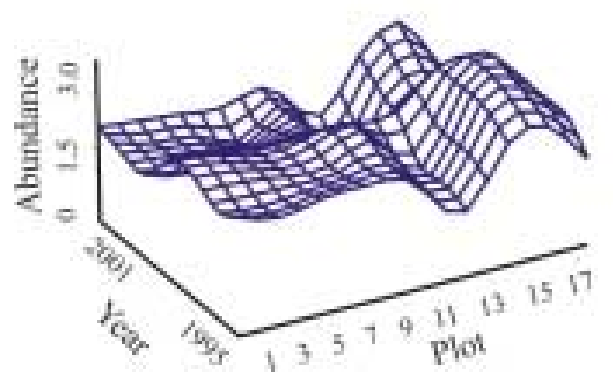

B. endropiaria
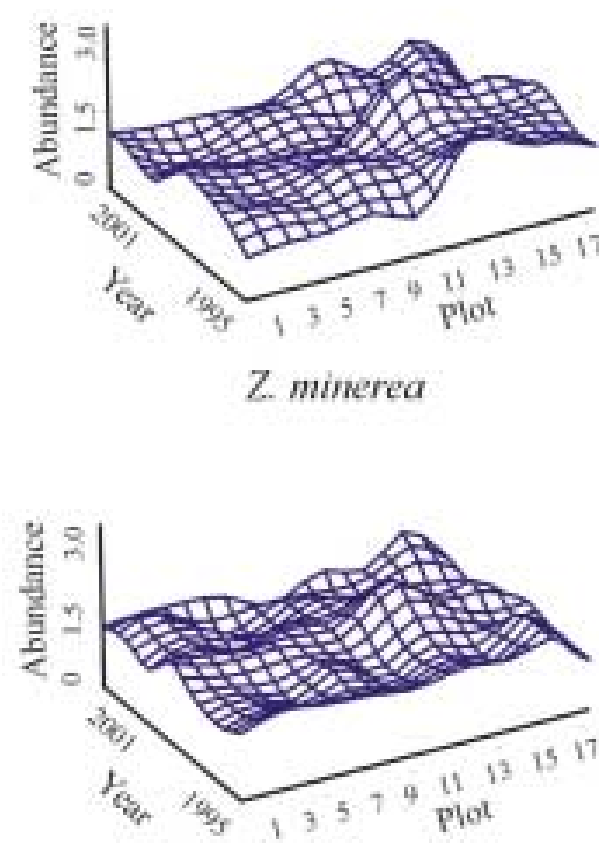
Figure 3.4. Interspecific synchrony of species present as larvae in the early season, late (mid-late) season, and all season. Arrows indicate significant region-wide crosscorrelations and the width of the arrow indicates the intensity of the correlation. 


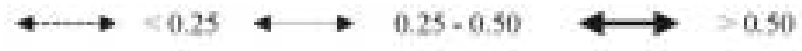

$\underline{\text { Season }}$

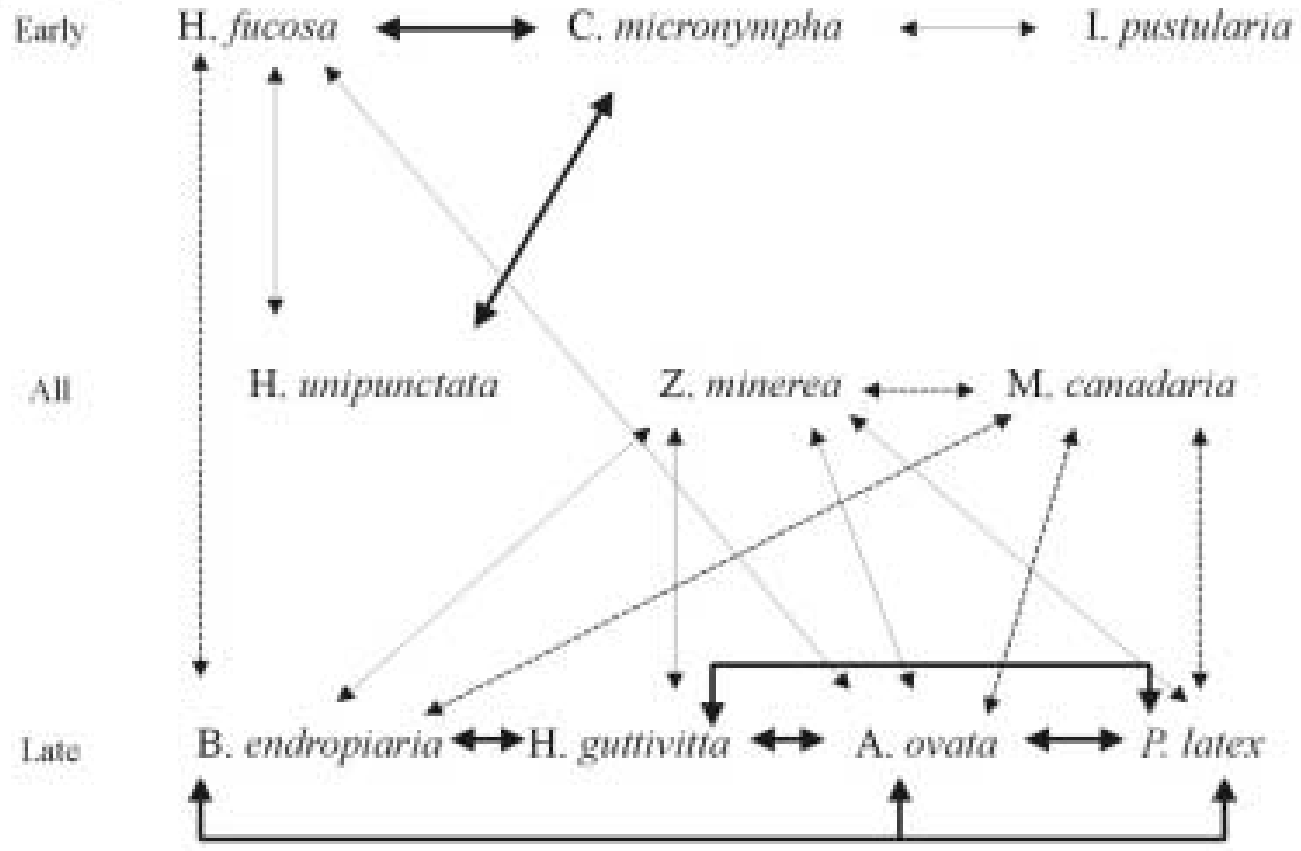


Figure 3.5. Species plotted against axis 1 and axis 2 of the Canonical Correspondence Analysis. Species are group according to their overall similarity with regard to site canopy vegetation. 


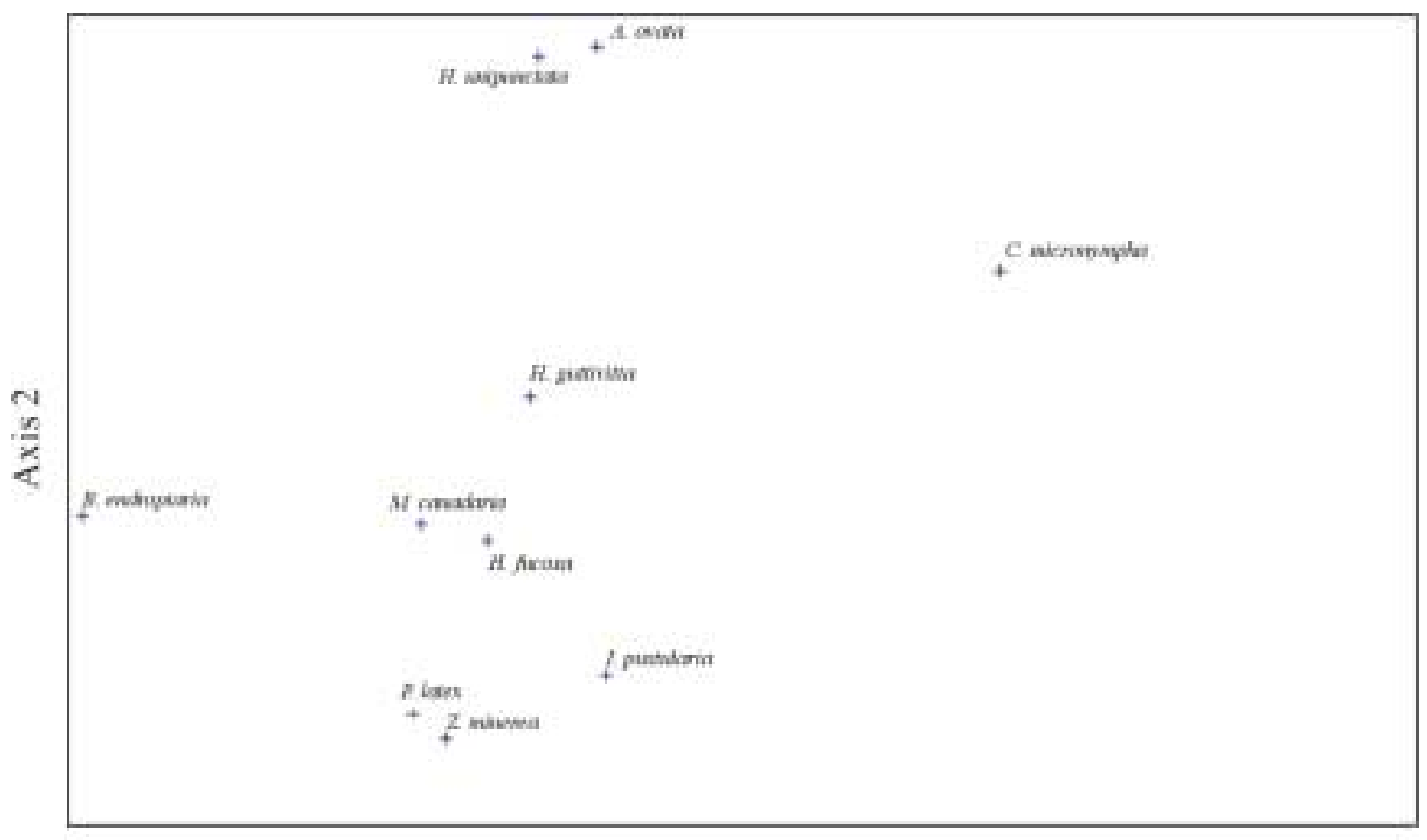

Axis 1 
Figure 3.6. Species plotted against axis 1 of the CCA. Horizontal distance is a relative unit of measurement demonstrating interspecific distances along the axis. 


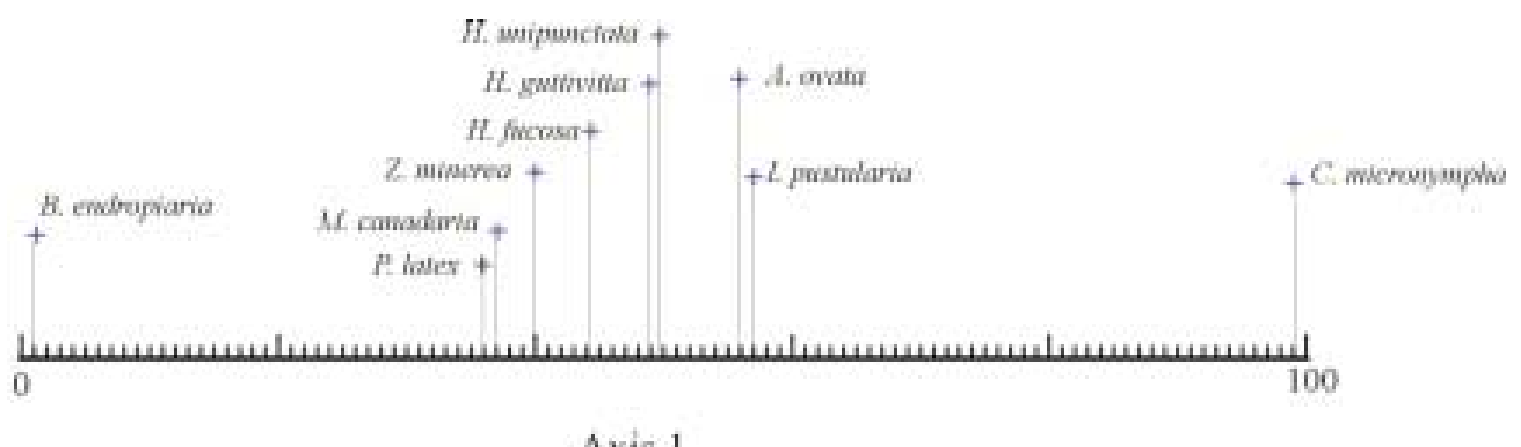

Axis 1 
Figure 3.7. Interspecific cross-correlation coefficient against the distance of axis 1 of the CCA separating respective species within a pair. 


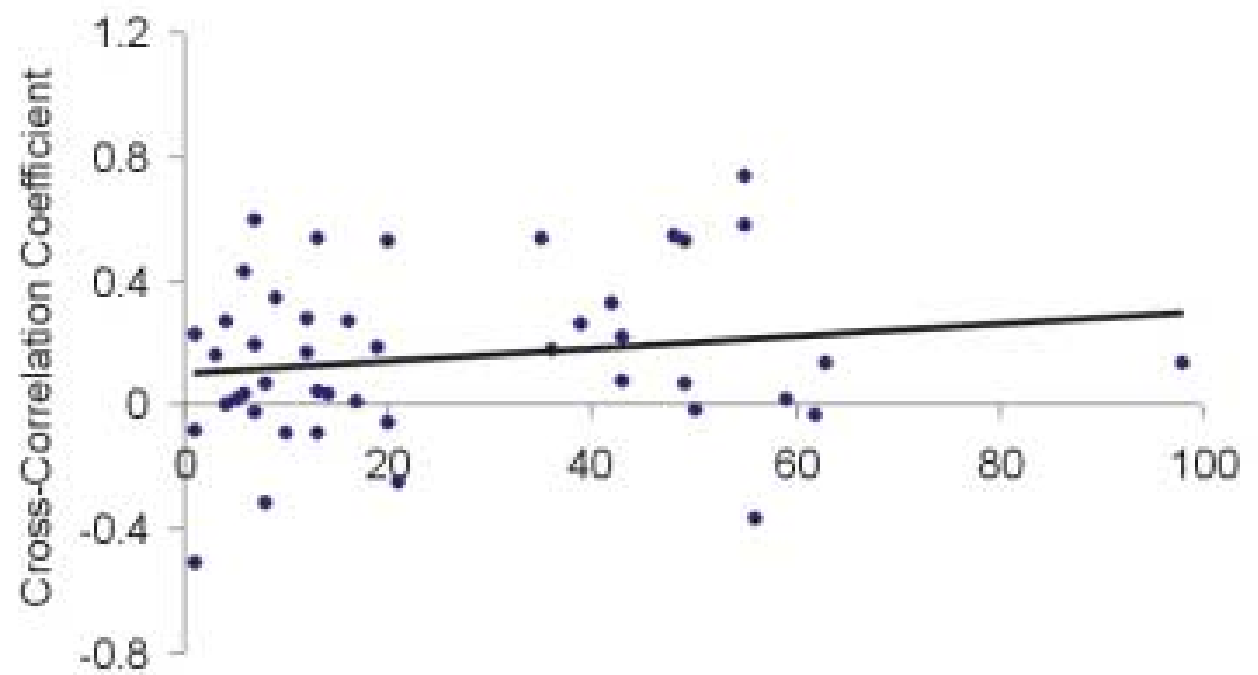

Axis 1 Distance 


\title{
Chapter 4
}

\section{Theoretical Approach to Interspecific Synchrony of Forest Lepidoptera: Theory of Guild-Level Synchrony by Generalist Predators}

\begin{abstract}
Despite documentation of interspecific synchrony occurring in several taxa, theoretical assessment of the causes of synchrony is extremely limited. Climatic factors and specialist predators have been implicated as potential synchronizing mechanisms. In the hypothesis of guild-level synchrony by generalist predators presented here, a simple mathematical model depicts how several species within a feeding guild may be synchronized by the functional response of generalist predators. In this model, species remained unsynchronized in the complete absence of predation or when predatory pressures were applied to only one species. Prey species projecting relatively similar search images to predators were more highly synchronized than species with distant search images. Prey handling time only influenced synchrony when very high relative to the total time prey was exposed to predators. This model synthesizes some modern advancements of spatial theory with predator functional responses to explore the guild level dynamics.
\end{abstract}

Key Words: Interspecific synchrony, functional response, generalist predators. 


\section{Introduction}

Spatial synchrony of local populations of a species is a ubiquitous feature of population dynamics and has been documented for a diversity of taxa (Bjørnstad 2000; Hanski and Woiwod 1993; Liebhold and Kamata 2000; Paradis et al. 2000; Peltonen et al. 2002; Pollard 1991; Ranta et al. 1995a,b). Interspecific synchrony of multiple species is less studied but has been documented for tetraonid birds (Lindström et al. 1996; Ranta et al. 1995b), small mammals (Norrdahl and Korpimäki 1996; Small et al. 1993), and insects (Miller and Epstein 1986), and has been attributed to both climatic events (Hawkins and Holyoak 1998; Lindström et al. 1996; Watson et al. 2000) and shared predators (Ims and Steen 1990; Marcstrom et al 1988; Ydenberg 1987). The importance of nomadic predators on interspecific synchrony has been demonstrated in both empirical and theoretical studies of small mammals (Ims and Steen 1990; Norrdahl and Korpimäki 1996; Ydenberg 1987). The Regional Synchrony Hypothesis proposed by Ims and Steen (1990) predicts that small rodent populations are synchronized within a geographical region as a result of numerical and functional responses of specialist predators.

Whereas specialist predators frequently exhibit numerical and functional responses to changes in prey density (Gotelli 2001), generalist predators often demonstrate only a functional response to changes in prey density (Linden and Wikman 1983; Weseloh 1990), particularly when prey species are not present throughout the entire predator hunting season. The latter scenario is exemplified by Lepidoptera in the spring defoliating feeding guild and their generalist predators such as birds and small mammals. Interspecific synchrony of Lepidoptera in central Appalachia has been found to be highest among species whose larvae are present during the same time of the season 
(Chapter 3) and the importance of generalist predators on the population dynamics of Lepidoptera is well known (Price 1997). Early ecologists suggested that species within a feeding guild may be regulated as a whole, rather than as individual species, through shared predation pressure (Comins and Hassell 1976; Hebert et al. 1974). This concept, originally termed "apparent competition", results when prey species that are not in direct competition affect each other's populations through a functional and/or numerical response of a shared predator (Holt 1977).

The following study suggests the hypothesis of guild-level synchrony by generalist predators. In this theoretical simulation of a multiple prey system, the predator functional response is the mechanism that induces synchrony among prey populations. A simple mathematical model has been developed to further evaluate this hypothesis and is based on the assumptions that 1) all prey species are present at the same time and for similar duration during the predator hunting season, 2) predators search at random in a sufficiently homogenous environment, and 3) predator density is dependent on numerous alternate prey, thus experience only a functional response to changes in prey density. Specifically, the role of predator search image and handling time of prey on interspecific synchrony is explored. The model demonstrates that two prey species that project similar search images to the predator are highly synchronized and synchrony decreases with increasing differences in search image.

\section{The Model System}

The model system can be idealized by the spring defoliating lepidopteran feeding guild and their generalist predators, such as birds and small mammals. Individual prey 
species are present for only a short period of the predator hunting season and predator recruitment is largely dependent on availability of alternate prey. The predators, therefore, exhibit only a functional response to the changes in prey density (Weseloh 1990). This system is realistic since generalist predators have repeatedly been shown to cause significant influence on the population dynamics of forest insects, particularly at non-outbreak densities (Atlegrim 1989; Campbell et al. 1983; Floyd 1996; Weseloh 1990).

For simplicity, the model will include only two prey species. In the absence of predation, individual prey dynamics are independent and are described by the secondorder autoregressive model of Royama (1992):

$$
\begin{aligned}
& N_{1(t)}=a_{0}+a_{1} N_{1(t-1)}+a_{2} N_{1(t-2)}+\varepsilon_{1} \\
& N_{2(t)}=b_{0}+b_{1} N_{2(t-1)}+b_{2} N_{2(t-2)}+\varepsilon_{2}
\end{aligned}
$$

where $N_{1}$ and $N_{2}$ are the densities of the two prey species at times $t, t-1$, and $t-2$. The variables $a$ and $b$ are parameters of the unique dynamics of species 1 and 2, respectively, and were assigned values to create oscillating dynamics based on Royama (1992). The stochastic variable, $\varepsilon$, had a mean and standard deviation of $(0,1)$ and was unique for both prey populations in order to remove the synchronizing effect of shared environmental factors.

A type II predator functional response was modeled using Holling's (1959) disc equation for two species (Murdoch 1973): 


$$
\begin{aligned}
& N_{1 a}=\frac{\gamma_{1} N_{1 t} T}{1+\gamma_{1} h_{1} N_{1 t}+\gamma_{2} h_{2} N_{2 t}} \\
& N_{2 a}=\frac{\gamma_{2} N_{2 t} T}{1+\gamma_{1} h_{1} N_{1 t}+\gamma_{2} h_{2} N_{2 t}}
\end{aligned}
$$

where $N_{i a}$ is the number of prey removed from population $i, h_{i}$ is the handling time of each species, and $T$ is the time that prey species are exposed to the predators. Since there is no predator numerical response, $T$ is assigned a random function of time to incorporate stochastic variation in generalist predation pressure (Turchin 2003). Predator search rate of each prey species, $\gamma_{i}$, is defined by the relative densities of each prey species modified by a constant search image $\left(\theta_{i}\right)$ such that,

$$
\begin{aligned}
& \gamma_{1}=\frac{\theta_{1} N_{1 t}}{\left(\theta_{1} N_{1 t}+\theta_{2} N_{2 t}\right)} \\
& \gamma_{2}=\frac{\theta_{2} N_{2 t}}{\left(\theta_{1} N_{1 t}+\theta_{2} N_{2 t}\right)}
\end{aligned}
$$

and $\gamma_{1}+\gamma_{2}=1$. This approach models the densities of the two prey species, and the behavioral mechanism employed by the generalist predator to switch between them and is a realistic approach to modeling the effect of generalist predators (Turchin 2003).

Model simulations were first conducted over 1000 generations and 500 iterations using a range of $\theta_{i}$ values in the sequence $(0,0.066,0.002)$ to assess the effects of search image only. For these simulations, handling time was held constant at 0.001 . To determine the combined effects of search image and handling time, similar simulations were conducted over a range of $\theta_{i}$ values in the sequence $(0,0.032,0.004)$ and $h_{i}$ values in the sequence $(0.05,12.05,1.5)$ for all possible combinations of $\theta_{i}$ and $h_{i}$. In both 
simulations, each iteration consisted of a pair of prey species with initial populations set in complete anti-phase. The first 500 generations of each iteration was removed prior to obtaining correlation coefficients for the time series to allow predation pressures to synchronize the populations. Average correlation coefficients were calculated from the 500 iterations for all combinations of $\theta_{i}$ and $h_{i}$.

\section{Results and Discussion}

In the absence of predation $\left(\theta_{1}=0, \theta_{2}=0\right)$, both prey populations maintained the independent dynamics of the autoregressive model and remained generally uncorrelated throughout the time series (Figure 4.1a). When predators hunted only one species (ie. $\theta_{1}$ $=0, \theta_{2}>0$ ), the two prey populations had an average correlation of approximately zero (Figure 4.2). When predators removed prey from both populations $\left(\theta_{1}>0, \theta_{2}>0\right)$, predation had a synchronizing effect on the prey populations (Figure 4.1b). Synchrony was highest between prey species that projected relatively similar search images.

Relative predator search images of the two prey species had a clear effect on the level of synchrony which occurred. Two prey species of equal search images were highly synchronized over all values of $\theta$, however populations were less synchronized when the two prey species had values of $\theta$ that were relatively distant from each other (Figure 4.2). These results lend to the conclusion that for prey species to be synchronized by generalist predators, they must share a similar degree of "preference" by the predator, otherwise the predation pressure is concentrated on the species with the greater search rate independent of prey density. This presumably results from the predator "favoring" one species over most density values. Holling's (1959) type III functional response models this effect, in 
which predators switch from a preferred prey species to an alternate prey species when the preferred species reaches low densities (see Appendix II for a more detailed discussion of the relationship between type II and III functional responses). This functional response arises when the predator cannot hunt with equal efficiency for different prey species and devotes more time to the "preferred" species (ie. the species with the greater search image) (Abrams and Matsuda 1996).

The level of synchrony decays further when a prey species with a relatively high search image also has relatively high handling time (Figure 4.2). The time spent handling prey reduces the time available to search for prey, so as prey consumption and handling increase, the total time spent searching decreases (Holling 1965). Therefore, if the prey species triggering higher search image requires more time to consume, the reduced search time results in lowered predation pressure that is not significant enough to synchronize populations. However, the values of handling time used in this simulation were unrealistically high compared to $T$, the total time prey species were exposed to predators (approximately $27-80 \%$ of total $T$ to handle one prey). At more realistic values of $h(<$ $1 \%$ of total $T$ ) variations in handling time had no effect on synchrony. Although handling time may change with learned efficiency associated with higher densities (Murdoch 1973) this effect was not modeled in this study.

Nomadic predators are thought to synchronize local populations of conspecific populations by concentrating in patches of high density and reducing the prey density within these patches to the average density of a larger area (Ydenberg 1987). The hypothesis of guild-level synchrony by generalist predators presented here functions in a similar manner, in which resident generalists concentrate on the prey species of higher 
density, reducing predation pressure on the prey species of lower density. This behavior is described by the predator functional response and an indirect interaction between prey species; an increase in density of one prey species decreases the predators' functional response to the other, in turn increasing the density of the other prey (Abrams and Matsuda 1996). When predators also experience a positive numerical response to prey densities, prey species can indirectly depress each other (“apparent competition") by increasing the abundance of shared predators, which lend to prey species fluctuating in anti-phase of each other or synchronous fluctuations with lag time (Abrams et al. 1998; Holt 1977). In Holt's (1977) original model of apparent competition, numerical responses outweighed functional responses, thereby resulting in asynchronous dynamics of prey species. The theory of guild-level synchrony by generalist predators assumes that predators experience only a functional response to prey density, thereby resulting in synchronization of prey species.

Modeling predator-prey interactions is complicated by food web dynamics and multi-species interactions, and classical models of one predator/one prey systems are often unrealistic. The system of forest Lepidoptera and generalist predators modeled here addresses the premise that generalist predators do not focus hunting on a particular species, but are in tune to a particular range of search images (Tinbergen 1960). Based on the results of the model presented here, prey species within a range of search images are hunted with relatively equal efficiency by the predator and in turn, are synchronized by the functional response of the predator. Using defoliating Lepidoptera as an example, species projecting the same search image may represent species within a genus or family, and may be viewed by generalist predators as one functional food choice. Several 
empirical studies have shown that avian predators reduce the abundance of insect species within exposed-feeding guilds (Atlegrim 1989; Floyd 1996; Greenberg et al. 2000; Marquis and Whelan 1994; Sanz 2001). Since species within a feeding guild exhibit relatively similar behaviors (Mason 1987) and have converged on a morphology that maximizes performance within their particular niche, it is reasonable to assume that they may project relatively similar search images and are subject to synchronization by generalist predators.

A review of spatial synchrony literature reveals very little work regarding interspecific synchrony (Liebhold et al. unpublished manuscript) and the theoretical groundwork is limited to models of nomadic specialist predators (Ims and Steen 1990). Climatic factors have both direct and indirect effects on insect populations (Martinat 1987) and have been implicated as the causal mechanism of interspecific synchrony (Hawkins and Holyoak 1998; Small et al. 1993). Koenig (2001) associated interspecific synchrony of birds with diet categories but found only a weak relationship between synchrony and diet, concluding that other factors were integral in synchronizing populations. The model presented here offers a new hypothesis of interspecific synchrony: synchronization of prey species through shared functional response of generalist predators. This work demonstrated that generalist predators can synchronize prey species as predicted by the guild-level synchrony hypothesis. In this model, synchronization resulted when prey species projected relatively similar search images, and synchrony decayed as two species triggered increasingly different search images in the predator. Although this hypothesis offers an alternative hypothesis of guild-level 
synchrony, there is still much room for more empirical and theoretical research of the dynamics of interspecific synchrony.

\section{Future Research}

The dynamical role of predators in prey dynamics is also believed to dampen the amplitude of oscillations or prevent diverging oscillations (Turchin et al. 1999), influence the period of population cycles (Ydenberg 1987), and generally stabilize multi-prey species complexes through predator switching (Murdoch 1969, Pelletier 2000). In addition to synchronizing prey populations, generalist predators modeled here may result in additional alterations of prey dynamics. This study is currently being expanded to include spectral analysis of the prey populations to identify other potential effects of generalist predators on prey species. Other areas of expansion and future research include incorporation of the type III functional response and species with non-linear dynamics.

\section{References Cited}

Abrams, P. A. and H. Matsuda. 1996. Positive indirect effects between prey species that share predators. Ecology. 77: 610-616.

Abrams, P. A., R. D. Holt, and J. D. Roth. 1998. Apparent competition or apparent mutualism? shared predation when populations cycle. Ecology. 79: 201-212.

Atlegrim, O. 1989. Exclusion of birds from bilberry stands: impact on insect larval density and damage to the bilberry. Oecologia 79: 136-139.

Bjørnstad, O. N. 2000. Cycles and synchrony: two historical 'experiments' and one experience. Journal of Animal Ecology. 69: 869-873.

Campbell, R. W., T. R. Torgersen, and N. Srivastava. 1983. A suggested role for predaceous birds and ants in the population dynamics of the western spruce budworm. Forest Science. 29: 779-790.

Comins, H. N. and M. P. Hassell. 1976. Predation in multi-prey communities. Journal of Theoretical Biology. 62: 93-114. 
Floyd, T. 1996. top-down impacts on creosotebush herbivores in a spatially and temporally complex environment. Ecology. 77: 1544-1555.

Gotelli, N. J. 2001. A Primer of Ecology. $3^{\text {rd }}$ ed. Sinauer Associates Inc. Sunderland, MA.

Greenberg, R. P. Bichier, A. C. Angon, C. MacVean, R. Perez, and E. Cano. 2000. The impacts of avian insectivory on arthropods and leaf damage in some Guatemalan coffee plantations. Ecology. 81: 1750-1755.

Hanski, I., and I. P. Woiwod. 1993. Spatial synchrony in the dynamics of moth and aphid populations. Journal of Animal Ecology. 62. 656-668.

Hawkins, B. A. and M. Holyoak. 1998. Transcontinental crashes of insect populations? The American Naturalist. 152: 480-484.

Hebert, P. D. N., P. S. Ward, and R. Harmsen. 1974. Diffuse competition in Lepidoptera. Nature. 252. 389-390.

Holling, C. S. 1959. Some characteristics of simple types of predation and parasitism. The Canadian Entomologist. 91: 385-398.

Holling, C. S. 1965. The functional response of predators to prey density and its role in mimicry and population regulation. Memoirs of the Entomological Society of Canada. 45: 3-60.

Holt, R. D. 1977. predation, apparent competition, and the structure of prey communities. Theoretical Population Biology. 12: 197-229.

Ims, R. A. and H. Steen. 1990. Geographical synchrony in microtine population cycles: A theoretical evaluation of the role of nomadic avian predators. Oikos. 57: 381-387.

Koenig, W. D. 2001. Synchrony and periodicity of eruptions by boreal birds. The Condor. 103: 725-735.

Liebhold, A. and N. Kamata. 2000. Are population cycles and spatial synchrony a universal characteristic of forest insect populations? Population Ecology. 42: 205-209.

Liebhold, A., W. D. Koenig, and O. Bjørnstad. unpublished manuscript. Spatial synchrony in population dynamics.

Linden, H. and M. Wikman. 1983. Goshawk predation on tetraonids: availability of prey and diet of the predator in the breeding season. Journal of Animal Ecology. 52: 953-968. 
Lindström, J., E. Ranta, and H. Linden. 1996. Large-scale synchrony in the dynamics of capercaillie, black grouse and hazel grouse populations in Finland. Oikos. 76: 221-227.

Marcström, V., R. E. Kenward, and E. Engren. 1988. The impact of predation on boreal tetraonids during vole cycles: an experimental study. Journal Animal Ecology. 57: 859872.

Marquis, R. J. and C. J. Whelan. 1994. Insectivorous birds increase the growth of white oak through consumption of leaf-chewing insects. Ecology. 75: 2007-2014.

Martinat, P. J. 1987. The role of climatic variation and weather in forest insect outbreaks. In Insect Outbreaks. P. Barbosa and J. C. Schultz (Eds.). Academic Press. San Diego, CA.

Mason, R. R. 1987. Nonoutbreak species of forest Lepidoptera. In Insect Outbreaks. P. Barbosa and J. C. Schultz (Eds.). Academic Press. San Diego, CA.

Miller, W. E. and M. E. Epstein. 1986. Synchronous population fluctuations among moth species (Lepidoptera). Environmental Entomology. 15: 443-447.

Murdoch, W. W. 1969. Switching in general predators: Experiments on predator specificity and stability of prey populations. Ecological Monographs. 39: 335-354.

Murdoch, W. W. 1973. The functional response of predators. Journal of Applied Ecology. 10: 335-342.

Norrdahl, K. and E. Korpimäki. 1996. Do nomadic avian predators synchronize population fluctuations of small mammals? A field experiment. Oecologia. 107: 478-483.

Paradis, E., S.R. Baillie, W. J. Sutherland, and R. D. Gregory. 2000. Spatial synchrony in populations of birds: Effects of habitat, population trend, and spatial scale. Ecology. 81: 2112-2125.

Pelletier, J. D. 2000. Are large complex ecosystems more unstable? A theoretical reassessment with predator switching. Mathematical Biosciences. 163: 91-96.

Peltonen, M., A. M. Liebhold, O. N. Bjornstad, D. W. Williams. 2002. Spatial synchrony in forest insect outbreaks: roles of regional stochasticity and dispersal. Ecology. 83: 3120-3129.

Pollard, E. 1991. Synchrony of population fluctuations: The dominant influence of widespread factors on local butterfly populations. Oikos. 60: 7-10.

Price, P. 1997. Insect Ecology. $3^{\text {rd }}$ ed. Wiley and Sons, Inc. New York, NY. 
Ranta, E., V. Kaitala, J. Lindström, and H. Linden. 1995a. Synchrony in population dynamics. Proceedings of the Royal Society of London: Series B. 262: 113-118.

Ranta, E., J. Lindström, and H. Linden. 1995b. Synchrony in tetraonid populations dynamics. Journal of Animal Ecology. 64: 767-776.

Royama, T. 1992. Analytical Population Dynamics. Chapman and Hall. London. UK.

Sanz, J. J. 2001. Experimentally increased insectivorous bird density results in a reductino of caterpillar density and leaf damage. Ecological Research. 16: 387-394.

Small, R. J., V. Marcström, and T. Willebrand. 1993. Synchronous and nonsynchronous population fluctuations of some predators and their prey in central Sweden.

Tinbergen, L. 1960. The natural control on insects in pine woods. I. Factors influencing the intensity of predation by songbirds. Archives Neerlandaises de Zoologie. 13: 265343.

Turchin, P. A. D. Taylor, and J. D. Reeve. 1999. Dynamical role of predators in population cycles of a forest insect: an experimental test. Science. 285: 1068-1071.

Turchin, P. 2003. Complex Population Dynamics: a Theoretical / Empirical Synthesis. Princeton Univeristy Press. Princeton, NJ. 536pp.

Watson, A., R. Moss, and P. Rothery. 2000. Weather and synchrony in 10- year population cycles of rock ptarmigan and red grouse in Scotland. Ecology. 81: 2126-2136.

Wesloh, R. M. 1990. Gypsy moth predators: an example of generalist and specialist natural enemies. In Population dynamics of forest insects. A.D. Watt, S. R. Leather, M. D. Hunter, and N.A.C. Kidd (Eds). Intercept L.T.D. Andover, England.

Ydenberg, R. C. 1987. Nomadic predators and geographical synchrony in microtine population cycles. Oikos. 50: 270-272. 
Figure 4.1. ${ }^{\mathrm{a}}$ Two prey species in the absence of predation, ${ }^{\mathrm{b}}$ Two prey species synchronized by the functional response of generalist predators (both species have search images of 0.005 and handling times of 0.02 ). 

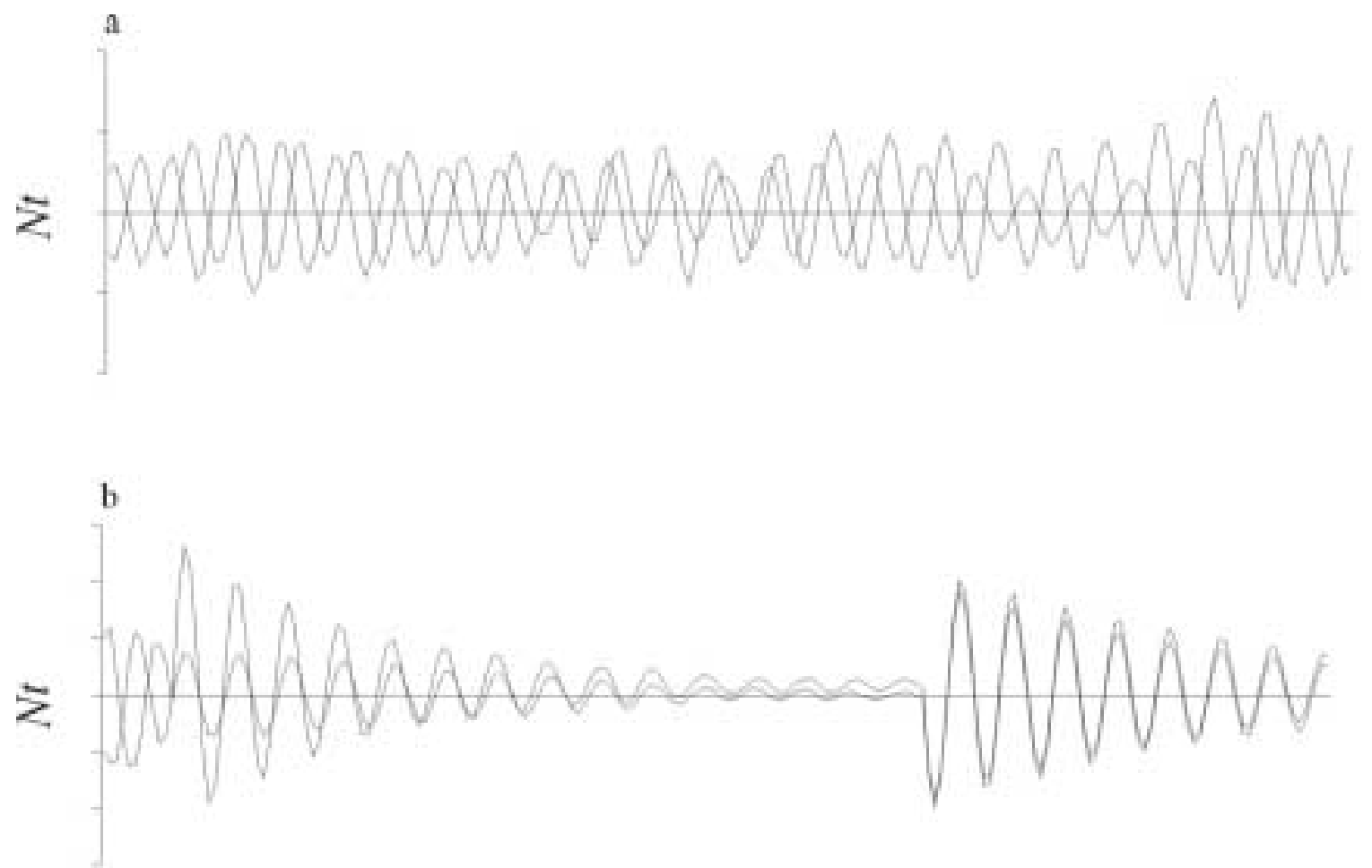

Time 
Figure 4.2. Level of synchrony between two prey species projecting various search images. Handling time $(h=0.001)$ is constant. The gray scale for each search image combination is the average (of 500 iterations) cross-correlation of the two prey species' time series. 


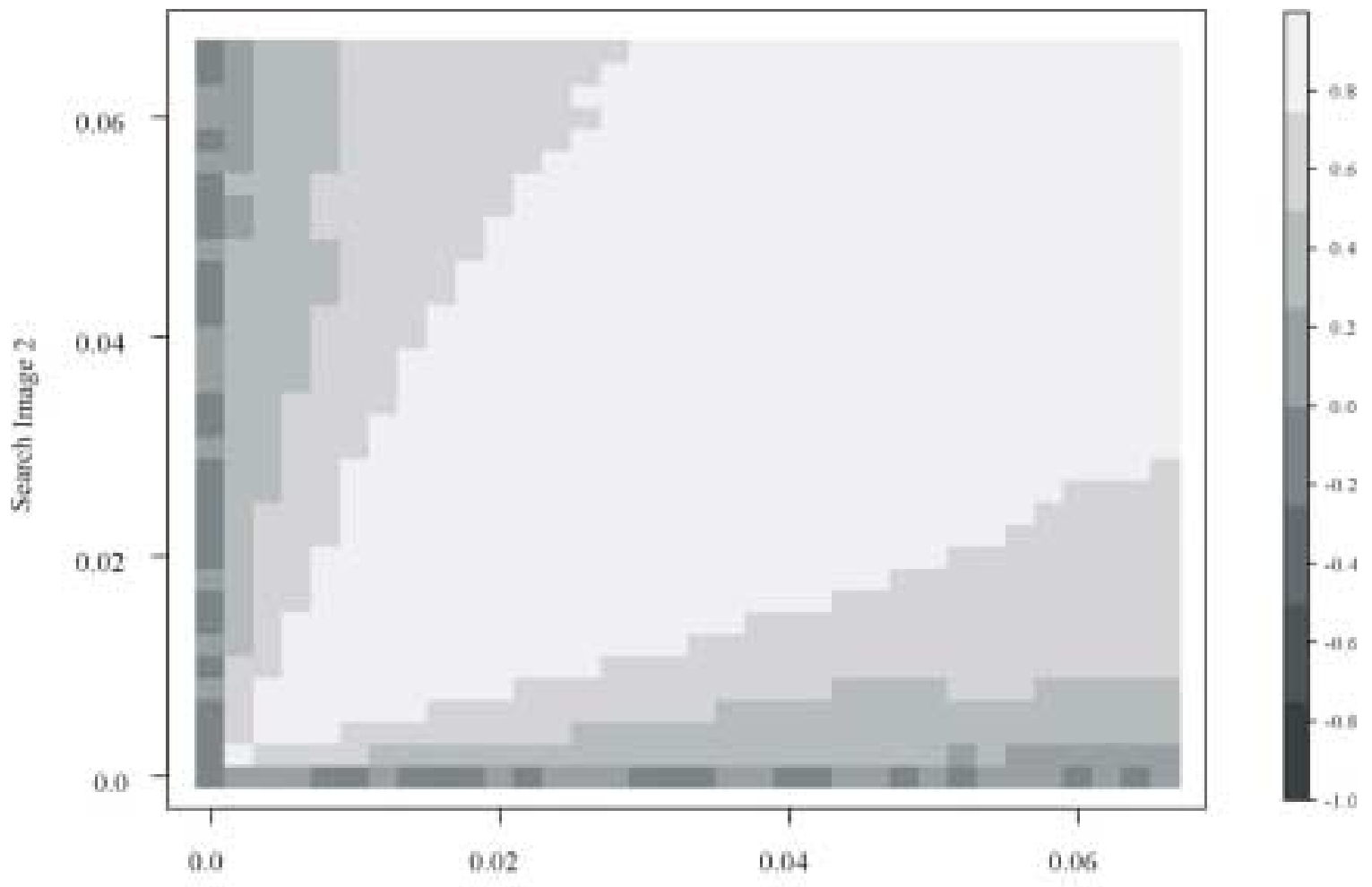

Search Image 1 
Figure 4.3. Simulation results of a 2- prey / generalist predator system. Each large box represents various values of search image for prey species 1 and 2 and are labeled by the primary $\mathrm{x}$ and $\mathrm{y}$-axes of the entire grid. The smaller grids within each large box represent varying values of handling time and are labeled by the secondary $\mathrm{x}$ and $\mathrm{y}$-axes. This figure represents every combination of 10 values of search image and 10 values of handling time for 2 prey species (10000 combinations). The gray scale for each search image / handling time combination represents the average (of 500 iterations) crosscorrelation of two prey species' time series. 
Handling Time 1

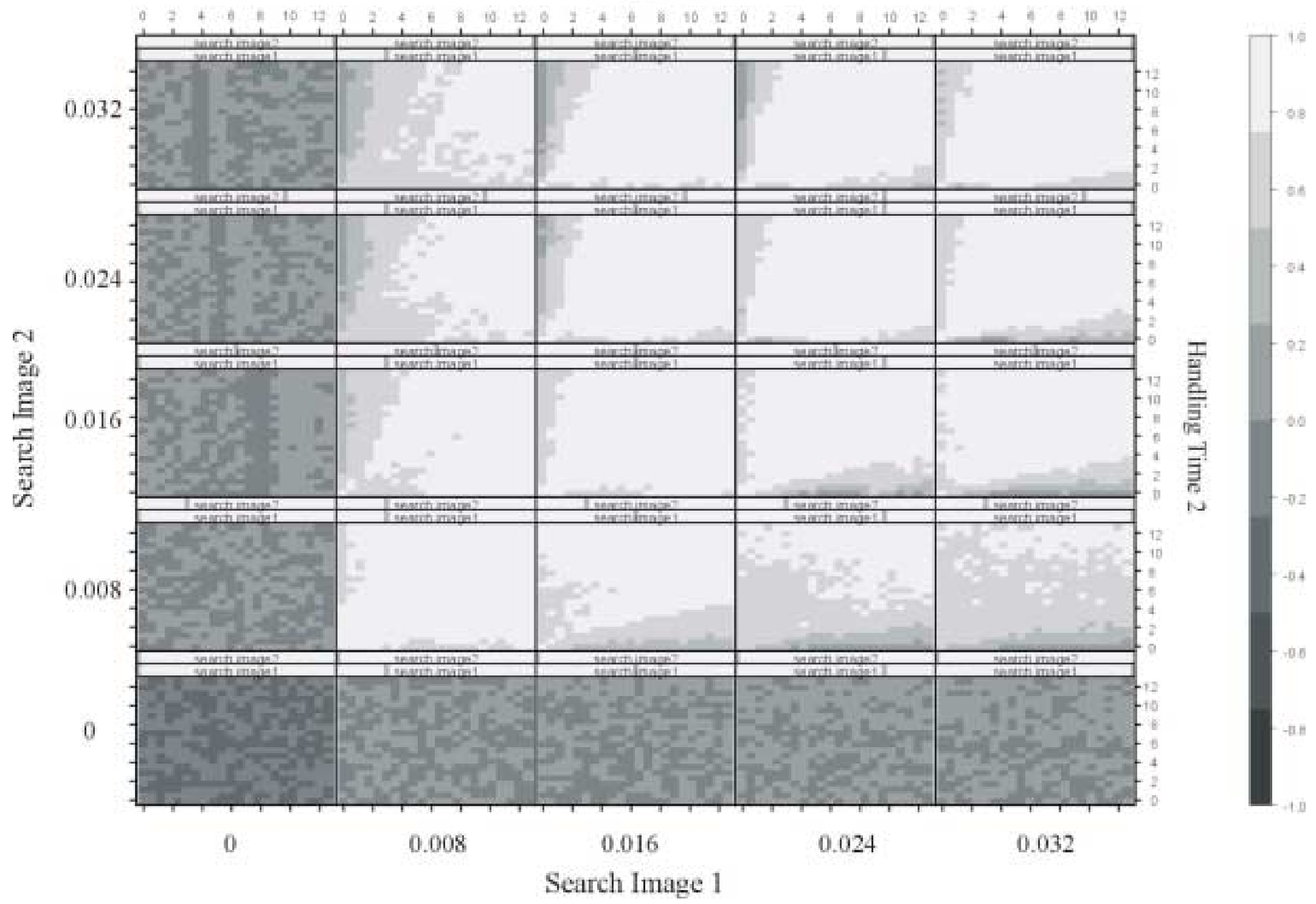




\section{Appendix I}

The following species descriptions are compilations from the literature. References used for each species are cited at the end of each species summary.

\section{FAMILY: ARCTIIDAE}

Hypoprepia fucosa Hübner Painted lichen moth

Range: North to Canada, south to Florida, West to Minnesota and Manitoba.

Larval food source: mosses and lichen

Larval dates: April - June

Flight dates: May - August

Over-wintering stage: larva

Number of generations: 1

Notes: Adult Lithosiinae have aposematic coloration and are toxic to predators. It is not known if toxins are synthesized by adults, sequestered by larval feeding, or both.

References: Covell 1984; Forbes 1960; Rawlins 1984; Wagner et al. 1997

\section{FAMILY: NOTODONTIDAE}

\section{Heterocampa guttivitta (Walker) Saddled prominent}

Range: north to Nova Scotia and Quebec, west to Colorado and Manitoba, south to Florida

Larval food source: polyphagous, prefers sugar maple, beeches, and birch

Larval dates: July - August

Flight dates: April - September

Over-wintering stage: pupa

Number of generations: $1-2$

Notes: Outbreaks have occurred every 10-12 years since 1907 in the northeastern forests of New England, north of Pennsylvania. Outbreaks have historically begun at high elevations and along ridge tops with high beech and sugar maple densities. Peak defoliation occurs from mid-July through early August. Impact of defoliation includes crown dieback of overstory trees and sapling/seedling mortality. This species is a midseason defoliator, feeding during the warmest and most stable period of the year with respect to weather.

References: Martinat and Allen 1987, 1988a, 1988b; Wagner et al. 1997 


\section{FAMILY: GEOMETRIDAE}

\section{Hypagyrtis unipunctata (Haworth) One-spotted variant}

Range: north to Quebec, west to Michigan, Texas and Oklahoma

Larval food source: polyphagous on forest trees and shrubs, possibly conifers

Larval dates: all year

Flight dates: April - September

Over-wintering stage: larva

Number of generations: 2-3

Notes: Larvae cryptic, twig mimic

References: Covell 1984; Forbes 1948; Wagner et al. 1997, 2001

Itame pustularia (Guenée) Lesser maple spanworm

Range: north to Nova Scotia, south to Florida and Texas, west to Wisconsin and Iowa Larval food source: maple (specifically $A$. rubrum)

Larval dates: May - August

Flight dates: May - September

Over-wintering stage: egg

Number of generations: 1

Notes: Eggs are laid singly in late July, scattered on tree bark, lichens or litter. Larvae hatch in the spring and feed on red maple from May to early July. Larvae are solitary feeders. Females may have reduced wing length. Outbreaks have been reported in areas treated to control spruce budworm (Choristoneura fumiferana (Clemens)) on adjacent conifers. Heavy defoliation results in an arthropod community with a higher index of diversity toward the end of the season.

References: Volney 1975, 1979; Wagner et al. 1997, 2001

Melanolophia canadaria (Guenée) Variable redmarked looper

Range: eastern

Larval food source: polyphagous, common on birch, elm, cherry, maple and oak

Larval dates: May - October

Flight dates: May - August

Over-wintering stage: pupa

Number of generations: 2

Notes: Larvae cryptic, twig mimics. Larvae feed mostly at night, resting during the day on the underside of leaves.

References: Butler et al. 2001; Wagner et al. 2001 
Besma endropiaria (Grote \& Robinson) Straw Besma

Range: Eastern Canada south to Georgia, west to Arkansas

Larval food source: Maple, alder, birch, and oak.

Larval dates: July - September

Flight dates: May - July

Over-wintering stage: pupa

Number of generations: 1

Notes: Larvae cryptic, twig mimics.

References: Butler et al. 2001; Wagner et al. 2001

FAMILY: NOCTUIDAE

Zale minerea (Guenée) Colorful zale

Range: Eastern

Larval food source: polyphagous prefers beech, birch, maples

Larval dates: May to October

Flight dates: May to August

Over-wintering stage: pupa

Number of generations: 1

References: Butler et al. 2001; Covell 1984; Wagner et al. 1997

\section{Catocala spp.}

The genus Catocala is known for congeneric sympatric diversity; the genus shows great diversity on highly restricted larval food plant use (Gall 1991a). Over 35 species have been recorded from one forested locality and several species are often found on one species of host plant (33\% of species feed on Juglandaceae) (Schweitzer 1982a). Early observers suggested that Catocala sp. are held at low numbers relative to leaf area (Schweitzer 1982a). Since the host plant is often shared by many species of Catocala, food is an unlikely limiting factor. "Competition" for predator avoidance is more likely to be a driving factor in the evolution of Catocala diversity. Differences in resting position have been suggested as the mode of partitioning among species (Schweitzer 1982b). Females lay eggs under exfoliating bark and cracks (Gall 1991b). Larvae generally feed at night (Gall 1991a).

Catocala micronympha Guenée Little nymph

Range: north to Ontario, south to Texas, west to Kansas.

Larval food source: oaks

Larval dates: May - June

Flight dates: June - August

Over-wintering stage: egg 
Number of generations: 1

Notes: see above

References: Butler et al. 2001, Covell 1984

Catocala amica (Hübner) Girlfriend underwing; friendly underwing

Range: Maine to Florida

Larval food source: Oaks, especially $Q$. alba

Larval dates: May - June

Flight dates: July - September

Over-wintering stage: egg

Number of generations: 1

Notes: see above

References: Covell 1984; Wagner et al. 1997

Acronicta ovata Grote Ovate dagger moth

Range: north to Nova Scotia and Manitoba, south to North Carolina, west to Colorado and Texas

Larval food source: primarily oaks

Larval dates: June - September

Flight dates: April - September

Over-wintering stage: pupa

Number of generations: 2-3

References: Butler and Strazanac 2000; Covell 1984; Wagner et al. 1997

Polia latex (Guenée) Fluid arches

Range: Nova Scotia to North Carolina, west to Manatoba and Arkansas

Larval food source: polyphagous on birch, cherry, maple, and oaks

Larval dates: June - September

Flight dates: May - August

Over-wintering stage: larva or pupa

Number of generations: 1

References: Covell 1984; Wood and Butler 1989 


\section{FAMILY: LYMANTRIIDAE}

\section{Lymantria dispar $\mathbf{L}$. gypsy moth}

Range: Nova Scotia to North Carolina, west to Michigan and Illinois.

Larval food source: polyphagous on hardwoods, specifically oak-dominated stands

Larval dates: May - June

Flight dates: July - September

Over-wintering stage: egg

Number of generations: 1

Notes: Females are flightless, deposit eggs in masses. Dispersal via larval ballooning. Gypsy moth densities may remain low for several years before increasing several orders of magnitude. Gypsy moth outbreaks occur on approximately 10-11 year cycles, although timing is generally irregular and difficult to predict.

References: Covell 1984; Liebhold et al. 2000; Wagner et al. 1995; Wagner et al. 1997

\section{References Cited}

Butler, L. and J. Strazanac. 2000. Occurrence of Lepidoptera on selected host trees in two central Appalachian national forests. Ann. Entomol. Soc. Amer. 93: 500-511.

Butler, L., V. Kondo, and J. Strazanac. 2001. Light trap catches of Lepidoptera in two central Appalachian forests. Proc. Entomol. Soc. Wash.. 103: 879 - 902.

Covell, C. Jr. 1984. A Field Guide to Moths of Eastern North America. Houghton Mifflin Company. Boston, MA. 496pp.

Forbes, W. T. M. 1948. Lepidoptera of New York and Neighboring States. Geometridae, Sphingidae, Notodontidae, Lymnatriidae. Part II. Memoir 274. Cornell Agricultural Experimental Station. Ithaca, New York. 263pp.

Forbes, W. T. M. 1960. Lepidoptera of New York and Neighboring States. Agaristidae through Nymphalidae Including Butterflies. Part IV. Memoir 371. Cornell Agricultural Experimental Station. Ithaca, New York. 188pp.

Gall, L. F. 1991a. Evolutionary ecology of sympatric Catocala moths (Lepidoptera: Noctuidae). I. Experiments on larval foodplant specificity. Journal of Research on the Lepidoptera. 29: 173-194.

Gall, L. F. 1991b. Evolutionary ecology of sympatric Catocala moths (Lepidoptera: Noctuidae). III. Experiments on female oviposition preference. Journal of Research on the Lepidoptera. 29: 217-233. 
Liebhold, A., J. Elkinton, D. Williams, R.-M. Muzika. 2000. What causes outbreaks of the gypsy moth in North America? Popul. Ecol. 42: 257-266.

Martinat, P. J. and Allen, D. C. 1987. Relationship between outbreaks of saddled prominent Heterocampa guttivitta (Lepidoptera: Notodontidae), and drought.

Environmental Entomology. 1987. 16: 246-249.

Martinat, P. J. and Allen, D. C. 1988a. Saddled prominent outbreaks in North America. Northern Journal of Applied Forestry. 5: 88-91.

Martinat, P. J. and Allen, D. C. 1998b. Behavior of saddled prominent Heterocampa guttivitta (Walker) (Lepidoptera: Notodontidae) larvae in the northern hardwood forest. Journal New York Entomological Society. 96: 470-478.

Rawlins, J. E. 1984. Mychophagy in Lepidoptera. In Fungus-insect relationships: perspectives in ecology and evolution (Q. Wheeler and M. Blackwell Eds). Columbia University Press. New York, NY.

Schweitzer, D. F. 1982a. Field observations of foodplant overlap among sympatric Catocala feeding on Junglandaceae. Journal of the Lepidopterists' Society. 36: 256-263.

Schweitzer, D. F. 1982b. Field observations of divergent resting behavior among hickory feeding Catocala larvae (Noctuidae). Journal of the Lepidopterists' Society. 36: 303.

Volney, W.J.A. 1975. The role of defoliators in the arthropod community of red maple crowns. Journal of new York Entomological Society. 83(4): 283

Volney, W.J.A. 1979. Estimating epidemic populations of the lesser maple spanworm (Lepidoptera: Geometridae). Canadian Entomologist. 111: 189-200.

Wagner, D. L., V. Giles, R. C. Reardon, and M. L. McManus. 1997. Caterpillars of Eastern Forests. Forest Health Technology Enterprise Team- Morgantown, WV. U.S.D.A. FHTET-96-34. 113pp.

Wagner, D. L., D. C. Ferguson, T. L. McCabe, and R. C. Reardon. 2001. Geometroid Caterpillars of Northeastern and Appalachian Forests. Forest Health Technology Enterprise Team- Morgantown, WV. U.S.D.A. FHTET-2001-10. 239pp.

Wood, P. S. and L. Butler. 1989. Biology and immature stages of Polia latex (Guenée) (Noctuidae). Journal of the Lepidopterists' Society. 45: 197-203. 


\section{Appendix II}

There is still a great deal of ambiguity surrounding the use of type II and type III functional responses in theoretical predator-prey systems. It is generally believed that specialist predators are characterized by the hyperbolic behavior of the type II functional response where generalist predators are expected to exhibit the sigmoid behavior of the type III functional response (Holling 1959). Since generalist predators kill several kinds of prey, they should switch the focus of their predation pressures to the prey of greatest density, resulting in the type III response curve (Turchin 2003). However, the phenomenological forms of the two functional responses vary only slightly and actual documentation of type III functional responses is limited in the empirical literature.

Recall the type II functional response used in equation 4.2:

$$
N_{l a}=\frac{\gamma_{1} N_{1 t} T}{1+\gamma_{1} h_{1} N_{1 t}+\gamma_{2} h_{2} N_{2 t}}
$$

The single species version of this model is reduced to:

$$
N_{a}=\frac{\gamma N_{t} T}{1+\gamma h N_{t}}
$$

With the differential form:

$$
f(N)=\frac{\gamma N_{t}}{1+\gamma h N_{t}}
$$

and is solidly based on the mechanisms of predation at the individual level (Holling 1959). 
To derive the type III functional response, the numerator and denominator in equation A.3 are divided by $\gamma h$ such that:

$$
f(N)=\frac{h^{-1} N_{t}}{(\gamma h)^{-1}+N_{t}}
$$

The variable $c$ is assigned to $h^{-1}$ and represents the maximum killing rate, and $d=(\gamma h)^{-1}$, the prey density at which the killing rate is half of the maximum (half-saturation constant). Equation A.4 then becomes:

$$
f(N)=\frac{c N_{t}}{d+N_{t}}
$$

Which can then be written as:

$$
f(N)=\frac{c N_{t}{ }^{1+q}}{d+N_{t}^{1+q}}
$$

The sigmoid functional response is derived from the hyperbolic response when $q$, the rate of detection, is greater than zero (Real 1979). Although equation A.6 is widely used in the theoretical literature, there is no clear mechanistic derivation of the variable $q$ (Turchin 2003).

Almost all predators show a type II functional response when only one prey species is present and the type III functional response is achieved when other prey species are added to the system or when hunting efficiency increases with experience (Murdoch 1973). Presumably, the change in functional response from type II to type III with the addition of other prey species is contingent on relative "preference" of the two species; type III curves model "preferred" and "alternate" prey species. As the results of Chapter 4 suggest, two prey species that project relatively similar search images may be viewed 
by the generalist predator with relatively equal preferences, which do not meet the assumptions of the type III response.

The work presented in Chapter 4 is not intended to be a theoretical evaluation of predator functional responses; speculation of the relative roles of type II and type III response curves is beyond the scope of this work. However, type III functional responses will be explored in future work regarding guild-level synchrony by generalist predators.

\section{References Cited}

Holling, C. S. 1959. Some characteristics of simple types of predation and parasitism. The Canadian Entomologist. 91: 385-398.

Murdoch, W. W. 1973. The functional response of predators. Journal of Applied Ecology. 10: 335- 342.

Real, L. A. 1979. Ecological determinants of functional response. Ecology. 60: 481-485.

Turchin, P. 2003. Complex Population Dynamics: a Theoretical / Empirical Synthesis. Princeton Univeristy Press. Princeton, NJ. 536pp. 


\title{
Curriculum Vitae - Sandra Raimondo
}

\section{Business Address:}

\author{
West Virginia University \\ Plant and Soil Sciences \\ P.O. Box 6108 \\ Morgantown, WV 26506 \\ home: (304) 291-6690 \\ office: (304) 293-6023 ext. 4306 \\ email: sandyraimondo@yahoo.com
}

\section{Education:}

Doctorate of Philosophy. Entomology. West Virginia University, Morgantown, WV. May 2003.

Master of Science. Biology. Marshall University, Huntington, WV. 1999. Highest Distinction.

Bachelor of Science. Biology. Pennsylvania State University, University Park, PA. 1996.

\section{Current Activities:}

West Virginia University, Morgantown, WV. Ph.D. Candidate. 1/00 to present

Dissertation title: Population dynamics of native Lepidoptera in two gypsy moth management areas in central Appalachia.

Developed model of interactions among generalist predators and multi-species prey complex. Used computer-based simulations to model synchronization of multiple prey species by generalist predators. Developed skills in temporal and spatial analyses.

Project title: Nontarget impacts from multiple applications of the native pathogen, Bacillus thuringiensis var. kurstaki and its interaction with the exotic pathogenic fungus, Entomophaga maimaiga (LTS).

Responsible for up to twelve undergraduate assistants. Led and coordinated field crews for insect collecting. Coordinated laboratory sorting and insect processing. Sorted and identified a diverse collection of insects. Worked with caterpillar rearing.

Marshall University, Huntington, WV. Insect taxonomist. 2/00 to present.

Project title: LTS

Identified insects for co-operative university within the study.

\section{Teaching Experience:}

Fall 2000. Aquatic Entomology. West Virginia University. Morgantown, WV.

Designed a new course taught to undergraduate and graduate students. Developed lectures, field trips, and laboratory exercises to teach aquatic insect taxonomy and ecology. Emphasized stream sampling, insect identification, and writing biological assessments using EPA protocol for rapid bioassessments.

Fall 1996. Aquatic Entomology. Pennsylvania State University. University Park, PA. Instructed laboratory section on the identification of aquatic insects. Conducted biweekly field trips for insect collection. Presented class lectures on caddisfly taxonomy and ecology. 


\section{Past Activities \& Research:}

US Geological Survey/National Park Service, Big Bend National Park, TX. Field Researcher. 5/99 to 9/99.

Project Title: Amphibian Surveys of Big Bend National Park.

Conducted field surveys of amphibians throughout the national park. Conducted research to test efficiency of amphibian monitoring techniques.

Marshall University. Huntington, WV. Graduate Research Assistant. 8/97 to 5/99.

Master's Thesis: Feeding niches of forest salamanders: Indirect effects of gypsy moth pesticides on prey selection and potential overlap between adults of six species.

Project title: Nontarget impacts of Bacillus thuringiensis var. kurstaki on salamanders in West Virginia (LTS)

Conducted field collections and surveys of salamander diversity and abundance on plots treated with gypsy moth pesticides.

Project title: West Virginia Herpetological Atlas.

Collected and/or recorded amphibian and reptile species throughout West Virginia.

Project title: Aquatic insect diversity in ponds on reclaimed mountaintop removal mine sites. Sampled and identified insects collected from mitigated wetlands on mountaintop removal mine sites.

West Virginia Division of Natural Resources. Charleston, WV.

Laboratory Assistant. 1/98 to 1/99.

Project title: Baseline survey of benthic macroinvertebrates in streams throughout West Virginia. Sorted aquatic insects using sub-sampling techniques.

Del Val Soil and Environmental Consulting. Doylestown, PA.

Environmental Consultant. 2/97 to 8/97.

Collected and identified aquatic macroinvertebrates from Waters of the Commonwealth and compiled Biological Assessments. Surveyed wetlands and constructed wetland reports for impact assessment and mitigation protocol. Assisted in wetland mitigation projects.

Frost Entomological Museum. University Park, PA. Laboratory Assistant. 9/93 to 2/97. Field collection, identification and curation of insects. Conducted independent research on caddisfly taxonomy and ecology in Pennsylvania.

Savannah River Ecology Laboratory. Aiken, SC. Summer Intern. 5/96 to 8/96.

Project title: Effects of coal ash on swimming performance and predator avoidance in larval bullfrogs.

Conducted laboratory tests to detect impaired predator escape behavior of bullfrog larvae reared in coal ash basins. Conducted field surveys of frogs, snakes, and turtles.

Entomology Department, Penn State University. University Park, PA.

Research Assistant. 5/95 to 8/95.

Field survey of aquatic insects throughout Pennsylvania with emphasis on mayflies. Field collection of soil samples to determine efficiency of turf grass pesticides.

Oak Ridge National Laboratory. Oak Ridge, TN.

Undergraduate Research Award Recipient. 8/95 to 12/95.

Project title: Nutrient cycling in aquatic ecosystems

Conducted research on nutrient cycling in aquatic ecosystems using snails as primary consumers.

Used chromatography techniques to analyze nitrates and sulfates in water samples. 


\section{Publications - Refereed Journals:}

Raimondo, S., J. S. Strazanac, and L. Butler. In review. Comparisons of Lepidoptera sampling techniques used to study population dynamics. Environmental Entomology.

Raimondo, S, T.K. Pauley, and L. Butler. 2003. Potential impacts of Bacillus thuringiensis var. kurstaki on five salamander species in West Virginia. Northeastern Naturalist. 10: 25-33.

Jung, R.E., K. E. Boone, M. L. Rosenshield, A. De la Reza, S. Raimondo, and S. Droege. 2002. Evaluation of canoe surveys for anurans along the Rio Grande in Big Bend National Park, Texas. Journal of Herpetology. 36: 390-397.

Raimondo, Sandra M., Christopher L. Rowe, and Justin D. Congdon. 1998. Exposure to coal ash impacts swimming performance and predator avoidance in larval bullfrogs (Rana catesbeiana). Journal of Herpetology 32. 289-291.

\section{Publications - Proceedings:}

Raimondo, Sandra and Linda Butler. 2000. Population trends of gypsy moth (Lymantria dispar [L.] and three non-target Lepidoptera species affected by Bacillus thuringiensis var. kurstaki in Virginia and West Virginia. Proceedings of the Entomological Society of America. Montreal, Quebec. Canada.

Raimondo, Sandra and Thomas K. Pauley. 1998. Examination of potential competition for food within a salamander community using two measures of dietary overlap. Proceedings of the West Virginia Academy of Sciences. Wheeling, WV. USA.

Raimondo, Sandra. 1995. The Rhyacophila of Pennsylvania. Proceedings of the Western Pennsylvania Symposium of Ecologists, Evolutionary Biologists and Systematists. Rector, PA. USA.

\section{Software Proficiencies}

SAS statistical software

Splus statistics and computing

Pc-ord statistical software

ArcGIS

Microsoft Office (MS word, excel, powerpoint)

Corel office (WordPerfect, Paradox, QuatroPro, Corel draw)

\section{Professional Awards}

A. D. Hopkins Award, 2002

\section{Professional Organizations and Honor Societies:}

Xerces Society, 2002 - present

Gamma Sigma Delta Agricultural Honor Society, 2001 - present

Entomological Society of America (ESA), 2000 - present

ESA Graduate Student Counsel representative, 2000- present

West Virginia Entomological Society, 2000 - present

Association of Southeastern Biologists, 1998 - present 


\section{Volunteer Activities:}

Educational Outreach. Provide outreach to elementary schools. 2000- present Friends of Decker's Creek. Stream restoration volunteer. August 2002

Cooper's Rock Foundation. Educational outreach program. May 2002

Friends of West Virginia Public Radio. Member. 1997- present

West Virginia Cultural Center. Volunteer. 1997- 1999

Girl Scouts of America. Volunteer. 1996

\section{Professional References:}

- $\quad$ Dr. Linda Butler

West Virginia University

Division of Plant and Soil Sciences

P.O. Box 6108

Morgantown, WV 26506

phone: (304) 293-6023

email: butler@wvu.edu

- Andrew Liebhold

USDA Forest Service

180 Canfield St.

Morgantown, WV 26505

phone: (304) 285-1512

email: aliebhold@fs.fed.us

- Dr. Thomas Pauley

Marshall University

Department of Biological Sciences

400 Hal Greer Blvd

Huntington, WV 25755

phone: (304) 696- 2376

email: pauley@,marshall.edu

- Dr. Robin Jung

USGS Patuxent Wildlife Research Center

12100 Beech Forest Rd.

Laurel, MD 20708

phone: (301) 497-5875

email: obin jung@usgs.gov 